2. To: (Receiving Organization)

Distribution

5. Proj./Prog./Dept./Div.:

W314/RPP

\section{Originator Remarks:}

This EDT releases the RVR HNF-4533 for AN Farm to $200 \mathrm{E}$ Waste Transfer System for Project $W-314$. Tank Farm Restoration \& Safe Operations.

11. Receiver Remarks: 11A. Design Baseline Document? [] Yes [X] No USQ notreguired per HNF-If 0842 , 00u D0, Section 5.4, rev1/6. This design [covered bythisRvR] will notresult in an exposure $7 l^{\circ}$ person-REm (whole bod)) or $\geqslant 10$ Aerson-REm(extremities) for the installation, maintenance and operation of the life of the modifection. ALARA reviews will be performed as a part of the normal work process. DEN 9/27/99
3. From: (Originating Organization) Tank Farm Restoration and Safe Operation

6. Design Authority/ Design Agent/Cog.

Engr.:

D.L. MCGrew
4. Related EDT No.:

N/A

7. Purchase Order No.:

N/A
9. Equip./Component No.:

N/A

10. System/Bldg./Facility: 200E/241AN

12. Major Assm. Owg. No.:

N/A

13. Permit/Permit Application No.:

N/A

14. Required Response Date: 9/23/99

\begin{tabular}{|c|c|c|c|c|c|c|c|c|}
\hline 15. & DATA TRANSMITTED & (F) & (G) & (H) & (I) \\
\hline $\begin{array}{c}\text { (A) } \\
\text { Item } \\
\text { No. }\end{array}$ & (B) Docunnt/Drawing No. & $\begin{array}{c}\text { (C) } \\
\text { Sheet } \\
\text { No. }\end{array}$ & $\begin{array}{c}\text { (D) } \\
\text { Rev. } \\
\text { No. }\end{array}$ & $\begin{array}{l}\text { (E) Title or Description of Data } \\
\text { Transmitted }\end{array}$ & $\begin{array}{c}\text { ApprovaI } \\
\text { Desig- } \\
\text { nator }\end{array}$ & $\begin{array}{c}\text { Reason } \\
\text { for } \\
\text { Trans- } \\
\text { mittal }\end{array}$ & $\begin{array}{c}\text { Origi- } \\
\text { nator } \\
\text { Dispo- } \\
\text { sition }\end{array}$ & $\begin{array}{c}\text { Receiv- } \\
\text { er } \\
\text { Dispo- } \\
\text { sition }\end{array}$ \\
\hline 1 & HNF-4533 & 0 & $\begin{array}{l}\text { Requirements Verification } \\
\text { Report: AN Farm to 200E } \\
\text { Waste Transfer System for } \\
\text { Project W-314. }\end{array}$ & ESO & 1 & 1 & 1 \\
\hline
\end{tabular}

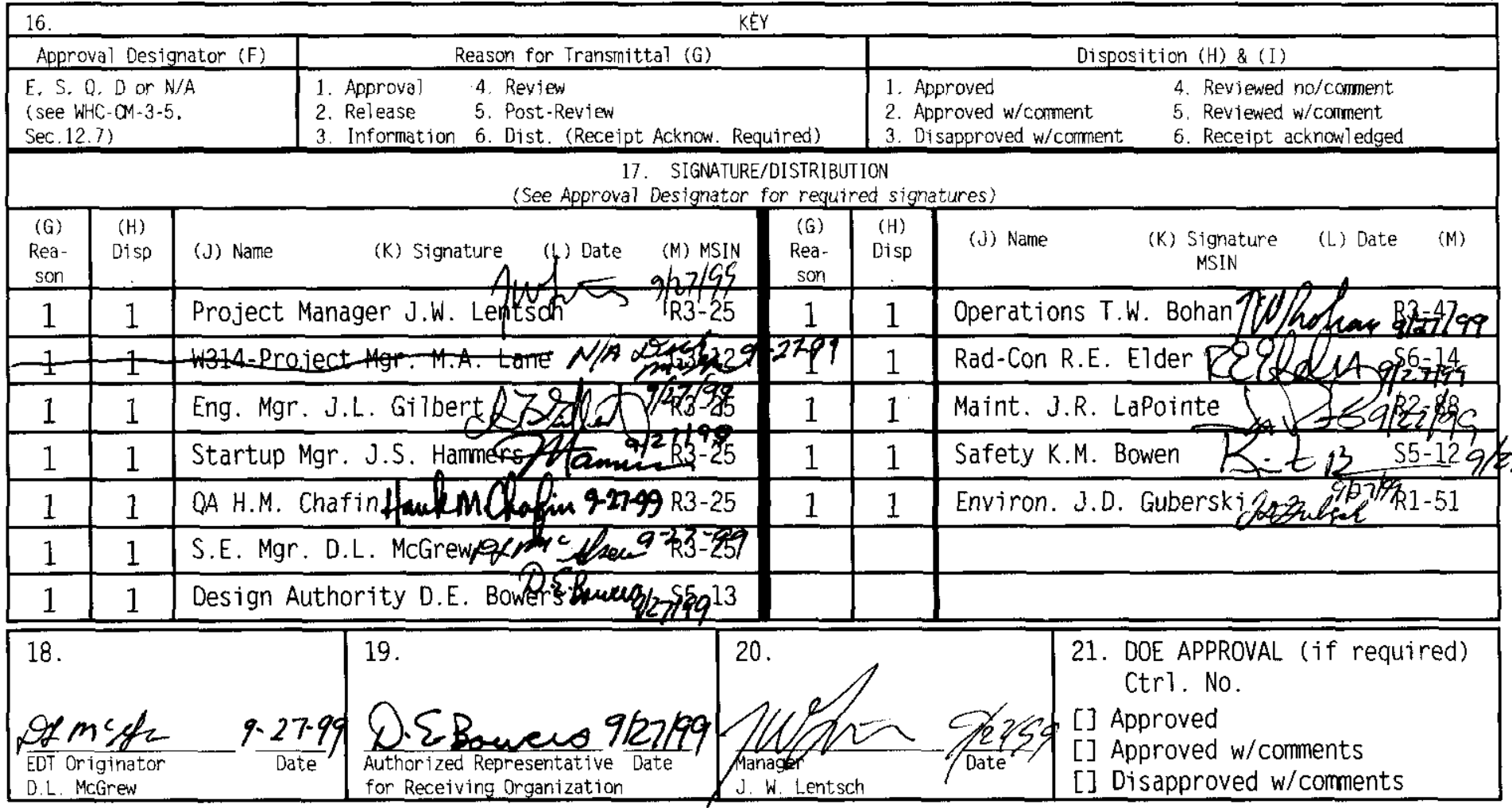




\title{
Requirements Verification Report: AN Farm to 200E Waste Transfer System for Project W-314. Tank Farm Restoration \& Safe Operations
}

\author{
D.L. McGrew \\ Numatec Hanford Company, Richland, WA 99352 \\ U.S. Department of Energy Contract DE-AC06-96RL13200 \\ EDT/ECN : 627811 \\ Org Code: $8 \mathrm{C} 620$ \\ B\&R Code: EW3130010 \\ UC: 510 \\ Charge Code: N311B \\ Total Pages 14
}

Key Words: Requirements Verification Report (RVR), Project W-314, Tank Farm Restoration and Safe Operations, AN Farm to 200E Waste Transfer System (WBS 1.4.L)

Abstract: This Requirements Verification Report (RVR) for Project $W$ 314 "AN Farm to 200E Waste Transfer System" package provides documented verification of design compliance to all the applicable Project Deveropment Specification (PDS) requirements. Additional PDS requirements verfication will be performed during the project's procurement, construction, and testing phases, and the RVR will be updated to reflect this information as appropriate.

TRADEMARK DISCLAIMER. Reference herein to any specific commercial product. process, or service by trade name, trademark, manufacturer, or otherwise, does not necessarily constitute or imply its endorsement, recormendation, or favoring by the United States Government or any agency thereof or its contractors or subcontractors.

Printed in the United States of America. To obtain opies of this document, contact: Document Control Services. P.0. Box 950. Mailstop H6372-2420; Fax (509) 376-4989.



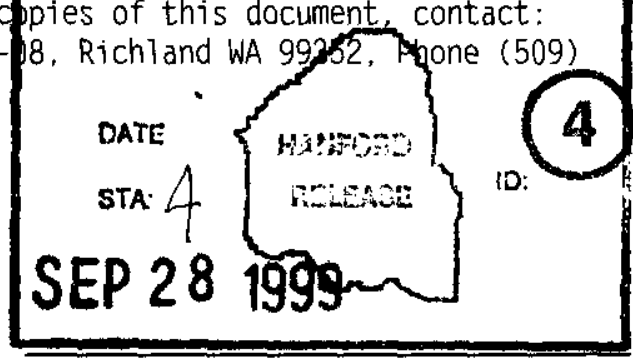

Release Stamp

\section{Approved for Public Release}




\section{Requirements Verification Report}

For

\section{AN Farm to 200E Waste Transfer System \\ (WBS 1.4.L)}

September 1999

Project W-314

Tank Farm Restoration and Safe Operations

Prepared by Fluor Daniel Northwest, Inc. for Lockheed Martin Hanford Corporation

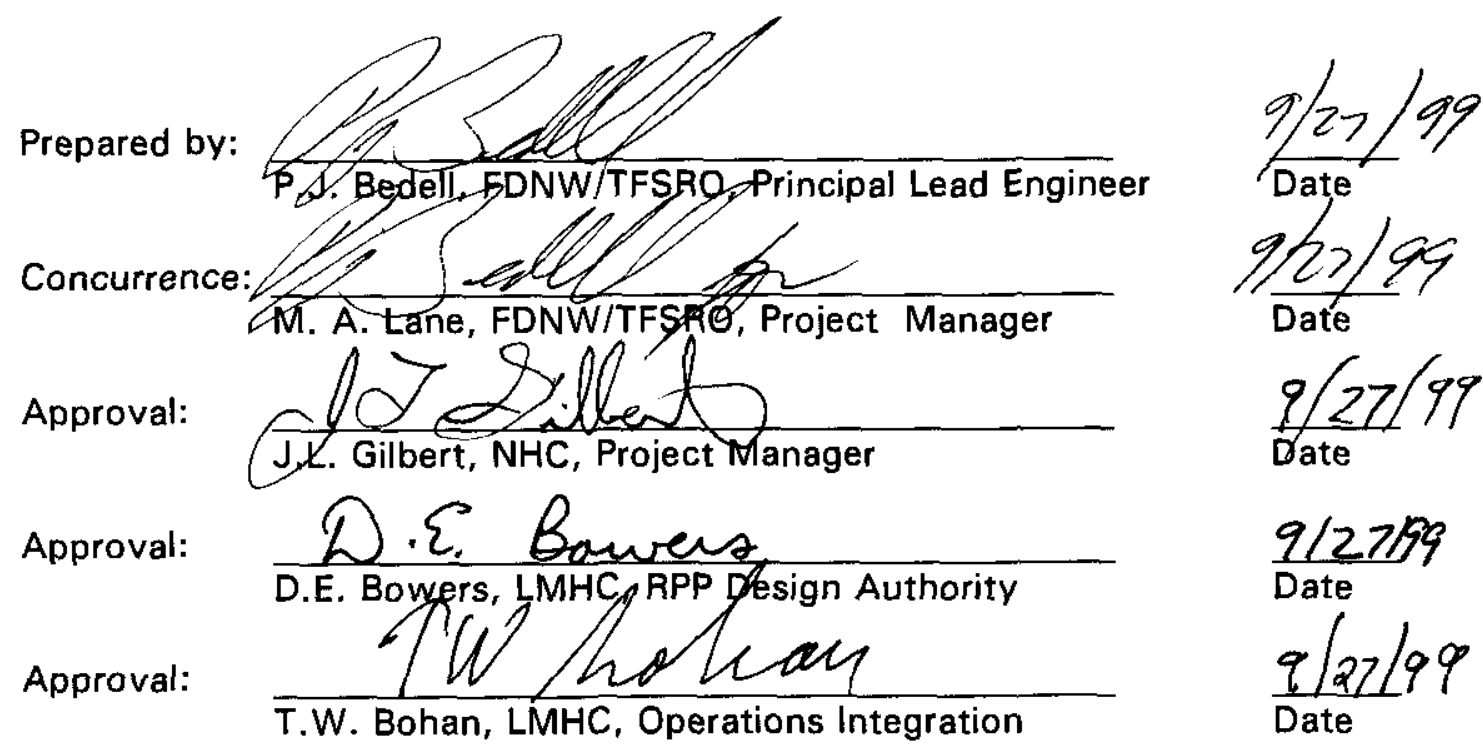




\section{Table of Contents}

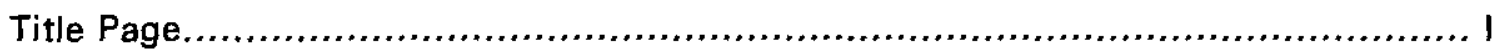

Table of Contents..................................................................... ii

$1.0 \quad$ INTRODUCTION................................................................. 1

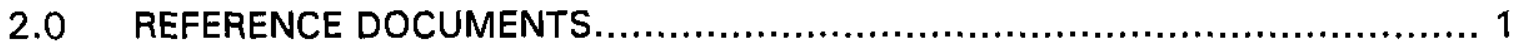

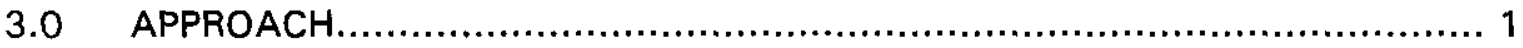

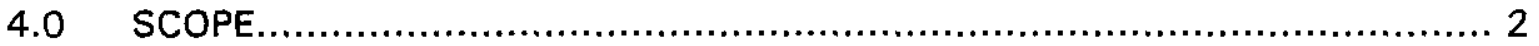

\section{APPENDICES}

Appendix A: Requirements Verification for PDS-001, Transfer Piping.................... A-1

Appendix B: Requirements Verification for PDS-002, Valve Pit Manifold................. B-1

Appendix C: Requirements Verification for PDS-003, Pit Leak Detection............... C-1

Appendix D: Requirements Verification for PDS-005, Special Protective Coating........ D-1 


\section{REQUIREMENTS VERIFICATION REPORT}

FOR

\section{AN Farm to 200E WASTE TRANSFER SYSTEM}

\subsection{INTRODUCTION}

This Requirements Verification Report provides the traceability of how Project W-314 fulfilled the Project Development Specification (PDS) requirements for the AN Farm to 200E Waste Transfer System Upgrade (WBS 1.4.L) package.

\subsection{REFERENCE DOCUMENTS}

HNF-SD-W314-PDS-001, Rev. 2, Project Development Specification for Transfer Piping

HNF-SD-W314-PDS-002, Rev. 2, Project Development Specification for Valve Pit Manifold

HNF-SD-W314-PDS-003, Rev. 2, Project Development Specification for Pit Leak Detection

HNF-SD-W314-PDS-005, Rev. 2, Project Development Specification for Special Protective Coating

\subsection{APPROACH}

This Requirements Verification Report was assembled to provide the documented basis of how the requirements specified in the referenced PDSs were met for the AN Farm to 200E Waste Transfer System Upgrade (WBS 1.4.L) package. Each appendix of this report contains a specific verification report for the applicable PDS associated with this work package. Each appendix is a stand alone document that follows the same section numbering as the applicable PDS for ease of cross referencing. Each requirement is listed and followed by a "verification" section that documents how the requirement has been verified. Table 4-1 of each applicable PDS lists the requirements and how they are to be verified.

The verification method listed in Table 4-1 is being considered as the minimum required verification method. This report is a "living document" and will be revised and updated as information changes and/or becomes available.

The following appendices are attached:

Appendix A Requirements Verification for PDS-001, Project Development Specification for Transfer Piping 
Appendix B Requirements Verification for PDS-002, Project Development Specification for Valve Pit Manifold

Appendix C Requirements Verification for PDS-003, Project Development Specification for Pit Leak Detection

Appendix D Requirements Verification for PDS-005, Project Development Specification for Special Protective Coating

\subsection{SCOPE}

In providing the PDS requirements verification associated with the AN Farm to $200 \mathrm{E}$ Waste Transfer System Upgrade package for Project W-314, only those requirements which are applicable to this specific package are analyzed. The specific scope of work associated with the AN Farm to 200E Waste Transfer System Upgrade package includes:

- Four (4) new process lines installed in the 241-AN Tank Farms

- New valve manifolds for Pump Pit 241-AN-01A

- New pit leak detector for 241-AN-04D, Slurry Receiver Pit

- New pit leak detection for Pump Pits 241-AN-01A and 04A

- Valve position indication system for new manifolds

- 1 new 3-inch nozzle in 241-AN-04A for new 3-inch SN-636 process line

- $\quad 2$ new 3-inch nozzles in 241-AN-01A for new 3-inch SNL-3150 and $\mathrm{SN}-630$ process lines

- New low point encasement pipe leak detectors for Waste Transfer Lines SN-630, and SN-636.

- $\quad$ Special Protective Coating for each pit

- New Pit 241-AN-04D, Slurry Receiver Pit and Cover Block

Approval of this document signifies the customer acceptance of the applicability of the requirements and how these requirements are fulfilled. 


\section{APPENDIX A}

\section{Requirements Verification}

For

PDS-001

Transfer Piping 


\section{REQUIREMENTS VERIFICATION}

FOR

\section{TRANSFER PIPING}

\subsection{SCOPE}

This appendix documents how the requirements listed in the Project Development Specification (PDS) for the Transfer Piping (HNF-SD-W314-PDS-001) are satisfied for the new process lines that will be installed by Project $W-314$ in the 241-AN Tank Farm.

\subsection{APPLICABLE DOCUMENTS}

For a list of the applicable documents, refer to the appropriate PDS.

\subsection{REQUIREMENTS}

\subsection{Item Definition}

\subsection{Characteristics}

\subsubsection{Performance Characteristics}

The primary and secondary transfer piping shall meet the performance requirements stated in this section.

\subsubsection{Confine Waste}

After the transfer pump has started, the waste transfer system shall confine the waste during transfers.

3.2.1.1.1 The transfer piping shall support an interior corrosion/erosion allowance of $0.01 \mathrm{~mm}$ per year $(0.4$ mils per year) for the life of the system.

Verification: (Analysis) The transfer piping pressure design for ASME B31.3 accounts for the corrosion allowance. The requirement is verified by Calculation W314-P-053, Pressure Design for Transfer Piping and Encasements.

3.2.1.1.2 The transfer piping shall be capable of transferring the waste at a Reynolds number greater than or equal to 20,000 .

Verification: (Analysis) The requirement depends on the transfer pump capacity, the transfer route pressure drop, the viscosity, and the specific gravity of the waste to be transferred. With the new 3-in transfer lines, a transfer 
from the AN-Farm to the AP-Farm would meet this requirement with a flow rate of $140 \mathrm{gpm}$ for waste with a specific gravity of 1.4 and viscosity of 10 centipoise (Ref. WHC-SD-WM-TI-750, page A-212). These parameters are used as the design point for Project $W$ 314. However, Calculation W314-P-101 verifies this requirement for several other transfer routes and corresponding flow parameters.

3.2.1.1.3 The transfer piping shall have a head loss no greater than 10 meters per 100 meters (or 10 feet per 100 feet) of equivalent length.

Verification: (Analysis) The "resistance coefficients K" for the transfer piping system components are used in calculating the equivalent length of straight pipe according to Crane Technical Paper No. 410, Flow of Fluids (Crane). The above requirement is for the equivalent length that includes all the piping components. The pressure drop per equivalent length 100 feet of 3 inch, sch. 40 steel pipe according to Crane is 2.24 psi for a $150 \mathrm{gpm}$ flow rate of water. The prorated pressure drop for a design flow rate of $140 \mathrm{gpm}$ and corrected for a fluid of specific gravity 1.4 is 2.78 psi. This is equivalent to a head loss of 6.44 feet of water per 100 feet of 3 inch pipe which meets the above requirement.

3.2.1.1.4 The transfer and new AZ Valve Pit drain piping (except lines WT-SNL3150 and WT-SLL-3160), including encasement piping, shall be capable of supporting a design pressure of 400 psig.

Verification: (Analysis) The piping and encasement will support a design pressure of $400 \mathrm{psig}$. The pressure design for the transfer piping per ASME B31.3 is documented in Calculation W314-P-053.

3.2.1.1.5 The secondary containment (encasement) piping for the transfer piping (except lines WT-SNL-3150 and WT-SLL-3160) shall be capable of supporting a design pressure of 400 psig.

Verification: (Analysis) The encasement piping will support a design pressure of 400 psig. The pressure design is documented in Calculation W314-P-053.

3.2.1.1.6 The primary piping for transfer lines WT-SNL-3150 and WT-SLL-3160 shall be capable of supporting a design pressure of 1490 psig.

Verification: (Analysis) The primary piping will support a design pressure of 1490 psig. The pressure design for the primary piping per ASME B31.3 is documented in Calculation W314-P-053. 
3.2.1.1.7 The secondary containment (encasement) piping for extensions transfer lines WT-SNL-3150 and WT-SLL-3160 shall be capable of supporting a design pressure of 50 psig.

Verification: (Analysis) The secondary containment for WT-SNL3150 and WT-SLL-3160 will support a design pressure of 50 psig and is documented in Calculation W314-P053.

3.2.1.1.7.1 WT-SNL-3150 and WT-SLL-3160 encasements shall be protected from overpressure.

Verification: (Analysis) The encasements are protected from over pressure by the installation of rupture disks, reference Drawings $\mathrm{H}-14-103335$ and $\mathrm{H}-14-103339$.

Rupture Disk AN01A-WT-PSE-423 protects line SNL3150 and Rupture Disk ANO4D-WT-PSE-103 protects line SLL-3160.

3.2.1.1.8 The transfer piping system shall be capable of maintaining the temperature of the contents of the piping system such that the contents do not lose more than $20^{\circ} \mathrm{F}$ during a worst case distance \& flow transfer.

Verification: (Analysis) This requirement is not met. Verified by Calculation W314-P-006, Inside Pit and Buried Pipeline Heat Loss Calculations. This calculation shows that for a worst case transfer from the AN-Tank Farm to the APTank Farm at $139 \mathrm{gpm}$ the total temperature drop would be less than $10^{\circ} \mathrm{F}$.

The additional runs of piping added by this project that extend the W-058 cross-site transfer lines will result in a $1{ }^{\circ} \mathrm{F}$ to $2^{\circ} \mathrm{F}$ additional temperature drop for a cross-site transfer to the AN Tank Farm. Based on the W-058 Calculation W-058-P-11, a $200^{\circ} \mathrm{F}$ transfer at $139 \mathrm{gpm}$ from SY to AN through the WT-SNL-3150 line will result in a temperature drop of about $28^{\circ} \mathrm{F}$ and for a transfer through the WT-SLL-3160 line the temperature drop will be about $22^{\circ} \mathrm{F}$ which is based on a $6^{\circ} \mathrm{F}$ rise through the booster pump.

3.2.1.1.9 The transfer piping shall be compatible with the waste chemical composition ranges listed in Table 3-1 and the waste radionuclide concentrations listed under the W-314 column in Table 3-2.

Verification: (Analysis) This requirement is verified by the use of ASTM A312 TP 304L Stainless Steel (ss) as the material of construction for the transfer piping components (Ref. 
Construction Specification W-314-C5, Section 15493, Pipe Codes). The 304L ss has a history of successful use and testing with the Hanford Site waste chemistry and was recommended as the material for the primary pipe according to the Internal Memo 7F540-94-019, June 10, 1994, and Projects W-058/W-028 Material of Construction Position Paper. The waste composition listed in the WHC-SD-W058-FDC-001, Rev. 4 is the worst case inventory composition for the TWRS transfer system. The W-058 FDC specifies 304L ss as the primary pipe material of construction. Therefore, $304 \mathrm{~L}$ ss will meet the requirement for waste chemical composition.

Metallic components of the transfer piping system are not affected by the radionuclide concentrations. The radiation requirements for the encasement leak detection system are addressed in para. 3.7.2.2.1.

3.2.1.1.10 The transfer piping shall be provided with radiation shielding which shall meet the design objective to maintain exposure levels below an average of $0.5 \mathrm{mrem}$ ( 5 microsieverts) per hour and as far below this average as is reasonably achievable. The goal for reasonably achievable is 0.05 mrem ( 0.5 microsieverts) per hour or less. Exposure rates shall be determined using the radionuclide concentrations listed under the W-314 column in Table 3-2 at a distance of 30 centimeters from any surface through which the radiation penetrates.

Verification: (Analysis) Verified by Calculation W314-P-016, Soil Requirement for Covering a 3" by 6" Encased Waste Transferring Line. The shielding meets the $0.5 \mathrm{mrem}$ requirement. To meet the 0.05 mrem goal, the soil covering would have to be increased by approximately 9 inches. This increase would require more berming of the transfer lines. Under normal transfer conditions an operator is not standing $30 \mathrm{~cm}$ from the transfer route. Based on engineering judgement, it was determined that meeting the $0.5 \mathrm{mrem}$ requirement is conservative due to the source term being worst case and exposure time being limited to transfers only. In addition, the 0.05 mrem goal will be met for a majority of the waste that will be transferred because its source term is not anticipated to be as high as the design case.

\subsubsection{Confine Flush}

After the flush of the transfer system has started, the waste transfer system shall confine the flush water during the flush. 
3.2.1.2.1 The transfer piping shall be capable of confining flush water with the following properties:

- Volumetric flow rate of $151-530 \mathrm{~L} / \mathrm{min}(40-140 \mathrm{gpm})$

- Temperature of $12.8-66^{\circ} \mathrm{C}\left(55-150^{\circ} \mathrm{F}\right)$

- $\quad \mathrm{pH}$ of no less than 7 and maximum of 14 .

Verification: (Analysis) The 3 inch, sch. 40 steel pipe was shown to be capable of handling a flow rate of $210 \mathrm{gpm}$ (Ref. para. 3.2.1.1.6). The transfer piping system is rated for the maximum design temperature of $200^{\circ} \mathrm{F}$ and the compliance for this requirement is the same as under para 3.2.1.1.7. The $\mathrm{pH}$ value $z 7$ is within the waste property $\mathrm{pH}$ range and the compliance for this requirement is the same as under para 3.2.5.2.3.

\subsubsection{Physical Characteristics}

3.2.2.1 The transfer lines shall be buried double-walled pipe (i.e., primary pipe within an encasement pipe).

Verification: (Analysis) A 3-inch primary pipe within a 6-inch encasement pipe is used for the new transfer piping as verified by Procurement Specification W-314-P3.

3.2.2.2 The transfer piping shall slope continuously in one direction at a minimum slope of $0.25 \%$ and a maximum slope of $10 \%$.

Verification: (Analysis) This requirement is verified by Drawings $\mathrm{H}-14-$ 103236 through $\mathrm{H}-14-103238$.

(Exam) This requirement is verified by the final as-built survey data.

3.2.2.3 Releases of hazardous materials postulated to occur because of Design Basis Accidents (DBAs) shall be limited by designing the transfer line such that at least one confinement system remains fully functional following any credible DBA (i.e., unfiltered/unmitigated releases of hazardous levels of such materials shall not be allowed following such accidents).

Verification: (Analysis) This requirement will be verified by the vendors design calculations per Procurement Specification W-314-P3. This Calculation will be a dynamic analysis of the transfer piping using the Safety Class response spectra provided in HNF-SD-W314-PDS001. The stress analysis results will show that even with the applied seismic load the piping system is within the allowables of ASME B31.3 and, therefore, would remain functional. 
Table 3-1. Chemical Composition Range (Sheet 1 of 2)

\begin{tabular}{|c|c|c|c|c|}
\hline \multicolumn{5}{|c|}{ Retrieved waste } \\
\hline \multirow[t]{3}{*}{ Species } & \multicolumn{2}{|c|}{ DST } & \multicolumn{2}{|c|}{ SST } \\
\hline & \multicolumn{2}{|c|}{ Anion/cation } & \multicolumn{2}{|c|}{ Anion/cation } \\
\hline & $\min \mathrm{mol} / \mathrm{L}$ & $\max \mathrm{mol} / \mathrm{L}$ & $\min \mathrm{mol} / \mathrm{L}$ & $\max \mathrm{mol} / \mathrm{L}$ \\
\hline $\mathrm{Ag}$ & 0 & 0.0013 & - & - \\
\hline Al & 0.05 & 1.1 & 0.029 & 0.5 \\
\hline As & 0 & 0.0066 & - & - \\
\hline B & 0 & 0.013 & - & - \\
\hline $\mathrm{Ba}$ & 0 & 0.0004 & 0 & 0.0014 \\
\hline $\mathrm{Bi}$ & - & - & 0 & 0.076 \\
\hline $\mathrm{Ca}$ & 0.0014 & 0.1 & 0 & 0.17 \\
\hline $\mathrm{Cd}$ & 0 & 0.0074 & 0 & 0.0007 \\
\hline $\mathrm{Cr}$ & 0.0067 & 0.28 & 0.0001 & 0.091 \\
\hline $\mathrm{Cu}$ & 0 & 0.02 & - & - \\
\hline $\mathrm{Fe}$ & 0.0004 & 0.26 & 0.0057 & 0.89 \\
\hline $\mathrm{Hg}$ & 0 & $2.8 \mathrm{E}-05$ & 0 & 0.0001 \\
\hline K & 0.044 & 0.55 & 0.0002 & 0.0095 \\
\hline $\mathrm{La}, \mathrm{Nd}$ & 0 & 0.0066 & 0 & 0.001 \\
\hline $\mathrm{Mg}$ & 0.0004 & 0.046 & - & - \\
\hline$M n$ & 0.0003 & 0.16 & 0.0009 & 0.41 \\
\hline Mo & 0 & 0.0029 & - & - \\
\hline $\mathrm{Na}$ & 1.6 & 10.7 & 1.6 & 7.1 \\
\hline $\mathrm{Ni}$ & 0.0002 & 0.008 & 0 & 0.042 \\
\hline $\mathrm{Pb}$ & 0 & 0.004 & 0 & 0.12 \\
\hline $\mathrm{Pd}, \mathrm{Rh}$ & 0 & 0.0063 & - & - \\
\hline $\mathrm{Si}\left(\mathrm{SiO}_{2}\right)$ & 0.0024 & 0.028 & 0.0004 & 0.46 \\
\hline $\mathrm{Ti}$ & 0 & 0.002 & - & - \\
\hline
\end{tabular}


Table 3-1. Chemical Composition Range (Sheet 2 of 2)

\begin{tabular}{|c|c|c|c|c|}
\hline \multicolumn{5}{|c|}{ Retrieved waste } \\
\hline \multirow[t]{3}{*}{ Species } & \multicolumn{2}{|c|}{ DST } & \multicolumn{2}{|c|}{ SST } \\
\hline & \multicolumn{2}{|c|}{ Anion/cation } & \multicolumn{2}{|c|}{ Anion/cation } \\
\hline & $\min \mathrm{mol} / \mathrm{L}$ & $\max \mathrm{mol} / \mathrm{L}$ & $\min \mathrm{mol} / \mathrm{L}$ & $\max \mathrm{mol} / \mathrm{L}$ \\
\hline U & 0 & 0.0092 & - & - \\
\hline $\mathrm{Zr}\left(\mathrm{ZrO}_{2}\right)$ & 0 & 0.3 & 0 & 0.065 \\
\hline Acetate & - & - & 0 & 0.0055 \\
\hline Citrate & 0 & 0.03 & 0.0042 & 0.06 \\
\hline EDTA & 0 & 0.016 & 0 & 0.011 \\
\hline HEDTA & 0 & 0.021 & - & - \\
\hline $\mathrm{Fe}(\mathrm{CN})_{6}$ & - & - & 0 & 0.025 \\
\hline $\mathrm{Cl}$ & 0.003 & 0.17 & 0 & 0.022 \\
\hline $\mathrm{CO}_{3}$ & 0.03 & 0.69 & 0.014 & 0.38 \\
\hline $\mathrm{F}$ & 0.014 & 1 & 0.001 & 0.71 \\
\hline $\begin{array}{l}\text { Fission } \\
\text { product }\end{array}$ & 0 & 0.0001 & - & - \\
\hline $\mathrm{NO}_{2}$ & 0.1 & 1.8 & 0.0086 & 0.83 \\
\hline $\mathrm{NO}_{\mathrm{x}}\left(\mathrm{NO}_{3}\right)$ & 0.15 & 3.6 & 0.64 & 5.1 \\
\hline $\mathrm{OH}$ & 0.24 & 4.4 & 0.25 & 6.9 \\
\hline $\mathrm{PO}_{4}$ & 0 & 0.4 & 0.0007 & 3.8 \\
\hline $\mathrm{SO}_{4}$ & 0.003 & 0.16 & 0.01 & 0.22 \\
\hline TOC & 0 & 2 & - & - \\
\hline $\begin{array}{l}\text { DST } \\
\text { EDTA } \\
\text { HEDTA } \\
\text { SST } \\
\text { TOC }\end{array}$ & $\begin{array}{l}=\text { Double-she } \\
=\text { Ethylenedi } \\
=N \text {-(hydroxy } \\
=\text { Single-shel } \\
=\text { Total orgar }\end{array}$ & $\begin{array}{l}\text { I)-ethylenedia } \\
\text { etracetic aci } \\
\text { arbon }\end{array}$ & iacetic aci & \\
\hline
\end{tabular}


Table 3-2. Radio Nuclide Concentrations

\begin{tabular}{|c|c|c|c|}
\hline \multirow{2}{*}{ Nuclide } & \multicolumn{3}{|c|}{ Nuclide concentrations $(\mathrm{Bq} / \mathrm{L})$} \\
\cline { 2 - 4 } & ${ }^{\text {a} A l l ~ l i q u i d s}$ & ${ }^{\text {a}}$ All solids & ${ }^{\mathrm{b}} \mathrm{W}-314$ \\
\hline${ }^{14} \mathrm{C}$ & $2.3 \mathrm{E}+05$ & $1.6 \mathrm{E}+05$ & $2.3 \mathrm{E}+05$ \\
\hline${ }^{60} \mathrm{Co}$ & $9.5 \mathrm{E}+06$ & $4.9 \mathrm{E}+08$ & $1.7 \mathrm{E}+08$ \\
\hline${ }^{79} \mathrm{Se}$ & $\mathrm{c}$ & $1.7 \mathrm{E}+04$ & $1.7 \mathrm{E}+04$ \\
\hline${ }^{90} \mathrm{Sr}$ & $1.1 \mathrm{E}+10$ & $2.9 \mathrm{E}+12$ & $9.6 \mathrm{E}+11$ \\
\hline${ }^{90} \mathrm{Y}$ & $1.1 \mathrm{E}+10$ & $2.9 \mathrm{E}+12$ & $9.6 \mathrm{E}+11$ \\
\hline${ }^{99} \mathrm{Tc}$ & $1.7 \mathrm{E}+07$ & $1.2 \mathrm{E}+10$ & $4.0 \mathrm{E}+09$ \\
\hline${ }^{106} \mathrm{Ru}$ & $9.9 \mathrm{E}+02$ & $7.2 \mathrm{E}+04$ & $2.4 \mathrm{E}+04$ \\
\hline${ }^{125} \mathrm{Sb}$ & $3.4 \mathrm{E}+04$ & $1.8 \mathrm{E}+08$ & $5.9 \mathrm{E}+07$ \\
\hline${ }^{129} \mathrm{I}$ & $2.0 \mathrm{E}+04$ & $6.4 \mathrm{E}+06$ & $2.1 \mathrm{E}+06$ \\
\hline${ }^{134} \mathrm{Cs}$ & $6.1 \mathrm{E}+06$ & $9.4 \mathrm{E}+06$ & $7.2 \mathrm{E}+06$ \\
\hline${ }^{137} \mathrm{Cs}$ & $8.8 \mathrm{E}+10$ & $1.0 \mathrm{E}+11$ & $9.2 \mathrm{E}+10$ \\
\hline${ }^{144} \mathrm{Ce}$ & $9.1 \mathrm{E}+00$ & $3.4 \mathrm{E}+02$ & $1.2 \mathrm{E}+02$ \\
\hline${ }^{147} \mathrm{Pm}$ & $3.6 \mathrm{E}+07$ & $\mathrm{c}$ & $3.6 \mathrm{E}+07$ \\
\hline${ }^{154} \mathrm{Eu}$ & $2.4 \mathrm{E}+09$ & $1.1 \mathrm{E}+10$ & $5.2 \mathrm{E}+09$ \\
\hline${ }^{155} \mathrm{Eu}$ & $5.9 \mathrm{E}+07$ & $5.0 \mathrm{E}+06$ & $5.9 \mathrm{E}+07$ \\
\hline${ }^{237} \mathrm{~Np}$ & $2.3 \mathrm{E}+05$ & $9.9 \mathrm{E}+08$ & $3.3 \mathrm{E}+08$ \\
\hline${ }^{238} \mathrm{Pu}$ & $1.8 \mathrm{E}+06$ & $1.9 \mathrm{E}+08$ & $6.4 \mathrm{E}+07$ \\
\hline${ }^{239} \mathrm{Pu}$ & $3.6 \mathrm{E}+07$ & $1.6 \mathrm{E}+09$ & $5.5 \mathrm{E}+08$ \\
\hline${ }^{241} \mathrm{Pu}$ & $2.6 \mathrm{E}+08$ & $3.8 \mathrm{E}+09$ & $1.4 \mathrm{E}+09$ \\
\hline${ }^{241} \mathrm{Am}$ & $4.2 \mathrm{E}+07$ & $1.1 \mathrm{E}+10$ & $3.7 \mathrm{E}+09$ \\
\hline${ }^{242} \mathrm{Cm}$ & $1.1 \mathrm{E}+01$ & $2.0 \mathrm{E}+02$ & $7.3 \mathrm{E}+01$ \\
\hline${ }^{244} \mathrm{Cm}$ & $4.2 \mathrm{E}+05$ & $6.1 \mathrm{E}+07$ & $2.0 \mathrm{E}+07$ \\
\hline
\end{tabular}

${ }^{a}$ From Table 1a., Van Keuren, J. C., 1996, Tank Waste Compositions and Atmospheric Dispersion Coefficients for use in Safety Analysis Consequence Assessments, WHC-SD-WM-SARR-016, Rev. 2, Westinghouse Hanford Company, Richland, Washington.

${ }^{b} \mathrm{~W}-314$ values represent a bounding mixture for design of $67 \%$ liquid and $33 \%$ solid, except for ${ }^{14} \mathrm{C}$ and ${ }^{155} \mathrm{Eu}$ where the maximum liquid value was used as it is higher than the mix and for ${ }^{79} \mathrm{Se}$ and ${ }^{147} \mathrm{Pm}$ where data is not available.

'No available data.

${ }^{d} \mathrm{The}{ }^{239} \mathrm{Pu}$ activity concentration also includes ${ }^{240} \mathrm{Pu}$. 
3.2.2.4 Transfer line design shall provide attenuation features for postulated accidents (up to and including DBAs) that preclude offsite releases that would cause doses greater than the DOE 5400 series limits for public exposure. In addition, to the extent practical, such releases shall be maintained as low as reasonably achievable (ALARA).

Verification: (Analysis) To attenuate postulated accidents, the transfer piping encasement has been designed as a Safety Class component (Ref. para. 3.3.6.1.1), with enhanced weld NDE requirements (Ref. Construction Specification W-314-C5, Section 15493 and Procurement Specification W-314-P3). This will provide adequate assurance that any releases will be maintained ALARA.

3.2.2.5 Pipe bends (i.e. at least five pipe diameters) are preferred to buttwelding elbows and shall be used where possible.

Verification: (Analysis) This requirement is verified in the Procurement Specification W-314-P3.

3.2.2.6 The primary piping shall be 3-inch, Schedule 40 .

Verification: (Analysis) A 3-inch schedule 40 primary pipe is used for the new transfer piping as verified by Procurement Specifications W-314-P3, W-314-P4 and Construction Specification W-314-C5.

(Exam) This requirement will be verified by receipt inspection of the piping. Reference Procurement Specification W-314-P4.

3.2.2.7 Encasement (secondary containment) piping shall have connections to introduce dry air or nitrogen for pneumatic testing.

Verification: (Analysis) This requirement is verified by Drawings $\mathrm{H}-14-$ 103333, $\mathrm{H}-14-103334$, and $\mathrm{H}-14-103335$.

3.2.2.8 The encasement pipe shall be capable of being isolated for periodic pressure testing.

Verification: (Analysis) This requirement is verified by Drawings $\mathrm{H}$ 14-103333, H-14-103334, and H-14-103335.

3.2.2.9 The encasement piping shall extend through the concrete wall of the pits to maintain secondary containment.

Verification: (Analysis) This requirement is verified by Drawings $\mathrm{H}-14$ 103333, $\mathrm{H}-14-103334$, and $\mathrm{H}-14-103335$. 
3.2.2.10 All transfer lines, shall be foam insulated and jacketed with fiberglassreinforced polyester resin (FRP) jacket.

Verification: (Analysis) The requirement is passed on to the contractor per Procurement Specification W-314-P3 and will be verified by $Q C$ during receipt inspection.

3.2.2.11 The cross-site extension lines SNL-3150 and SLL-3160 shall use a continuous leak detection system with pull ports provided in the encasement pipe to match the existing cross-site transfer lines leak detection system. In addition, SLL-3160 shall utilize a leak detection system based on a pressure rise in the encasement. All other transfer piping shall use a low-point leak detection system.

Verification: (Analysis) The cross-site extension lines SNL-3150 and SLL-3160 continuous leak detection systems are not included in this package. The line SLL-3160 pressure monitoring system (ANO4D-WT-PASTA-101 and ANO4DWT-PASTA-102) is verified by Drawing $\mathrm{H}-14-103366$. The low point encasement leak detectors included in this package are ANO1A-WT-LDE-202 and ANO4A-WT-LDE204. See Drawings H-14-103354 and H-14-103360.

\subsubsection{Reliability}

3.2.3.1 The design life of the transfer piping shall be 35 years with the exception of the W-058 extension lines, WT-SLL-3160 and WT-SNL3150 , which shall have a design life of 40 years. Replaceable components shall have a design life of 12 years.

Verification: (Analysis) This requirement is verified by Calculation W314-P-053, Pressure Design for Transfer Piping and Encasement. In this analysis, the piping wall thickness is reduced by 0.014 -in which is 0.4 mils/year (para. 3.2.1.1.1) over a 35-year design life. This is also done for the encasement closure analysis shown in Calculations W314-P-017 and W314-P-018.

3.2.3.2 Normal operation of the cathodic protection system shall be 24 hours per day throughout the year.

Verification: (Analysis) This design package is only providing bonding jumpers to electrically tie to the existing cathodic protection system (see Drawing H-14-103384). Electrically jumping the new pipe stub outs into the existing cathodic protection system supports current operation of the system. 
3.2.3.3 The leak detection system shall be capable of detecting a leak with a probability of detection of 0.95 and a probability of false alarm of 0.05 .

Verification: (Analysis) The leak detection system availability based on a mean-time-to-repair of 4 hours and a mission time of 5 years is 0.9965 based on Calculation W314-1-055. The probability of a false alarm for the leak detection systems in a period of one year is 0.0135 per Calculation W314-1-058.

\subsubsection{Fault Detection/Fault Isolation}

Designs shall provide for the detection and isolation of faults to systems, structures, and components as necessary in order to minimize the risks associated with faulty operation to plant, personnel and environment. Protection systems and associated instrumentation and controls shall be designed in accordance with DOE 6430.1a, Section 1660-99.0.2.

Verification: (Analysis) Isolation: Each leak detection relay cabinet enclosure is equipped with a disconnect switch. This mechanical device will terminate power when activated manually. Each cabinet is also equipped with an internal dc power supply. This supply is energized from the enclosure power that terminates when the disconnect is operated. Detection: The encasement leak detection relay cabinets are supplied 120 volts from a circuit breaker panel. In the event a fault occurs anywhere in this circuit, the breaker would isolate all encasement leak detectors fed from this circuit. This design complies with the requirements of DOE Order $6430.1 \mathrm{a}$, Section 1660-99.0.2 (Ref. FDNWs DOE 6430.1a Checklist).

\subsubsection{Maintainability}

3.2.4.1 The process pit located and buried portions of the transfer piping system shall require no preventive or corrective maintenance for the design life of the system.

Verification: (Analysis) The transfer piping system is designed to the requirements for corrosion allowance (para 3.2.1.1.1), double-walled pipe (para 3.2.2.1), minimum design life of 35 years (para 3.2.3.1), and for seismic loads (para 3.2.5.1.3). Satisfying these requirements provides adequate assurance that no preventive or corrective maintenance will be required. 
3.2.4.2 The replaceable components of the transfer piping system shall be designed to allow for corrective maintenance within 25 days.

Verification: (Analysis) The only replaceable component of the system is the encasement leak detection probe. The leak detection probe is a fabricated component and it is assumed that spares will be available on site to meet the 25-day requirement. In addition, the probe wire/cable has a special radiation resistant coating and spare cable should be maintained. The continuous leak detection cable is not anticipated to require replacement but can be replaced if required. It cannot be replaced within the 25 days.

3.2.4.3 The accessible components of the transfer piping system shall have a preventive maintenance frequency no less than annually.

Verification: (Analysis) The probes are capable of being removed from the top of the cover block prior to or without the removal of the cover block. See drawing H-14-100981 for details of this design.

3.2.4.4 The maximum time to repair the low point encasement leak detection system, excluding craft time to mobilize and enter tank farms, shall be equal to or less than 4 hours.

Verification: (Analysis) All components of the leak detection system, with the exception of the leak detection probes, and probe wire, are commercially available, off-the-shelf items. It is assumed that spare components will be maintained on-site to support maintenance requirements. The design of the system allows for easy access to all components outside the pit. The probes inside the pits are also designed to allow for removal without the cover blocks being removed. With the current design and after setup time, the components can be repaired within a 3.9 hour time period as documented by Calculation W314-1056.

3.2.4.5 The low point encasement leak detection system sensors shall be testable in place by the addition of water. The encasement leak detection pressure alarm system shall be testable by addition of air or inert gas.

Verification: (Analysis) The low point encasement leak detection system can be tested in place by introducing water into the encasement. The water may be introduced into the encasement from a test riser for each waste transfer line, SN-630 and SN-636, shown on Drawings $\mathrm{H}-14$ - 
103347 and $\mathrm{H}-14-103348$. For details on how the leak detection system is activated, refer to section 3.7.2.1.1.

The encasement leak detection pressure alarm system can be tested in place by addition of air or inert gas via a test tee and isolation valve. See Drawing H-14-103367.

(Test) This requirement will be verified by ATP after construction.

3.2.4.6 Access capability shall be provided along the buried transfer piping route for periodic verification that no excavation is in progress within 15 feet of the transfer line, periodic radiological survey of the line in use to verify shielding is adequate, periodic access for herbicide spraying and inspection for continuity, and periodic capability to perform a civil survey of the berm to ensure no transfer line settling has occurred and that no erosion detrimental to access and shielding is occurring.

Personnel will have foot traffic access to the top of bermed section of buried transfer lines; vehicles will not have access to the top of the berm.

Verification: (Analysis) The transfer lines are located within the AN Tank Farm. No berming is required. The Tank Farm grade is essentially flat with foot traffic access unrestricted and vehicular access restricted by the Tank Farm operating procedures only. Thus the transfer lines design complies with this requirement. Verification provided by the design package Drawings $\mathrm{H}-14-103236$ through H-14-103238.

\subsubsection{Environmental Conditions}

The systems and components covered by this specification shall be compatible with the environmental conditions listed below, as applicable. Performance Category (PC) 3 is assigned to Safety Class systems and PC1 is assigned to general service systems. The design and analysis of loads associated with existing systems shall, as a minimum, be performed to the design requirements of the existing system.

\subsubsection{Natural Environments}

\subsection{Ambient Air Temperature}

The ambient air temperature range is $48.9^{\circ} \mathrm{C}\left(120^{\circ} \mathrm{F}\right)$ to $-35.5^{\circ} \mathrm{C}$ ($\left.32^{\circ} \mathrm{F}\right)$, and with a maximum 24 hour differential of $28.9^{\circ} \mathrm{C}\left(52^{\circ} \mathrm{F}\right)$.

Verification: (Analysis) Vendor data for the leak detection/pressure monitoring systems active components are as follows: 
Potter Brumfield - General Purpose Relay Type KRPA ($45^{\circ} \mathrm{C}$ to $70^{\circ} \mathrm{C}$ )

Potter Brumfield - Dual Coil Latch Relay Type KBP (-45

${ }^{\circ} \mathrm{C}$ to $85^{\circ} \mathrm{C}$ )

B/W Controls - Intrinsically Safe Relay Series 5300

$\left(-30^{\circ} \mathrm{F}\right.$ to $\left.175^{\circ} \mathrm{F}\right)$

MTL - Trip Amplifier, General Purpose MTL2313A or B $\left(-20^{\circ} \mathrm{C}\right.$ to $\left.60^{\circ} \mathrm{C}\right)$

MTL - Repeater Power Supply, MTL2441B $\left(-20^{\circ} \mathrm{C}\right.$ to $\left.60^{\circ} \mathrm{C}\right)$

Edwards - Strobe Light, 94DV2 $\left(-35^{\circ} \mathrm{F}\right.$ to $\left.50^{\circ} \mathrm{F}\right)$

The disconnect switch was verified to operate between $0^{\circ}$ and $140^{\circ} \mathrm{F}$ as documented per CGI Data Transmittal W-314-C1-29.2B Data Transmittal, Section 2.2.2.4.

Wiring inside the cabinet is type MTW which is required by UL508. High temperature rating for the MTW wire is $195^{\circ} \mathrm{F}$ per the NEC and UL1063. Insulation of the MTW wire is PVC per UL1063. The low temperature rating of PVC insulation is $-5^{\circ} \mathrm{F}$ per vendor catalog data.

Based on this design criteria, a heating element was needed to assure that the temperature inside the enclosure will not drop lower than $-20^{\circ} \mathrm{C}$. The heaters AN01A-WT-HTR-202, AN04A-WT-HTR-204, AN04DWT-HTR-101, and AN04D-WT-HTR-102 will be for the general purpose trip amplifiers AN01A-WT-EY-202, ANO4A-WT-EY-204, ANO4D-WT-PSHL-101 and ANO4DWT-PSHL-102 and the repeater power supplies ANO4DWT-PY-101 and AN04D-WT-PY-102. If the temperature inside the enclosure were to drop below $-20^{\circ} \mathrm{C}$, the trip amplifier would not be operating in the temperature zone specified by the manufacturer. This problem was resolved with the addition of the thermostatically controlled heater. By adding the heater, the temperature will not drop below the operating range for any device in the leak detection or pressure monitoring relay cabinets.

Passive components such as wire, fittings, disconnect switch and other metallic non-moving devices used in this design are vendor certified to operate within the ambient air temperature limits. 
This requirement is not applicable to the buried piping as the system is below grade where the minimum ambient temperature is the same as the minimum soil temperature $33.5^{\circ} \mathrm{F}$ (para 3.2.5.1.2).

\subsection{Soil Temperature}

The minimum soil temperatures below ground surface is:
$1.3 \mathrm{~cm}(0.5 \mathrm{in}):$
$-19.5^{\circ} \mathrm{C}\left(-3.0^{\circ} \mathrm{F}\right)$
$38 \mathrm{~cm}(15 \mathrm{in}):$
$-8.8^{\circ} \mathrm{C}\left(16.1^{\circ} \mathrm{F}\right)$
$92 \mathrm{~cm}(36 \mathrm{in})$ :
$0.8^{\circ} \mathrm{C}\left(33.5^{\circ} \mathrm{F}\right)$

Verification: (Analysis) The transfer piping system is below grade where the minimum ambient temperature is the same as the minimum soil temperature. The minimum soil temperature value is used in the piping flexibility analysis and will be documented in the submittals from the vendor per Procurement Specification W-314-P3.

\subsection{Seismic Loads}

\section{PC1 structures, systems, and components}

Earthquake load design of PC1 SSCs shall comply with the UBC, Seismic Zone 2B, for standard occupancy facilities.

\section{PC3 structures, systems, and components}

Earthquake load design of PC3 SSCs shall use dynamic analysis and site-specific design response spectra listed in Table 3-3.

Transfer piping primary and encasement shall be designed and analyzed to PC3 loads.

Dynamic values used in the dynamic analysis shall not exceed those listed for Response Level 2 damping values in Table 3-4.

Verification: (Analysis) This requirement is verified by vendors Calculations per Procurement Specification W-314-P3. Calculations W314-C-029, Pump Pits 01A and 04A Pump Structural Evaluation, W314-C-030, Pit Wall Evaluation, W314-C-034, Riser 10, i.e. Slurry Receiver, Pit Design and W-314-C-033, AN and WTS Wind Missile Shield. 
Table 3-3 - Response Spectra

\begin{tabular}{|c|c|c|c|c|c|c|}
\hline \multicolumn{7}{|c|}{ Horizontal Response Spectra "g" } \\
\hline \multirow{2}{*}{$\begin{array}{c}\text { Frequency } \\
\text { (Hertz) }\end{array}$} & \multicolumn{6}{|c|}{ Damping } \\
\hline & $0.50 \%$ & $2 \%$ & $5 \%$ & $7 \%$ & $10 \%$ & $12 \%$ \\
\hline 100 & 0.26 & 0.26 & 0.26 & 0.26 & 0.26 & 0.26 \\
\hline 33.3 & 0.26 & 0.26 & 0.26 & 0.26 & 0.26 & 0.26 \\
\hline 13.3 & 0.57 & 0.48 & 0.41 & 0.38 & 0.36 & 0.35 \\
\hline 10 & 0.77 & 0.59 & 0.47 & 0.43 & 0.38 & 0.36 \\
\hline 5 & 1.04 & 0.76 & 0.58 & 0.52 & 0.45 & 0.42 \\
\hline 3.3 & 0.98 & 0.72 & 0.54 & 0.48 & 0.42 & 0.39 \\
\hline 2 & 0.74 & 0.55 & 0.41 & 0.37 & 0.33 & 0.30 \\
\hline 1 & 0.45 & 0.34 & 0.26 & 0.23 & 0.21 & 0.19 \\
\hline 0.5 & 0.22 & 0.17 & 0.13 & 0.12 & 0.11 & 0.10 \\
\hline 0.25 & 0.08 & 0.06 & 0.05 & 0.05 & 0.04 & 0.04 \\
\hline \multicolumn{7}{|c|}{ Vertical Response Spectra "g" } \\
\hline \multirow{2}{*}{$\begin{array}{c}\text { Frequency } \\
\text { (Hertz) }\end{array}$} & \multicolumn{6}{|c|}{ Damping } \\
\hline & $0.50 \%$ & $2 \%$ & $5 \%$ & $7 \%$ & $10 \%$ & $12 \%$ \\
\hline 100 & 0.18 & 0.18 & 0.18 & 0.18 & 0.18 & 0.18 \\
\hline 33.3 & 0.18 & 0.18 & 0.18 & 0.18 & 0.18 & 0.18 \\
\hline 13.3 & 0.60 & 0.46 & 0.37 & 0.33 & 0.30 & 0.28 \\
\hline 10 & 0.66 & 0.49 & 0.37 & 0.33 & 0.29 & 0.27 \\
\hline 5 & 0.60 & 0.44 & 0.33 & 0.30 & 0.26 & 0.24 \\
\hline 3.3 & 0.48 & 0.36 & 0.27 & 0.24 & 0.21 & 0.19 \\
\hline 2 & 0.32 & 0.24 & 0.18 & 0.16 & 0.14 & 0.13 \\
\hline 1 & 0.19 & 0.14 & 0.11 & 0.10 & 0.09 & 0.08 \\
\hline 0.5 & 0.14 & 0.11 & 0.08 & 0.07 & 0.07 & 0.06 \\
\hline 0.25 & 0.06 & 0.05 & 0.04 & 0.03 & 0.03 & 0.03 \\
\hline
\end{tabular}


Table 3-4 - Response Level

\begin{tabular}{|l|c|}
\hline & Damping (\% of critical) \\
\cline { 2 - 2 } & Response Level 2 \\
\hline Demand/capacity ratio & 0.5 to 1.0 \\
\hline Welded and friction bolted metal structures & 4 \\
\hline Bearing-bolted metal structures & 7 \\
\hline $\begin{array}{l}\text { Prestressed concrete structures without } \\
\text { complete loss of prestress }\end{array}$ & 5 \\
\hline Reinforced concrete structures & 7 \\
\hline Masonry shear walls & 7 \\
\hline Wood structures with nailed joints & 10 \\
\hline Distribution systems & 5 \\
\hline $\begin{array}{l}\text { Massive low stressed components (pumps, } \\
\text { motors, etc.) }\end{array}$ & 3 \\
\hline Light welded instrument racks & 3 \\
\hline Electrical cabinets and other equipment & 4 \\
\hline $\begin{array}{l}\text { Liquid containing metal tanks } \\
\text { Implusive mode }\end{array}$ & 3 \\
\hline $\begin{array}{l}\text { Liquid containing metal tanks } \\
\text { Sloshing mode }\end{array}$ & 0.5 \\
\hline \begin{tabular}{l} 
a. \\
\hline
\end{tabular} & \\
\hline
\end{tabular}

\subsection{Wind Loads}

For PC3 systems:

"Fastest Mile" wind velocity:

"Three Second Gust" wind velocity:

Missile (horizontal):
$36 \mathrm{~m} / \mathrm{s}(80 \mathrm{mi} / \mathrm{h})$

$44 \mathrm{~m} / \mathrm{s}(100 \mathrm{mi} / \mathrm{h})$

$50 \times 100 \mathrm{~mm}(2 \times 4$ in.)

Timber plank weighing $7 \mathrm{~kg}$

(15 lb) @ $22 \mathrm{~m} / \mathrm{s}(50 \mathrm{mi} / \mathrm{h})$.

Maximum trajectory

height $=9 \mathrm{~m}(30 \mathrm{ft})$.

For PC1 systems:

"Fastest Mile" wind velocity:

$31 \mathrm{~m} / \mathrm{s}(70 \mathrm{mi} / \mathrm{h})$

"Three Second Gust" wind velocity: $\quad 38 \mathrm{~m} / \mathrm{s}(85 \mathrm{mi} / \mathrm{h})$ 
Verification: (Analysis) This requirement is verified by Calculations W314-C-008, AN Misc. Equipment Supports and W314C-033, AN and WTS Wind Missile Shield for the encasement leak detection relay cabinets. The calculation shows that the resulting load due to wind is very low and produces a design to protect from wind missiles. This requirement does not affect the design of the buried piping components.

\subsection{Snow Loads}

The ground snow loads are: $720 \mathrm{~Pa}\left(15 \mathrm{lb} / \mathrm{ft}^{2}\right)$

Verification: (Analysis) This requirement is verified by Calculations W314-C-008, AN Misc. Equipment Supports and W314C-033, AN and WTS Wind Missile Shield for the encasement leak detection relay cabinets. The calculation shows that the snow load for this relay cabinet is minimal compared to the structural strength of the relay cabinet material and supporting frame assembly. This requirement does not affect the design of the buried piping components.

\subsection{Relative Humidity}

The relative humidity range is 0 to $100 \%$ (Rate of change is negligible).

Verification: (Analysis) The buried piping components are not affected by this requirement. All devices affected by relative humidity are located in a NEMA $4 X$ rated enclosure as shown on Drawings $\mathrm{H}-14-100983$ and $\mathrm{H}$ 14-103368. The enclosure will be sealed and rated for rain, sleet, dust $\&$ hail. In addition, the operating limits of the trip amplifier, the repeater power supply and the switch operated relay are $5-95 \% \mathrm{RH}$. The humidity inside the enclosure is governed by the pressure and temperature inside and outside the enclosure. With the addition of a combination breather and drain (Refer to Drawing $\mathrm{H}-14-100983$ and $\mathrm{H}-14-103368$ ), the temperature and pressure inside the enclosure will equalize. Any additional build-up of condensation will drain out of the enclosure. Although the addition of the breather/drain cannot quantify what the humidity would be inside the enclosure if the humidity outside the enclosure was $100 \%$, it will be less than $100 \%$ due to the heat produced inside the cabinet from normally energized equipment. In the case where the humidity inside the enclosure falls below $5 \% \mathrm{RH}$, the breather will allow moisture absorption from the outside environment which will raise the relative humidity inside the enclosure. 
Engineering judgement with regards to relative humidity induced failure, is that electronic components would fail in a safe condition.

\subsection{Surface Precipitation}

The surface precipitation is 25 year, 24 hour, $4 \mathrm{~cm}$ (1.56 in).

Verification: (Analysis) The instrumentation components located outside the pits that would be affected by surface precipitation are protected by the leak detection relay enclosure or the pressure monitoring relay enclosure. The enclosures are designed as NEMA type $4 X$ with gaskets to protect the components inside from dust, dirt, oil and water. In addition, the electrical junction boxes and field terminal boxes have been specified to NEMA 4 to provide the necessary protection against dust and water.

\subsection{Hail Events}

The hail diameter is less than or equal to $1.9 \mathrm{~cm}(0.75 \mathrm{in})$.

Verification: (Analysis) All components that could be affected by hail are located within NEMA rated enclosures. These enclosures will provide adequate protection against the hail event. The buried piping components are not affected by this requirement.

\subsection{Sand and Dust}

The sand/dust concentration is $0.177 \mathrm{gm} / \mathrm{m}^{3}$ with a typical size of 350 $\mu \mathrm{m}$.

Verification: (Analysis) All components that could be affected by sand and dust are located within NEMA rated enclosures. These enclosures will provide adequate protection against sand and dust. The buried piping components are not affected by this requirement.

\subsection{Solar Radiation}

The solar radiation range is between $4 \mathrm{Watts} / \mathrm{m}^{2}$ and $406 \mathrm{Watts} / \mathrm{m}^{2}$.

Verification: (Analysis) The leak detection relay enclosure, the pressure monitoring relay enclosure and the electrode holder are the only components directly exposed to solar radiation. The inside temperature of the leak detection and pressure monitoring enclosures is limited by the maximum operating temperature limit of the trip amplifier and repeater power supply of $60^{\circ} \mathrm{C}$. At a maximum solar radiation of $406 \mathrm{Watts} / \mathrm{m}^{2}$, the temperature of the enclosure will increase significantly. 
However, Calculation W314-I-004 shows that with a maximum solar radiation of $406 \mathrm{Watts} / \mathrm{m}^{2}$ and a maximum ambient air temperature of $120^{\circ} \mathrm{F}$, the increased temperature due to solar radiation will not exceed the trip amplifier's temperature limit. In addition, this calculation considered the heat generated inside the enclosure from normally energized components. It was concluded that the enclosure would still be below the operating maximum of $60^{\circ} \mathrm{C}$ without the use of forced air moving through the cabinet. The buried piping components are not affected by this requirement.

\subsection{Glaze (See definition in Section 5.1)}

The glaze is $2.54 \mathrm{~cm}$ (1 in.).

Verification: (Analysis) All active components that glaze would affect are located inside an enclosure that is rated to protect against ice formation. In addition, Calculation W314-C-008 shows that as a design load, glaze (at 5.2 psf) does not affect the structural analysis of the enclosure. The rest of the buried piping components are not affected by this requirement.

\subsection{Ashfall Events}

A total combination load of snow fall and ash fall of $960 \mathrm{~Pa}\left(20 \mathrm{lb} / \mathrm{ft}^{2}\right)$ shall be used.

Verification: (Analysis) All active components that would be affected by ash are located inside an enclosure that is rated to protect against dust. In addition, Calculation W314-C008 shows that design loading due to an ashfull event would be negligible. The rest of the buried piping components are not affected by this requirements.

\subsection{Dead loads}

Dead loads include the weights of all permanent materials and equipment, including the structure's own weight. Design dead loads shall include the weight of all permanent service equipment. Load calculations shall include an allowance for any loadings anticipated to be added at a later date. Initially assumed loads shall be revised so that the final design reflects the configuration shown on the drawings.

The unit weights of materials and construction assemblies for buildings and other structures shall be those given in ASCE 7-95. Where unit weights are neither established in that standard nor determined by test or analysis, the weights shall be determined from data in manufacturer drawings or catalogs.

Verification: (Analysis) This requirement is met by the design of this transfer piping utilizing the soil surcharge in it's design. 
HNF-4533

Rev. 0

\subsection{Creep and Shrinkage Forces}

Concrete and masonry structures shall be investigated for stresses and deformations induced by creep and shrinkage. For concrete and masonry structures, the minimum linear coefficient of shrinkage shall be assumed to be $0.0002 \mathrm{~mm} / \mathrm{mm}$, unless a detailed analysis is undertaken. The theoretical shrinkage displacement shall be computed as the product of the linear coefficient and the length of the member.

Verification: (Analysis) This requirement is not applicable as the transfer piping, utilizes no structural concrete or masonry.

\subsection{Load Combinations and Allowable Stresses}

Load combinations, allowable stresses, and strength requirements for load conditions that include live load, dead load, snow load, and normal operating loads for all SSCs shall comply with the UBC or applicable system national codes and standards.

Load combinations, allowable stresses, and strength requirements for load conditions that include live load; dead load; snow load; normal operating loads; and NPH loads of extreme wind, earthquake, flood, and ashfall for all SSCs shall comply with DOE-STD-1020.

Load factors and load combinations for PC1 structures. systems, and components

Combine response from various loadings to determine the structural demand by using the UBC-specified load combination rules (e.g., load factors for ultimate strength design and unit load factors for allowable stress design).

Where:

$\begin{array}{lll}\mathrm{DL} & = & \text { DEAD LOAD } \\ \mathrm{LL} & = & \text { LIVE LOAD } \\ \mathrm{RL} & = & \text { ROOF LIVE LOAD } \\ \mathrm{S} & = & \text { SNOW LOAD } \\ W & = & \text { WIND LOAD } \\ \mathrm{E} & = & \text { EARTHOUAKE } \\ T & = & \text { THERMAL } \\ \mathrm{C} & = & \text { CREEP/SHRINKAGE }\end{array}$

Allowable Stress (AS) Design: All Construction

$A S=D L+L L+R L$ (or $S$ )

$A S=0.75[\mathrm{DL}+\mathrm{LL}+\mathrm{W}$ (or E) $]$

$A S=0.75[\mathrm{DL}+\mathrm{LL}+\mathrm{W}+\mathrm{S} / 2]$

AS $=0.75[\mathrm{DL}+\mathrm{LL}+\mathrm{S}+\mathrm{W} / 2]$

Ultimate Strength (U) Design: Reinforced Concrete

$U=1.4 \mathrm{DL}+1.7 \mathrm{LL}+1.7 \mathrm{RL}$ (or $1.7 \mathrm{~S}$ ) 


$$
\begin{array}{ll}
= & 0.75[1.4 D L+1.7 L L+1.7 W] \\
= & 1.05[D L+L L+E] \\
= & 0.9 D L+1.3 W(\text { or } 1.4 E) \\
= & 1.4[D L+T(\text { or } C)] \\
= & 0.75[1.4 D L+1.7 L L+1.4 T \text { (or } 1.4 C)]
\end{array}
$$

Strength (S) Design: Steel (Load \& Resistance Factor Design)

$$
\begin{array}{lll}
\mathrm{S} & = & 1.4 \mathrm{DL} \\
\mathrm{S} & = & 1.2 \mathrm{DL}+1.6 \mathrm{LL}+0.5(\mathrm{RL} \text { or } \mathrm{S}) \\
\mathrm{S} & = & 1.2 \mathrm{DL}+0.5 \mathrm{LL} \text { (or } 0.8 \mathrm{~W})+1.6(\mathrm{RL} \text { or } \mathrm{S}) \\
\mathrm{S} & = & 1.2 \mathrm{DL}+1.3 \mathrm{~W}+0.5 \mathrm{LL}+0.5(\mathrm{RL} \text { or } \mathrm{S}) \\
\mathrm{S} & = & 1.2 \mathrm{DL}+1.5 \mathrm{E}+0.5 \mathrm{LL} \text { (or } .2 \mathrm{~S}) \\
\mathrm{S} & = & 0.9 \mathrm{DL}-1.3 \mathrm{~W} \text { (or } 1.5 \mathrm{E})
\end{array}
$$

Load factors and load combination for PC3 structures, systems, and components

Combine response from various loadings to determine structural demand as follows.

Where:

$\begin{array}{lll}\mathrm{DL} & = & \text { DEAD LOAD } \\ \mathrm{LL} & = & \text { LIVE LOAD } \\ \mathrm{RL} & = & \text { ROOF LIVE LOAD } \\ \mathrm{S} & = & \text { SNOW LOAD } \\ \mathrm{W} & = & \text { WIND LOAD } \\ \mathrm{E} & = & \text { EARTHOUAKE } \\ \mathrm{A} & = & \text { ASHFALL } \\ \mathrm{T} & = & \text { THERMAL } \\ \mathrm{C} & = & \text { CREEP/SHRINKAGE }\end{array}$

Allowable Stress (AS) Design:

$$
\begin{array}{lll}
\mathrm{AS} & =\mathrm{DL}+\mathrm{LL}+\mathrm{RL} \text { (or } \mathrm{S}) \\
\mathrm{AS} & =0.62[\mathrm{DL}+\mathrm{LL}+\mathrm{RL} \text { (or } \mathrm{S})+\mathrm{W}+\mathrm{T} \text { (or } \mathrm{C})]
\end{array}
$$

for shear stress

$$
A S=0.71[D L+L L+R L(\text { or } S)+E(\text { or } A)+T(\text { or } C)]
$$

for all stress other than shear stress

$$
A S=0.59[D L+L L+R L(\text { or } S)+E(\text { or } A)+T \text { (or } C)]
$$

Ultimate Strength (U) Design:

$$
\begin{array}{lll}
U & = & 1.4 D L+1.7 L L+1.7 R L(\text { or } 1.7 S) \\
U & = & 1.4[D L+T \text { (or } C)] \\
U & = & D L+L L+R L(\text { or } S)+W(\text { or } E \text { or } A)+T(\text { or } C)
\end{array}
$$

Strength (S) Design: Steel (Load \& Resistance Factor Design)

$$
\begin{array}{lll}
S & = & 1.4 D L \\
S & = & 1.2 D L+1.6 L L+0.5(R L \text { or } S) \\
S & = & 1.2 D L+0.5 L L+1.6(R L \text { or } S) \\
S & = & D L+L L+R L(\text { or } S)+W(\text { or } E \text { or } A)+T
\end{array}
$$


Verification: (Analysis) This requirement is verified by Calculation W314-C-008, AN Misc. Equipment Supports and Calculation W314-C-033, AN and WTS Wind Missile Shield and meets the requirements.

3.2.5.2 Induced Environments

3.2.5.2.1 Waste Properties

Materials used that come in contact with the waste shall be capable of safely handling waste with the following properties:

Specific Gravity

Viscosity

Miller Number

$\mathrm{pH}$

Temperature

Solids Content

Particle Size

Note: $95 \%$

$<1$ percent of total particies 500 to 4000 microns
1 to 1.5

1 to 30 centipoise (Newtonian)

100 maximum

7 to 14

10 to $93^{\circ} \mathrm{C}\left(50\right.$ to $\left.200^{\circ} \mathrm{F}\right)$

$30 \mathrm{Vol} . \%$

0.5 to 4000 microns

Verification: (Analysis) The material of construction of the transfer piping component is ASTM A312 TP 304L Stainless Steel (ss) as referenced in the Pipe Codes of Construction Specification W-314-C5, Section 15493 and Procurement Specifications W-314-P3 and W-314P4. The $304 \mathrm{~L}$ ss has a history of successful use and testing with the Hanford Site waste chemistry and was recommended as the material for the primary pipe according to the Internal Memo, 7F540-94-019, dated June 10, 1994, Projects W-058/W-028, Material of Construction Position Paper. The waste properties listed above are identical of those of Project $W-058$ and are the worst case for Project W-314.

In addition, the encasement leak detection probe, probe insulating cover, and wire covering may come in contact with the waste. Therefore, the probe cover is made of PEEK (Polyetheretherketone) filled with glass and graphite. PEEK is a high performance thermoplastic that resists continuous temperatures of up to $480^{\circ} \mathrm{F}$. It features excellent chemical resistance, and high tensile strength and moisture absorption. Due to the application of the probe and probe cover, the only requirements that need to be addressed are the $\mathrm{pH}$ range, from $60 \%$ sulfuric acid to $40 \%$ sodium hydroxide, and at high temperatures. With this percentage range, PEEK meets the $\mathrm{pH}$ requirement. The waste temperature is far below that of PEEK breakdown temperatures (at $480^{\circ} \mathrm{F}$ ). For this design, PEEK is the most suitable material with radiation tolerances well 
above that required to be used in this application, while remaining to be machinable. The probe cover is considered an insulator and will protect the probes from unnecessary contact of metallic devices.

The probe wire coating is made of Tefzel 280 or HT2183 (DuPont) which exhibits some of the same properties as the probe cover. The wire insulation is approximately 5 inches from the bottom of the encasement pipe which is only 2 inches in diameter. In order for the leaking fluid to come in direct contact with the probe wire, pit floor would have to fill up beyond the height of the drain assembly and fill up the riser pipe. In the event the waste does contact the coated probe cable, Tefzel 280 will not break down with a pH in this range as it is specified by the vendor to have an excellent base and acidic resistance. The temperature at which Tefzel breaks down is $270^{\circ} \mathrm{C}$, which is above the waste temperature requirement.

The probe is made of solid stainless steel that has stable metallic properties that will withstand all of the above requirements.

\subsection{Radiation Tolerance}

\subsection{Inside Pit Radiation Level}

Materials used that are located inside a pit shall be capable of operating in the following radiation environment:

Total accumulated dose: $\quad 6 \times 10^{7}$ rads Dose rate: $1 \times 10^{7} \mathrm{mr} / \mathrm{hr}$

Verification: (Analysis) The instrument sensing line tubing portion of the pressure monitoring system used inside a pit is specified as Grade TP 304L Stainless Steel. See Construction Specification W-314-C5, Section 13440 , Pipe Code 1-28.

\subsection{Background Radiation Level}

Materials used that are located outside a pit, above grade, shall be capable of operating in the following radiation environment.

Total Accumulated Dose: $0.5 \mathrm{rad} /$ year Dose Rate: $0.25 \mathrm{mrem} / \mathrm{hour}$

Verification: (Analysis) All equipment outside the pit is protected in a metal enclosure and based on representative manufacturer information, will not break down at this radiation level. In addition, the equipment is similar to 
equipment that has previously been used in the tank farms without any adverse affects.

\subsection{Live Loads}

The transfer piping shall be designed for an AASHTO $\mathrm{H} 20-44$ wheel loading or a 110 ton wheeled Grove crane in the tank farm area.

Verification: (Analysis) This requirement is verified by Calculation for buried piping generated by Procurement Specification W314-P3.

\subsection{Encasement Temperature}

The encasement piping design temperature shall be $180^{\circ} \mathrm{F}$.

Verification: (Analysis) The encasement design temperatures is $180^{\circ} \mathrm{F}$ and is specified as such in Procurement Specification W314-P3 and Construction Specification W-314-C5.

\subsubsection{Transportability}

Not Applicable to this Specification.

\subsubsection{Flexibility and Expansion}

Each system design shall, to the maximum extent practicable, provide sufficient flexibility to accommodate for programmatic changes or operation modifications.

Verification: (Analysis) Not applicable to this package.

\subsection{Design and Construction}

\subsubsection{Materials, Processes, and Parts}

3.3.1.1 The transfer piping system shall meet the applicable design and construction requirements contained in DOE Order 6430.1 A.

Verification: (Analysis) Compliance with the DOE Order 6430.1A is verified by FDNWs DOE $6430.1 \mathrm{~A}$ Checklist. Specifically, the transfer system meets the following design and construction requirements of DOE Order 6430.1A:

- Design of the transfer piping system to ASME B31.3 (see para. 3.3.1.2) with the additional enhancements (Ref. FDNWs Checklist, W314-DOE6430-AN200E-P-1, Attachment 1) meets the requirement of DOE Order 6430.1A, Section 1300-3.2.

- The use of double-walled piping (see para. 3.2.2.1) and encasement leak detection meets the requirements of DOE Order 6430.1A, Sections 1300-7.4 and 1323-5.2. 
- Designing the transfer system such that at least one confinement system remains fully functional following any credible DBA (see para. 3.2.2.3) and providing attenuation features for postulated accidents (see para. 3.2.2.4) meets the requirements of DOE Order 6430.1A, Sections 1300-1.4.2 and 1323-5.2.

- $\quad$ Constructing the transfer system of fully welded piping (see para. 3.3.1.5) meets the requirement of DOE Order 6430.1A, Sections 1323-5.2 and 1540-99.0.6.

The primary and encasement piping, except PUREX nozzles, shall meet the applicable design and construction requirements contained in ASME B31.3.

Verification: (Analysis) Verified by incorporating this requirement in the Construction Specification W-314-C5, Section 15493, para. 2.2.9 and Procurement Specification W314-P3.

(Exam) This requirement will also be verified by examination during receiving inspection and/or construction.

3.3.1.3 The buried piping shall be designed in accordance with the guidelines provided in BNL 52361 .

Verification: (Analysis) Chapter 7 of BNL 52361 stipulates load conditions to be considered for the design of buried piping. These guidelines are satisfied by using the soil module in the Autopipe program. Both the primary and the encasement pipes are modeled and the applicable load conditions are entered into the Autopipe program. This will be verified in the vendor Calculations per Procurement Specification W-314-P3.

3.3.1.4 All concrete work shall meet the applicable design and construction requirements contained in $\mathrm{ACl}-318$.

Verification: (Analysis) This requirement is not applicable as there is no structural concrete used in the transfer piping.

(Exam) Not applicable to this package.

3.3.1.5 The buried transfer piping shall be fully welded construction.

Verification: (Analysis) This requirement is verified by Construction Specification W-314-C5, Section 15493, and Procurement Specification W-314-P3.

(Exam) This requirement will also be verified by examination during construction. 
3.3.1.6 Buried piping must be provided with a backfill material that is a noncorrosive, porous, homogeneous substance that is carefully installed so that the backfill is placed completely around the piping and compacted to ensure that the piping is fully and uniformly supported. Controlled density fill (CDF) will be used under and up to horizontal centerline of transfer pipe system.

Verification: (Analysis) The transfer lines will be backfilled with controlled density fill as detailed on Drawing $\mathrm{H}-14$ 103232 , to the spring line of the pipe and compacted bedding material above the CDF per Construction Specification W-314-C5, Section 02220.

(Exam) The requirement will also be verified by examination during construction and documented in the CWP.

3.3.1.7 Contaminated soil, displaced during excavation activities, shall be returned to the ground in the general vicinity of the original excavation, unless this creates ALARA concerns in the general area.

Verification: (Analysis) Construction Specification W-314-C5, Section 02220 allows for reuse of excavated soil per Construction Engineers direction.

(Exam) This requirement will also be verified by examination during construction and documented.

3.3.1.8 Taps for instrumentation and test connections shall be made on the top of the pipe.

Verification: (Analysis) Instrumentation taps are shown on Drawing $\mathrm{H}-14-103335$.

3.3.1.9 The cathodic protection system shall be designed in accordance with the guidelines provided in NACE RPO169-92.

Verification: (Analysis) This requirement is verified by Calculation W314-E-011 and placement of a NACE stamp and signature on the drawing.

3.3.1.10 The encasement leak detection system shall comply with NFPA 70, UL 508A, and DOE Order 6430.1a, Div. 16.

Verification: (Analysis) Compliance with UL 508A and NFPA 70 are verified by Construction Specification, W-314-C5 Section 16400 para. 3.2.1.1, and Procurement Specification W314-P6, para. 3.5.4. ANSI C2 deals with the requirements for utilities of which this package has none.

3.3.1.11 Electrical materials and equipment shall be UL or FM tested, with label attached, for the purpose intended, whenever such products are 
available. Where there are no UL or FM listed products of the type, testing and certification by another nationally recognized testing agency may be acceptable.

Verification: (Analysis) Construction Specification W-314-C5, Section 13440, Part 1, Paragraph 1.3.2 and 1.3.3 require components of the leak detection system to be UL or FM listed components. Procurement Specification W-314-P6, Section 4.2 requires components of the leak detection system to be UL or FM listed components. Additionally, if material or equipment is not UL or FM tested, other nationally recognized testing labs are allowed per DOE 6430.1a.

(Exam) This requirement will also be verified by examination during construction.

3.3.1.12 Electrical equipment enclosures shall be as a minimum NEMA Type 4, per NEMA ICS 6.

Verification: (Analysis) Verified by incorporating this requirement in the Construction Specification W-314-C5, Section 16400, para. 2.2.9 and Procurement Specification W314-P6, para. 3.3.5 and Drawings $\mathrm{H}-14-100983, \mathrm{H}-14-$ 101341 and $\mathrm{H}-14-103368$.

(Exam) This requirement will also be verified by examination during receiving inspection and/or construction.

3.3.1.13 During the design of facilities, optimization principles, as discussed in ICRP Publication 37, shall be utilized in developing and justifying facility design and physical controls.

Verification: (Analysis) ICRP Publication 37 addresses techniques for use in the optimization of radiation protection based on cost-benefit analysis to various radiation levels. Project W-314 is upgrading existing facilities where the architecture is constrained, the operational practices are already in place, and the acceptable risk and detriment to individuals is already provided and the applicable radiation levels are listed as separate requirements in this specification.

3.3.1.14 The equipment used for installation and maintenance shall comply with the DST dome loading constraints.

Verification: (Analysis) If equipment is located outside a 20' exclusion zone around the DST, dome loading effects are mitigated. It is anticipated that no equipment associated with the transfer piping system installation or maintenance will be required within the exclusion zone. The requirement will be verified by the issuing of dome 
loading permits for locating the equipment from Tank Farm Engineering and Operations.

3.3.1.15 The primary pipe shall be stainless steel.

Verification: (Analysis) Piping installed by this project is stainless steel per Procurement Specifications W-314-P3 and W314-P4 and Construction Specification W-314-C5.

(Exam) This is verified and documented per Construction Specification W-314-C5, Section 15493 and

Procurement Specifications W-314-P3 and W-314-P4.

\subsubsection{Electromagnetic Radiation}

3.3.2.1 Hand held radio and cell phone wattage frequency shall not interfere with leak detection system components at a distance of $1.0 \mathrm{~m}(3.3-\mathrm{ft})$.

Verification: (Analysis) The electrical/electronic components are located in a stainless steel NEMA rated enclosure. Based on prior operational experience and the voltage of the leak detection system, it is anticipated the shielding provided by the enclosure will be sufficient to protect the system from interference due to hand held radios or cell phones.

(Test) This requirement will also be verified by demonstration during ATP.

3.3.2.2 The low-point encasement leak detection system shall not be adversely affected by outside electromagnetic forces generated by a 60 horse power, $480 \mathrm{Vac}$, induction type motor operating at frequencies between 0 and 60 hertz and located 1 meter away from the leak detection system.

Verification: (Analysis) Any 60hp or larger motor is to be located above the pit cover blocks.

Any electromagnetic interference (EMI) to the signals located inside the pit below the cover blocks will be shielded by the cover blocks. The cover blocks contain a grid of grounded concrete reinforcing steel rods, steel sleeves and steel conduit.

Any EMI to the signals located outside the pit above the cover blocks next to the motor are shielded either by a grounded metal enclosures or conduit. In addition the cabling is shielded with metal (aluminum) foil which is also grounded to the electrical system ground in the 241-AN-271 building. 
The grounded shielding drains away any stray induced currents caused by the motor electromagnetic field.

\subsubsection{Identification and Marking}

3.3.3.1 New equipment and/or modifications to existing equipment shall be labeled in a standardized format in accordance with the tank farm labeling program as specified in HNF-IP-0842, Volume II, Section 6.1, Rev. 0.

Verification: (Analysis) This requirement is verified by the fact that the new $\mathrm{H}-14$ drawings were prepared using equipment numbering formats provided by LMHC. In addition, Construction Specification W-314-C5, Section 13440 , para. 2.2.4 specifies that labeling will be by LMHC OCM per their existing procedures.

(Exam) This requirement will also be verified by examination at completion of the project.

3.3.3.2 A master equipment list consisting of electronic database for structures, systems, and components shall be generated in accordance with HNF-IP-0842, Volume II, Section 6.1, Rev. 0. The list contains such information as: unique equipment label, drawing reference, procedures, vendor information, Safety Classification, nameplate data, etc.

Verification: (Analysis) This requirement will be met by providing the information into an electronic database.

(Exam) This requirement will also be verified by examination at completion of the project.

3.3.3.3 Operations and Maintenance Drawings (as-built $\mathrm{H}-14$ essential drawings) shall be prepared as the system master drawings showing as-built configuration changes in accordance with HNF-IP-0842, Volume II, Section 6.1, Rev. 0.

Verification: (Analysis) The compliance with this requirement will take place and be verified at the end of construction.

(Exam) This requirement will also be verified by examination at completion of the project.

\subsubsection{Workmanship}

The design of the transfer piping shall determine and specify appropriate levels of workmanship for the fabrication and installation of the piping according to the requirements of ASME B31.3.

Verification: (Analysis) This requirement is verified by incorporating it in the Construction Specification W-314-C5, Section 15493 and Procurement Specification W-314-P3. 


\subsubsection{Interchangeability}

All like equipment (e.g., sensors, alarm lights, etc.) shall have interchangeable parts.

Verification: (Analysis) This requirement is verified by the fact that all like equipment in this design package and other design packages for $W$ 314 will be of identical make and model and, therefore, have interchangeable parts. The equipment that are identical and identified as Safety Class can be used in a non-Safety Class application but a non-Safety Class item can not be used as a Safety Class item until special qualifications are performed on the item.

\subsubsection{Safety}

\subsubsection{Nuclear Safety}

\subsection{Safety Classification}

3.3.6.1.1.1 The encasement pipe is identified as Safety Class (SC) structures, systems and components (SSCs). The Safety Class function of the encasement pipe is to ensure that a leak in the primary waste transfer system piping is directed to a waste transfer associated structure.

Verification: (Analysis) The encasement piping is purchased from a qualified supplier or as a commercial grade item in Procurement Specification W-314-P3. The completed system is tested for leak tightness and surveyed for proper slope in Construction Specification W-314-C5.

3.3.6.1.1.2 The primary pipe for transfer lines SNL-3150 and SLL-3160 is identified as Safety Class (SC) structures, systems and components (SSCs). The Safety Class function of the primary pipe is to ensure containment of the waste being transferred.

Verification: (Analysis) The piping is procured from a qualified supplier, analyzed for Safety Class loading and constructed with enhanced NDE requirements in Procurement Specifications W-314-P4, W-314-P3 and Construction Specifications $W-314-C 5$ respectively.

3.3.6.1.1.3 The cross-site slurry line SLL-3160 encasement pressure alarm system shall be identified as SC. The safety class function of the pressure alarm system is to detect a pressure buildup in the encasement that would cause a waste release if the encasement failed.

Verification: (Analysis) Components of the encasement pressure alarm system are procured from qualified suppliers or are tested to ensure they meet the critical characteristics identified in the commercial grade item analysis. See Construction Specification W-314-C5, Section 13440 and Procurement Specification W-314-P6. 
3.3.6.1.1.4 The rupture disks for the cross-site lines SNL-3150 and SLL-3160 encasement overpressure protection shall be identified as SC. The SC function is to protect the environment from a release due to overpressuring the encasement.

Verification: (Analysis) The rupture disks are identified as SC item and are procured from a qualified supplier. See Construction Specification W-314-C5, Section 13440.

\subsection{Flammable Gas Hazardous Environment}

The components of the encasement leak detection system installed in ex-tank intrusive locations shall be intrinsically safe, designed to meet NFPA 70 Class I, Division 1, Group B criteria for hazardous locations.

Verification: (Analysis) The leak detection relay is approved by FM as intrinsically safe. The leak detector itself meets the criteria for a Simple Apparatus as defined by the NEC and therefore needs no approval. A Simple Apparatus is a device that will neither generate nor store more than 1.2 volts, 0.1 amperes, 25 milliwatts, or 20 microjoules. Therefore, this is an intrinsically safe circuit and is accepted by the NEC for use in a Class I, Division 1 or 2, Group B location.

\subsubsection{Human Performance/Human Engineering}

The following human factors criteria shall apply to the encasement leak detection system as applicable.

3.3.7.1 Each control device shall be in accordance with NUREG 0700, Section 6.4 and MIL-STD-1472E, Section 5.4.

Verification: (Analysis) Verified by the Calculation W314-I-002, Human Factor Analysis Pit Leak Detection Warning Lights.

3.3.7.2 Warning systems shall be in accordance with the general guidelines found in MIL-STD-1472E, Section 5.3. Auditory signal guidelines shall be in accordance with NUREG 0700, Section 6.2.

Verification: (Analysis) Verified by the Calculation W314-I-002, Human Factor Analysis Pit Leak Detection Warning Lights.

\subsection{Documentation}

3.4.1 Records, documents, and document control pertinent to design functions shall be in accordance with HNF-PRO-224 and HNF-PRO-233.

Verification: (Analysis) The overall record management for identification and storage of drawings, calculations, and specifications pertinent to 
design functions were performed according to HNF-PRO-229 and HNFPRO-233.

(Exam) This requirement will also be verified by $Q A$ assessment of the documents.

3.4.2 Drawings shall be prepared according to the formats set forth in "HNF-PRO-242, Rev. 0, Engineering Drawing Requirements", for documents produced prior to June 15, 1999 and "HNF-PRO-709, Rev. 1, Preparation and Control Standards for Engineering Drawings", for documents produced after June 15, 1999.

Verification: (Analysis) $\mathrm{H}$ - Series Drawings were prepared and will be released according to the guidelines set forth in "HNF-PRO-709, Rev. 1.

\subsection{Logistics}

\subsubsection{Maintenance}

3.5.1.1 Fully Remote Maintenance and Operation. Each system or portion of a system having radiation levels greater than $50 \mathrm{mrem} / \mathrm{hr}$ contact exposure shall be designed to be remotely maintained and operated or designed to require no maintenance and be remotely operated.

Verification: (Analysis) The buried transfer piping system is designed to require no preventive or corrective maintenance. See analysis 3.2.4.1.

3.5.1.2 Limited Contact Maintenance and Operation. Each system or portion of a system having radiation levels greater than $0.1 \mathrm{mrem} / \mathrm{hr}$ to less than or equal to $50 \mathrm{mrem} / \mathrm{hr}$ shall be designed for limited contact maintenance and operation.

Verification: (Analysis) This requirement is not applicable as the buried transfer piping system is designed to require no preventive or corrective maintenance. See analysis 3.2.4.1.

3.5.1.3 Full Contact Maintenance and Operation. Each system or portion of a system having radiation levels less than or equal to $0.1 \mathrm{mrem} / \mathrm{hr}$ shall be designed for full contact maintenance and operation.

Verification: (Analysis) Each leak detection or pressure monitoring relay panel is accessible at a maximum of $6 \mathrm{ft}$ above grade. See Drawings H-14-100983 and H-14-103368. Each active component in the relay circuit can be replaced and adjusted by accessing through the panel door.

3.5.1.4 The sources of impressed current for the cathodic protection system shall have the capability of being tested every two (2) months.

Verification: (Analysis) The requirement is not applicable to this package. 
3.5.1.5 The cathodic protection system shall have the capability of being checked annually.

Verification: (Analysis) The requirement is not applicable to this package.

3.5.1.6 The cross-site slurry line SLL-3160 encasement monitoring system shall be functionally tested and calibrated remotely without a pit entry.

Verification: (Analysis) The portions of the cross-site slurry line SLL3160 encasement pressure monitoring system that require functional testing and calibration are located outside the 241-AN-04D, Slurry Receiver Pit, therefore, no pit entry is required. See Drawing H-14-103366.

\subsubsection{Supply}

3.5.2.1 The system design shall, to the greatest extent practicable, use readily available parts and components.

Verification: (Analysis) All components in the leak detection systems, and pressure monitoring systems, except the leak detection probes, are off the shelf items and can be readily purchased from off site suppliers.

\subsubsection{Facilities and Facility Equipment}

Not Applicable to this Specification.

\subsection{Personnel and Training}

The transfer piping system shall be designed for operation by personnel possessing qualifications in accordance with DOE 5480.20, Chapter IV, and trained in accordance with Chapter I.

Verification: (Analysis) The design package was prepared with the assumption that the operating personnel are qualified according to DOE 5480.20. The package includes equipment, fittings, and materials already installed and operated throughout the Hanford Site. No new material or technology was introduced which would require additional training or special skill of the operating personnel.

\subsection{Major Component Characteristics}

\subsubsection{Encasement Protection System}

3.7.1.1 Performance Characteristics 


\subsection{Transfer System Compatibility with Existing Cathodic Protection System}

Installation of the insulated piping system shall not adversely affect the existing Cathodic Protection system in the area. Additional bonding jumpers shall be provided for the new transfer pipelines around the valve/pump pits as required.

3.7.1.1.1.1 The voltage measurements at each existing test station shall indicate a negative (cathodic) potential of at least $850 \mathrm{mV}$ relative to a saturated copper/copper sulfate reference electrode, or a minimum of $100 \mathrm{mV}$ of cathodic polarization between the structure surface and a stable reference electrode contacting the electrolyte.

Verification: (Analysis) This requirement is not applicable. This design package is only providing bonding jumpers to electrically tie the new pipe stub-outs to the existing cathodic protection system (see Drawing H-14-103384).

\subsubsection{Physical Characteristics}

3.7.1.2.1 Connections at joints shall ensure electrical continuity except where insulating joints are installed. Insulating joints shall be used to electrically isolate protected sections from unprotected sections and from neighboring metallic structures as required.

Verification: (Analysis) This requirement is not applicable. This design package is only providing bonding jumpers to electrically jumper the new pipe stub-outs to the existing cathodic protection system and no joints are part of the design.

(Exam) This requirement is not applicable to this design package.

\subsubsection{Encasement Leak Detection System}

\subsubsection{Performance Characteristics}

\subsection{Monitor for Leaks}

A low-point leak detection system with requirements specified below shall be installed for all transfer lines except SNL-3150 and SLL-3160. Transfer lines SNL-3150 and SLL-3160 shall use the continuous leak detection system specified in section 3.7.2.2. In addition, SLL-3160 shall use a rise in encasement pressure detection system with requirements specified below.

3.7.2.1.1.1 The leak detection system shall detect the presence of a leak within twenty-four hours (See Section $\mathbf{5 . 1}$ for a definition of a leak).

Verification: (Analysis) The upgraded encasement leak detection system is designed such that a conductivity probe is 
installed in the low point of the encasement to detect the presence of liquid when it reaches the probe. The encasement drains to a $2 "$ drain trap. There has been an agreement between LMHC and the Washington State Department of Ecology that the maximum allowable quantity of leakage that is necessary to detect in 24hours is 10 gallons or less. Calculation W314-I-53 shows that the placement of the probes at the center of a 2" diameter drain pipe will detect a quantity of slightly over 1 gallon. The 10 gallons in 24-hours corresponds to a leak rate of 0.0069 gallons per minute. Any rate less than that may not be detected in the 24-hour period.

3.7.2.1.1.2 The encasement pressure alarm system shall monitor the pressure between atmosphere and the pressure of the encasement during preoperational encasement line testing.

Verification: (Analysis) The encasement pressure monitoring system measures the gage pressure in the encasement within the range of 0 to $100 \mathrm{psig}$. The encasement line is tested at a pressure of $62.5 \mathrm{psig}$ which is well within the range of the pressure monitoring system. See Construction Specification W-314-C5, Section 13440, Data Sheet DS-2 and Drawings $\mathrm{H}-14-103367, \mathrm{H}-14-$ 103370 and $\mathrm{H}-14-103371$.

3.7.2.1.1.3 The encasement pressure alarm system shall monitor for pressure during a waste transfer and shall provide a signal when a pressure of 10 psig is detected.

Verification: (Analysis) The pressure monitoring system is continuously monitoring for an increase in pressure above the set point of 10 psig. When the set point is reached, the pressure switch (ANO4D-WT-PSHL-101 or ANO4D-WT-PSHL-102) high alarm output contacts will open de-energizing the high pressure relay (ANO4D-WT$\mathrm{K}-101 \mathrm{E}$ or ANO4D-WT-K-102E) which in turn energizes the latch coil on the latching relay (ANO4D-WT-K-101D or ANO4D-WT-K-102D) which activates the local alarm light. The pressure monitoring circuitry is shown on Drawings $\mathrm{H}-14-103370$ and $\mathrm{H}-14-103371$.

3.7.2.1.1.4 The leak detection system shall monitor for liquids or a rise in pressure in the encasements during a waste transfer and shall provide a signal when a leak volume or a build-up in encasement pressure is detected.

Verification: (Analysis) The low-point encasement leak detection system monitors for liquids continuously, both when there is a transfer in progress and when there is no transfer in progress, as long as power is applied to the system. Any liquid that enters the encasement pipe will flow to the lowest point (the drain) and be held up by 
the seal loop in the drain jumper. When the liquid reaches a height of $61 / 2$ in. maximum from the bottom of the encasement riser pipe section the probe electrical circuit is completed and the alarm light (AN01A-WTLDE-202 or ANO4A-WT-LDE-204) is activated by the leak detection relay (AN01A-WT-LDA-202A or ANO4AWT-LDA-204A) and the automatic MPS shutdown signal is initiated. See Calculation W314-J-053 for setting the probe height. The MPS shutdown signal will first be connected into the existing MPS shutdown system and later connected into the new MPS system when installed at a later date. The leak detection circuitry is shown on Drawings $\mathrm{H}-14-103358$ and $\mathrm{H}-14-103363$.

The encasement pressure alarm system for line SLL3160 monitors for pressure continuously, both when there is a transfer in progress and when there is no transfer in progress, as long as there is power applied to the system. When the pressure reaches $10 \mathrm{psig}$, the local alarm is activated, and the automatic MPS shutdown signal is initiated. See Drawings $\mathrm{H}-14-$ 103370 and $\mathrm{H}-14-103371$ for pressure alarm circuitry.

3.7.2.1.1.5 The monitoring frequency of the leak detection system shall be continuous.

Verification: (Analysis) The low-point encasement leak detection system monitors for leaks within the encasements. This is accomplished with the use of a continuously energized leak detection relay (ANO1A-WT-LDK-202 or ANO4AWT-LDK-204) and conductivity probe (ANO1A-WT-LDE202 or AN04A-WT-LDE-204). Upon failure of power to the leak detection relay or probe circuit, an alarm is activated so operators can respond. The leak detection circuitry is shown on Drawings $\mathrm{H}-14-103358$ and $\mathrm{H}-14$ 103363.

The encasement pressure alarm system for line SLL3160 monitors the pressure continuously. This is accomplished with the use of a pressure transmitter and a 4-20 $\mathrm{mA}$ signal that is continuously monitored by the pressure alarm switch. If at any time the 4-20 $\mathrm{mA}$ signal ceases to exist, the local alarm is activated. See Drawings $\mathrm{H}-14-103370$ and $\mathrm{H}-14-103371$ for pressure alarm circuitry.

3.7.2.1.1.6 The required response time of the low-point leak detection system shall be instantaneous (See Section 5.1 for a definition of instantaneous response time).

Verification: (Analysis) The low-point leak detection system is continuously monitoring for leaks. When a leak is detected, the contacts of the leak detection relay 
(AN01A-WT-LDK-202-1 or AN04A-WT-LDK-204-1) will close and instantaneously initiate the local alarm light (AN01A-WT-LDA-202A or AN04A-WT-LDA-204A). The active components that would primarily contribute to the response time are the components that change state, i.e., the leak detection relay and the latching coil relay (ANO1A-WT-LDK-202-1 or AN04A-WT-LDK-204-1 and AN01A-WT-K-202D or ANO4A-WT-K-204D). Calculation W314-I-054 verified leak detection system response time to be 0.525 seconds. A signal is also sent to the master pump shutdown system by opening contacts AN01A-WT-LDK-202-2 or ANO4A-WT-LDK-204-2 and de-energizing the first of a series of trip relays within the master pump shutdown logics. The leak detection circuitry is shown on Drawings $\mathrm{H}-14-103358$ and $\mathrm{H}-14-$ 103363.

The pressure monitoring system is continuously monitoring for an increase in pressure above the set point of $10 \mathrm{psig}$. When the set point is reached, the pressure switch (ANO4D-WT-PSHL-101 or ANO4D-WTPSHL-102) high alarm output contacts will open deenergizing the high pressure relay (ANO4D-WT-K-101E or ANO4D-WT-K-102E) which in turn energizes the latch coil on the latching relay (ANO4D-WT-K-101D or ANO4D-WT-K-102D) which activates the local alarm light. Calculation W314-I-061 verified pressure monitoring system response time to be 0.635 seconds. A signal is also sent to the master pump shutdown system by opening contacts ANO4D-WT-K-101E-2 or ANO4D-WT-K-102E-2. The pressure monitoring circuitry is shown on Drawings $\mathrm{H}-14-103370$ and $\mathrm{H}-14-103371$.

3.7.2.1.1.7 The wiring between the low-point leak detection system sensor and control panel shall be electrically supervised. (See definition of "electrically supervised" in Section 5.0).

Verification: (Analysis) Supervision for the wiring between the probes and the leak detection control panel is performed by the trip amplifier (ANO1A-WT-EY-202 or ANO4A-WTEY-204). This device monitors the voltage (at the probes) and is located in the leak detection control panel. Upon loss of probe voltage or wire failure, the trip amplifier will activate the local alarm (ANO1A-WTLDA-202A or ANO4A-WT-LDA-204A) and initiate the master pump shutdown system. The leak detection circuitry is shown on Drawings $\mathrm{H}-14-103358$ and $\mathrm{H}-14-$ 103363.

Supervision for the wiring between the pressure transmitter and the pressure alarm station is performed by the pressure switch (ANO4D-WT-PSHL-101 or ANO4D-WT-PSHL-102). This device monitors the 
voltage across the $150 \mathrm{ohm}$ resistor and is located in the pressure alarm station. Upon loss of the 4-20 ma signal from the pressure transmitter, the pressure switch will activate the local alarm (ANO4D-WT-PAH-101A or ANO4D-WT-PAH-102A) and initiate the master pump shutdown system. The pressure monitoring circuitry is shown on Drawings $\mathrm{H}-14-103370$ and $\mathrm{H}-14-103371$.

(Test) This requirement will be verified by ATP during construction.

\subsection{Monitor for Leak Detector Malfunction}

After the waste transfer system is up and operating and after the administrative lock has been removed, the MPS system shall monitor for a leak detector malfunction. The MPS shall notify the operator(s) when a leak detector malfunction occurs.

3.7.2.1.2.1 Loss of power to the leak detection system shall provide an output signal to the local alarm and MPS system.

Verification: (Analysis) The leak detection probe circuit voltage is monitored at the probe by the trip amplifier (ANO1A-WTEY-202 or ANO4A-WT-EY-204). Upon loss of power to the leak detection relay (AN01A-WT-LDK-202 or ANO4A-WT-LDK-204) the probe voltage will no longer be present. The trip amplifier will sense the loss of voltage at the probe created by the power failure of the leak detection relay and initiate the local alarm. The leak detection circuitry is shown on Drawings $\mathrm{H}-14-103358$ and $\mathrm{H}-14-103363$. Since the system does not require backup power per design direction loss of power to the leak detection relay cabinet would not provide a local alarm, but an output signal would be provided to the MPS system.

Loss of power to the repeater power supply (ANO4DWT-PY-101 or AN04D-WT-PY-102) or the pressure switch (ANO4D-WT-PSHL-101 or ANO4D-WT-PSHL-102) will open the low pressure/power failure contacts on the pressure switch which will de-energize the low pressure/power failure relay (ANO4D-WT-K-101C or ANO4D-WT-K-102C) which in turn energizes the latch coil on the latching relay (ANO4D-WT-K-101D or ANO4D-WT-K-102D) which activates the local alarm light. The low pressure/power failure relay also sends a signal to the MPS system (ANO4D-WT-K-101C-1 or AN04D-WT-K-102C-1). See Drawings H-14-103370 and $\mathrm{H}-14-103371$ for pressure monitoring circuitry. Loss of power to the pressure monitoring system cabinet would not provide a local alarm, but an output signal would be provided to the MPS system. 
(Test) This requirement will also be verified by demonstration during the ATP.

3.7.2.1.2.2 A detected failure in the leak detection system shall provide a local alarm and an output signal to the local alarm and MPS.

Verification: (Analysis) The leak low-point detection system is designed to initiate the local alarm and master pump shutdown given the following failures. The first failure is the leak detection relay (ANO1A-WT-LDK-202 or ANO4A-WT-LDK-204) failure. Upon failure of the leak detection relay, the probe voltage will no longer be present and the shutdown signal will be generated from the trip amplifier as verified by section 3.7.2.1.1.5. The second failure is the probe wire and wire connectors failing. Upon failure of any leak detection probe wire or connector, the local alarm and the master pump shutdown is activated. In addition to these failures, the local warning light and the master pump shutdown system will also activate upon failure of the trip amplifier (AN01A-WT-EY-202 or ANO4A-WT-EY-204) and the failsafe relay (AN01 A-WT-K-202C or ANO4A-WT-K204C). The leak detection circuitry is shown on Drawings $\mathrm{H}-14-103358$ and $\mathrm{H}-14-103363$.

The pressure monitoring system is designed to initiate the local alarm and MPS system upon failure of power to the repeater power supply, power to the pressure switch, power to the $\mathrm{C}$ or $\mathrm{E}$ relays. Wire or connector failures in the 4-20 mA signal loop will provide a local alarm and provide an output to the MPS system as verified in Section 3.7.2.1.1.7. The pressure alarm circuitry is shown on Drawings $\mathrm{H}-14-103370$ and $\mathrm{H}-14$ 103371.

(Test) This requirement will also be verified by demonstration during the ATP.

3.7.2.1.2.3 The encasement leak detection system shall perform an operation test of itself when commanded by the MPS System. The test shall include alarm, circuitry, and sensor functions of the leak detection system.

Verification: (Analysis) The leak detection relay cabinet was designed with two general purpose relays used for testing (AN01A-WT-K-202A\&B or AN04A-WT-K-204A\&B). The selector switch (AN01A-WT-SS-202 or ANO4A-WT-SS204 ) is used for two operations. The first operation is for testing the leak detection relay by simulating leak in the pit with the addition of a $8.2 \mathrm{kohm}$ resistor between the probes from the leak detection relay cabinet. The second test is to interrupt (open) the leak detection sensing circuit at the leak detection relay cabinet and verify the leak detection failsafe circuit is operational. 
The leak detection circuitry is shown on Drawings $\mathrm{H}$-14103358 and $\mathrm{H}-14-103363$.

The pressure alarm station was designed with two general purpose relays used for testing (ANO4D-WT-K$101 \mathrm{~A} \& \mathrm{~B}$ or ANO4D-WT-K-102A\&B). The A relay is used to simulate high pressure. The $B$ relay is used to simulate power failure. The pressure alarm circuitry is shown on Drawings $\mathrm{H}-14-103370$ and $\mathrm{H}-14-103371$.

(Test) This requirement will also be verified by demonstration during the ATP.

\subsection{Activate Local Alarm}

After a leak or leak detector malfunction is detected, the leak detection system shall activate a local alarm. The local alarm shall stay activated until acknowledged by the operator(s).

3.7.2.1.3.1 The local alarm shall be a warning light for the encasement leak detection systems. The alarm shall identify where the leak or malfunction has occurred. Each warning light location shall be determined from Human Factors Analysis.

Verification: (Analysis) Verified by the Calculation W314-1-002, Human Factor Analysis Pit Leak Detection Warning Lights.

3.7.2.1.3.2 The reset/acknowledgment of the local alarm for the encasement leak detection system shall either be from the MPS System or locally at the leak detector relay cabinet.

Verification: (Analysis) The reset/acknowledgment of the local alarm can be activated locally at the LDSTA or PASTA cabinet and from HMI locations. This is accomplished by operating the reset switch (AN01A-WT-PB-202C, AN04A-WT-PB-204C, ANO4D-WT-PB-101C or ANO4DWT-PB-102C). The local alarm can also be reset by the MPS system (installed at a later date). This is accomplished from a PLC (Programmable Logic Controller) output generated from the $\mathrm{HMI}$ at terminal block No. 15 at the leak detection relay cabinet or terminal block No. 8 at the pressure alarm relay cabinet. The leak detection circuitry is shown on Drawings $\mathrm{H}$-14103358 and $\mathrm{H}-14-103363$. The pressure alarm circuitry is shown on Drawings $\mathrm{H}-14-103370$ and $\mathrm{H}-14-103371$.

(Test) This requirement will also be verified by demonstration during the ATP. 
3.7.2.1.3.3 The local alarm for the leak detection system shall operate as follows:

- Immediately upon detecting a rise in encasement pressure, a leak or a malfunction, the local alarm shall flash and the MPS System shall be activated and produce an audible signal.

- After the local alarm is acknowledged by an operator located at the local alarm cabinet or the MPS System, the local alarm shall remain flashing until recovery occurs.

- When recovery occurs (the leak or malfunction has been corrected) and after the local alarm is acknowledged, the local alarm shall cease.

Actual methods used to accomplish MPS System functions above are described in the MPS Systems PDS.

Verification: (Analysis) As stated in the analysis of section requirement 3.7.2.1.1.4, the local alarm consisting of a local flashing (strobe) light and a horn operated by the MPS system is instantaneously activated. For the second requirement, the local warning light will remain flashing until the latch coil of the latch relay (ANO1AWT-K-202D, AN04A-WT-K-204D, ANO4D-WT-K-101D or AN04D-WT-K-102D) is reset. The reset coil can be activated from the HMI by generating a signal to the leak detection relay cabinet on terminal block No. 15 or to the pressure alarm relay cabinet terminal block No. 8 . The latching relay will only reset providing contacts on the leak detector relay or the $E$ relay are in a state not representing a leak or high pressure condition within the encasement. If liquid or high pressure is still present within the encasement, the local warning light will continue to flash even if the reset coil is energized from the HMI. For the last requirement, the local alarm light will cease to illuminate only upon recovery of the leaking or overpressure condition within the encasement. Upon recovery and acknowledgment, the local alarm (strobe light) will cease to illuminate. The leak detection circuitry is shown on Drawings $\mathrm{H}-14-103358$ and $\mathrm{H}-14-103363$. The pressure alarm circuitry is shown on Drawings $\mathrm{H}-14-$ 103370 and $\mathrm{H}-14-103371$.

(Test) This requirement will also be verified by demonstration during the ATP.

\subsubsection{Physical Characteristics}

3.7.2.2.1 The encasement low point leak detector components exposed to the encasement environment shall be designed to meet the following minimum requirements:

a. Design Temperature

b. Design Pressure
10 to $93^{\circ} \mathrm{C}\left(50\right.$ to $\left.200^{\circ} \mathrm{F}\right)$ 400 psig 
c. Radiation

Verification:
$6.0 \mathrm{E}+05 \mathrm{mSv} / \mathrm{hr}(6.0 \mathrm{E}+07$

$\mathrm{mrad} / \mathrm{hr}$ )

(Analysis) The components subject to the effects of waste are the probe, probe cover, and wire coating. The probe cover is made of PEEK (Polyetheretherketone) filled with glass and graphite. PEEK is a high performance thermoplastic that resists continuous temperatures of up to $480^{\circ} \mathrm{F}$. It features excellent chemical resistance, plus high tensile strength and wear resistance. In addition, PEEK resists abrasion, radiation and exhibits low moisture absorption. The waste temperature is far below that of PEEK breakdown temperatures (at $480^{\circ} \mathrm{F}$ ). For this design, PEEK is the most suitable material with radiation tolerances well above that required to be used in this application, while remaining to be machinable. The probe cover is considered to be an insulator and will protect the probes from unnecessary contact of metallic devices.

The probe wire coating is made of Tefzel 280 or HT2183 (DuPont) which exhibits some of the same properties as the probe cover. In the event the waste does come in contact with the coated probe cable, Tefzel 280 will not break down. The temperature at which Tefzel breaks down is $270^{\circ} \mathrm{C}$, which is above the waste temperature requirement.

The probe is made of solid stainless steel that has stable metallic properties that will withstand all of the above requirements.

The electrode holder and plug is pressure rated for 2000 psi up to $200^{\circ} \mathrm{F}$.

3.7.2.2.2 The cross-site encasement leak detection system components exposed to the encasement environment shall be designed to meet the following minimum requirements:
a. Design Temperature
10 to $93^{\circ} \mathrm{C}\left(50\right.$ to $\left.200^{\circ} \mathrm{F}\right)$
b. Design Pressure
50 psig
c. Radiation
$6.0 \mathrm{E}+05 \mathrm{mSv} / \mathrm{hr}(6.0 \mathrm{E}+07$
$\mathrm{mrad} / \mathrm{hr}$ )
d. Piping Code Requirements
ASME B31.3

Verification: (Analysis) Vendor cables for leak detection have no exposed metal and are designed for radioactive and corrosive chemical applications.

3.7.2.2.3 The continuous leak detection system for cross-site transfer lines SNL3150 and SLL-3160 shall be PermAlert AGW-Gold/RT cable. 
Verification: (Analysis) The leak detection cable is specified in Procurement Specification W-314-P3.

3.7.2.2.4 The encasement high pressure alarm system components exposed to the encasement environment shall be designed to meet the following minimum requirements:
a. Design Temperature
10 to $93^{\circ} \mathrm{C}$ (50 to $\left.200^{\circ} \mathrm{F}\right)$
b. Design Pressure
50 psig
c. Radiation
$6.0 \mathrm{E}+05 \mathrm{mSv} / \mathrm{hr}(6.0 \mathrm{E}+07$
d. Piping Code Requirements $\mathrm{mrad} / \mathrm{hr}$ )

Verification: (Analysis) The pressure transmitter is specified to meet the above environmental requirements. See Construction Specification W-314-C5, Section 13440, Data Sheet DS-2.

\subsubsection{Sitework}

\subsubsection{Performance Characteristics}

3.7.3.1.1 The site soils shall support the 200E Waste Transfer System transfer lines and its major components.

Verification: (Analysis) A site soil investigation performed by Dames $\&$ Moore indicates the soils will support the waste transfer system lines and major components.

3.7.3.1.2 The site soils and CDF located below and immediately around the 2OOE Waste Transfer System transfer lines and its major components shall limit differential settlements to maintain minimum specified transfer lines slopes and assure that the lines are self-draining.

Verification: (Analysis) A site soil investigation performed by Dames $\&$ Moore indicates the soils will support the waste transfer system lines and major components.

3.7.3.1.3 Soil cover over the transfer lines shall be adequate in combination with other engineered controls to protect the transfer lines from those maninduced external events specified in the TWRS BIO Addendum update as applicable to the 200E Waste Transfer System.

Verification: (Analysis) This requirement is satisfied by details shown on Drawing H-14-103232 and Calculation W314-P-016.

3.7.3.1.4 Access control to radiological and hazardous waste areas shall be provided by fencing consistent with existing fencing for RPP operations.

Verification: (Analysis) Construction Specification W-314-C5, Section 02831 and Drawings $\mathrm{H}-14-103233$ and $\mathrm{H}-14-103242$ direct fencing installation to satisfy this requirement. 


\subsubsection{Physical Characteristics}

3.7.3.2.1 All areas disturbed by construction shall be stabilized subsequent to construction.

Verification: (Analysis) Construction Specification W-314-C5, Section 02220 and the design drawings provide for stabilization.

3.7.3.2.2 Three-inch wide detectable plastic sheet marker tape shall be placed continuously above the transfer pipes in the backfill or berm soils. Route markers which extend 60 inches above grade shall be provided at a minimum of every 150 feet along the pipe line and at every change in direction to post the location of the underground transfer lines that are outside the Tank Farm fencing. A system of monuments and bench marks shall be provided along the pipeline routes.

Verification: (Analysis) This requirement is met in Construction Specification W-314-C5, Section 02220 and by details on Drawing No. H-14-103232.

\subsubsection{Encasement Overpressure Protection}

\subsubsection{Performance Characteristics}

\subsection{Protect for Encasement Overpressure (FFBD 3.4)}

After the waste transfer system is up and operating, a rupture disk shall burst allowing the contents of the encasement to drain to a waste tank whenever the encasement pressure reaches a pressure of 60 psig. The intent of this function is to de-pressurize the transfer lines encasement.

3.7.4.1.1.1 The cross-site extension lines SNL-3150 and SL-3160 encasements shall be equipped with a rupture disk designed to burst at 60 psig.

Verification: (Analysis) This is verified by Construction Specification W-314-C5, Section 13440, Data Sheets DS-3 and DS-4.

3.7.4.1.1.2 The rupture disk size shall be 2 inches.

Verification: (Analysis) This is verified by Construction Specification W-314-C5, Section 13440, Data Sheets DS-3 and DS-4.

3.7.4.1.1.3 The rupture disk capacity shall be determined by utilizing method of calculation defined in ASME, BPV Code, Section VIII.

Verification: (Analysis) This capacity shall be determined by the rupture disk manufacturer as required by Construction Specification W-314-C5, Section 13440, Data Sheets DS-3 and DS-4. 
3.7.4.1.1.4 Use waste properties per Section 3.2.5.2 and flush properties per Section 3.2.1.2.1.

Verification: (Analysis) This requirement is verified by Construction Specification W-314-C5, Section 13440, Data Sheets DS-3 and DS-4.

3.7.4.1.1.5 Rupture Disk for waste line SLL-3160 shall drain to waste tank AN104.

Verification: (Analysis) This requirement is verified by P\&ID Drawing H-14-103331.

3.7.4.1.1.6 Rupture Disk for waste transfer line SNL-3150 shall drain to waste tank AN101 via Pump Pit ANO1A.

Verification: (Analysis) This requirement is verified by P\&ID Drawing H-14-103327.

\subsubsection{Physical Characteristics}

The encasement overpressure protection system is subject to the same characteristics as the encasement piping system. See Section 3.7.2.2.4 for requirements.

\subsubsection{Burst Encasement Rupture Disk Indication System}

\subsubsection{Performance Characteristics}

\subsection{Monitor for Burst Rupture Disk}

After the waste transfer system is up and operating and after the administrative lock has been removed, the Burst Disk Indication system shall monitor for burst disks protecting the encasement piping systems.

3.7.5.1.1.1 The burst disk indication system shall monitor for the presence of a burst rupture disk located in the encasement cross-site transfer line SLL-3160.

Verification: (Analysis) The burst disk indication system monitors for a burst disk. Upon disk rupture, the burst disk indicator strip is severed, disrupting the electric current through the strip. The rupture disk alarm monitor then transmits a signal to the MPS System. See Drawing H-14-103373 for rupture disk monitoring circuitry.

3.7.5.1.1.2 The monitoring frequency of the burst disk Indication system shall be continuous.

Verification: (Analysis) The rupture disk alarm monitor continuously monitors for a burst disk as long as power is applied to the system. See Drawing $\mathrm{H}-14-103373$ for the rupture disk monitor circuit diagram. 
3.7.5.1.1.3 The required response time of the burst disk indication system shall be instantaneous (See Section 5.1 for a definition of instantaneous response time).

Verification: (Analysis) Immediately upon severing the burst disk indicator strip, the rupture disk alarm monitor transmits a signal to the MPS System. See circuit diagram on Drawing $\mathrm{H}-14-103373$.

3.7.5.1.1.4 Loss of power to the Burst Disk Indicator sensor shall provide an output signal to the MPS system.

Verification: (Analysis) Upon loss of power to the burst disk indicator the burst disk output signal will be activated. See circuit diagram on Drawing $\mathrm{H}-14-103373$.

3.7.5.1.1.5 An open circuit in the burst disk indicator system shall provide an output signal to MPS System.

Verification: (Analysis) Just as in the case of severing the burst disk indication strip (See Para. 3.7.5.1.1.1) an open circuit at another point in the loop will provide an output signal to the MPS System.

3.7.5.1.1.6 The encasement burst disk indicator system shall perform an operation test of itself when commanded by the MPS System. The test shall include alarm, circuitry, and sensor functions of the burst disk indicator system.

Verification: (Analysis) This requirement is verified by Drawing $\mathrm{H}-14$ 103373 and Construction Specification W-314-C5, Section 13440, Data Sheet DS-3.

\subsection{Activate MPS System}

After a burst disk or burst disk indicator malfunction is detected, the burst disk indicator system shall activate the MPS System. The activation shall remain until acknowledged by the operator(s).

3.7.5.1.2.1 The burst rupture disk alarm shall be displayed by the MPS System.

Verification: (Analysis) This requirement is not applicable to this package.

3.7.5.1.2.2 The reset/acknowledgment of the burst disk alarm shall be accomplished by the MPS System.

Verification: (Analysis) This burst disk indicator has a remote reset capability. See Drawing H-14-103373 and Construction Specification W-314-C5, Section 13440, Data Sheet DS3. 


\subsubsection{Physical Characteristics}

3.7.5.2.1 For components of the encasement burst disk indication system subject to the encasement environment, see Section 3.7.2.2.4 for physical characteristics.

Verification: (Analysis) This requirement is verified by Construction Specification W-314-C5, Section 13440, Data Sheet DS3.

3.7.5.2.2 Components of the encasement burst disk indication system subjected to the environment of an instrument building shall be designed to meet the following requirements:
a. Temperatures
$0^{\circ}$ to $40^{\circ} \mathrm{C}\left(32\right.$ to $\left.104^{\circ} \mathrm{F}\right)$
b. Humidity
0 to $90 \%$
c. Earthquake
see Section 3.2.5.1.3

Verification: (Analysis) The rupture disk monitor (AN271-WT-YS-103) is located in the instrument building. The temperature and humidity requirements are verified by Construction Specification W-314-C5, Section 13440, Data Sheet DS3. The rupture disk alarm monitor is general service and is mounted per the manufacturer's instructions.

\subsection{QUALITY ASSURANCE PROVISIONS}

No requirements are specified in this section.

\subsection{NOTES}

\subsection{Definitions}

\subsubsection{Local Alarm}

A local alarm is an alarm located at or near the point of measurement (e.g., the leak detector local alarm would be at or near the pit where the sensor is).

\subsubsection{Instantaneous Response Time}

The time allowed for the leak detection system to produce an output signal after it has detected a leak. The time is defined as 1 second.

\subsubsection{Equivalent Length}

The equivalent length is the actual length of piping plus the friction loss of all valves and fittings in the system expressed in terms of equivalent feet of piping.

\subsubsection{Leak}

Leaks are established for each specific project at the Hanford Site. Each project must demonstrate to the Washington State Department of Ecology that the proposed 
system meets state regulations. The leak that will be detected by the W-314 leak detection system is established as a minimum of 10 gallons in 24 hours.

\subsubsection{Glaze}

Glaze is a coating of ice formed when rain or drizzle freezes on contact with any surface that has a temperature that is below freezing.

\subsubsection{Electrically Supervised Wiring}

Electrically supervised wiring means that the continuity of wiring interconnecting system components is monitored. If continuity is not detected, a signal or alarm is initiated identifying that condition. 


\title{
APPENDIX B
}

\author{
Requirements Verification \\ For \\ PDS-002
}

Valve Pit Manifold

B-1 


\section{REQUIREMENTS VERIFICATION}

FOR

VALVE PIT MANIFOLD

\subsection{SCOPE}

This appendix documents how the requirements listed in the Project Development Specification (PDS) for the Valve Manifold (HNF-SD-W314-PDS-002) are satisfied for the new valve manifolds that will be installed by Project W-314 for Pump Pits 241 AN-01A and 241-AN-04A and the 241-AN-04D Slurry Receiver Pit.

\subsection{APPLICABLE DOCUMENTS}

For a list of the applicable documents, refer to the appropriate PDS.

\subsection{REQUIREMENTS VERIFICATION ANALYSIS}

\subsection{Item Definition}

The valve manifold piping systems provide a confined routing for the transfer of tank waste between storage locations. The valve manifolds addressed by this analysis study are discrete segments of the Hanford tank farm waste transfer system.

This analysis study covers the design basis for the installation of manifoldsljumpers in the following pits:

241-AN-A and 241-AN-B Valve Pits

241-AW-A and 241-AW-B Valve Pits

241-AP Valve Pit

241-AN-01A and -04A Central Pump Pits

241-AY-01A Central Pump Pit

241-AZ-01A and -02A Central Pump Pits

241-AZ-VP Valve Pit

This analysis study also covers the design basis for the installation of valve position sensor systems in the following pits:

241-AN-A and 241-AN-B Valve Pits

241-AW-A and 241-AW-B Valve Pits

241-AP Valve Pit

241-AN-01A Central Pump Pit

241-AZ-VP Valve Pit

This analysis study also covers the design basis for the installation of new pit cover blocks in the following pits:

241-AN-A and 241-AN-B Valve Pits

241-AW-A and 241-AW-B Valve Pits

241-AZ-VP Valve Pit

214-AN-O4D Slurry Receiver Pit 
The above pits are designed to route tank waste between tanks within the tank farms in which they are located via the waste transfer lines. Control over transfers is currently achieved through the configuration of the pit jumpers, i.e., which pit nozzles are tied together and the alignment of the valves on the jumpers, within the pits. Routing can be changed through the valves in the jumpers within the pits.

The nozzle configurations for the valve manifolds within the above pits are shown in the Table 3.1-1. Valve manifolds shall be connected only to the 3-inch transfer system, except as noted in this table. All applicable 3-inch nozzles inside a pit will be connected by a manifold assembly while all applicable 2 -inch nozzles will be connected by a separate manifold assembly. Isolation/process blanks identified in Table 3.1-1 are within Project W-314. If during construction, any unused nozzle is discovered to not have an isolation/process blank, one shall be provided and installed.

The valve manifolds, the pit cover blocks, and new and existing pits provide the primary and secondary confinement of the waste. The major components of the pit upgrades are as follows: (1) pump pit manifolds; (2) valve position sensor systems; (3) pit cover blocks, as required, (4) new process pit(s), as required, and (5) tank farm lighting, as required. The components of the pit upgrades and their relationship to the rest of the W-314 Waste Transfer System are shown graphically in Figure 3-1. The functional and physical relationship of the valve manifolds, valve position sensor system, and cover blocks to the tank farm waste transfer system is described in paragraphs 3.1.1 and 3.1.2.

\subsection{Characteristics}

\subsubsection{Performance Characteristics}

The valve manifold piping system and the piping in 241-AN-04D Slurry Receiver Pit components shall meet the performance requirements stated in this section.

\subsubsection{Position Manifold Valves}

After the appropriate valve manifolds have been selected, the waste transfer system shall position the valves on the selected manifold.

3.2.1.1.1 The valve manifoldljumper valves shall be remote manually operated from above the pit cover blocks.

Verification: (Analysis) The design placed the manual operators above the cover blocks. See Drawings H-14-103349 and H-14-103350.

(Exam) This requirement will also be verified by examination at the end of construction. 


\begin{tabular}{|c|c|c|c|}
\hline Nozzle No. & Size & Pipe No. & Descriptions \\
\hline \multicolumn{4}{|c|}{ Location: 241-AN-A Valve Pit } \\
\hline$L 1$ & 3" & 3" SN-267 & To Central Pump Pit 07A (A) \\
\hline $\mathrm{L2}$ & 2" & & Isolation Blank \\
\hline L3 & $2 "$ & 2" SL-167 & To Central Pump Pit 07A (B) \\
\hline$\llcorner 4$ & $2 "$ & & Isolation Blank \\
\hline L5 & 2" & 2" SL-164 & To Central Pump Pit 04A (B) \\
\hline L7 & $2 "$ & 2" SL-165 & To Central Pump Pit 05A (B) \\
\hline L9 & 2" & 2" SL-166 & To Central Pump Pit 06A (B) \\
\hline L10 & $2^{\prime \prime}$ & & Isolation Blank \\
\hline L11 & $3 "$ & & Isolation Blank \\
\hline L12 & 3" & & Isolation Blank \\
\hline L13 & 3" & & Isolation Blank \\
\hline$L 14$ & $3 "$ & 3" SN-266 & To Central Pump Pit 06A (A) \\
\hline L15 & $3 "$ & 3" SN-264 & To Central Pump Pit 04A (A) \\
\hline L16 & $3 "$ & 3" SN-265 & To Central Pump Pit 05A (A) \\
\hline L17 & $2 "$ & & Process Blank (existing) \\
\hline L18 & $2 "$ & & Isolation Blank \\
\hline L19 & $3^{\prime \prime}$ & $3^{\prime \prime} \mathrm{SN}-268$ & To Valve Pit AN-B (R19) \\
\hline$\llcorner 21$ & 3" & New 3" Flush & Note: only new nozzle installed. \\
\hline \multicolumn{4}{|c|}{ Location: 241-AN-B Valve Pit } \\
\hline R1 & 3" & & Isolation Blank \\
\hline $\mathrm{R} 2$ & 2" & & Isolation Blank \\
\hline R3 & $2 "$ & & Isolation Blank \\
\hline R4 & $2 "$ & & Isolation Blank \\
\hline R5 & 2" & 2" SL-161 & To Central Pump Pit 01A (B) \\
\hline R7 & $2 "$ & 2" SL-162 & To Central Pump Pit 02A (B) \\
\hline R9 & 2" & 2" SL-163 & To Central Pump Pit 03A (B) \\
\hline R10 & $2 "$ & & Isolation Blank \\
\hline$R 11$ & $3^{\prime \prime}$ & & Isolation Blank \\
\hline
\end{tabular}




\begin{tabular}{|c|c|c|c|}
\hline Nozzle No. & Size & Pipe No. & Descriptions \\
\hline$R 12$ & 3" & & Isolation Blank \\
\hline$R 13$ & $2 "$ & & Isolation Blank \\
\hline R14 & $3^{\prime \prime}$ & 3" SN-263 & To Central Pump Pit 03A (A) \\
\hline R15 & $3^{\prime \prime}$ & 3" SN-261 & To Central Pump Pit 01A (A) \\
\hline R16 & $3 "$ & 3" SN-262 & To Central Pump Pit 02A (A) \\
\hline R17 & $2^{\prime \prime}$ & & Isolation Blank \\
\hline R18 & $2 "$ & & Isolation Blank \\
\hline R19 & $3 "$ & 3" SN-268 & To Valve Pit AN-A (L19) \\
\hline $\mathrm{R} 20$ & $2 "$ & New 2" Flush & From Blending Tank TK-301 \\
\hline \multicolumn{4}{|c|}{ Location: 241-AY-01A Central Pump Pit } \\
\hline U3 & $4 "$ & Spare & Isolation Blank \\
\hline บ8 & $2 "$ & Spare & Isolation Blank \\
\hline U9 & 3" & Spare & Isolation Blank \\
\hline $\mathrm{U} 12$ & $2 "$ & SL-505 & To Distributor (Existing) \\
\hline U13 & $3 "$ & New SN-635 & Process blank \\
\hline U13A & $2 "$ & New 2" DR & New SN-635 Encasement DR \\
\hline \multicolumn{4}{|c|}{ Location: 241-AY-02A Central Pump Pit } \\
\hline U5 & 3" & New SN-633 & Process blank \\
\hline U12 & $3^{n}$ & New SN-635 & Process blank \\
\hline \multicolumn{4}{|c|}{ Location: 241-AZ-01A Central Pump Pit } \\
\hline U11 & $3 "$ & New SN-631 & Process blank \\
\hline U11A & $2 "$ & New 2" Drain & New SN-631 Encasement Drain \\
\hline U12 & $3 "$ & New SN-632 & Process blank \\
\hline U12A & $2 "$ & New 2" DR & New SN-632 Encasement DR \\
\hline UXX & $3 "$ & New 3" DR-100 & New Floor Drain from 241-AZ-VP \\
\hline UXXA & $2 "$ & New 2" Drain & New DR-100 Encasement Drain \\
\hline \multicolumn{4}{|c|}{ Location: 241-AZ-01A Central Pump Pit } \\
\hline U11 & 3" & & Process blank \\
\hline $\mathrm{U} 12$ & $3 "$ & & Process blank \\
\hline
\end{tabular}




\begin{tabular}{|c|c|c|c|}
\hline Nozzle No. & Size & Pipe No. & Descriptions \\
\hline U12A & $2 "$ & New 2" DR & New SN-631 Encasement DR \\
\hline \multicolumn{4}{|c|}{ Location 241-AZ-02A Central Pump Pit } \\
\hline U13 & 3" & & Process blank \\
\hline U13A & 2" & 2" DR & New SN-632 Encasement DR \\
\hline \multicolumn{4}{|c|}{ Location: 241-AW-A Valve Pit } \\
\hline $\mathrm{L} 1$ & $3 "$ & 3"SN-267 & To Pump Pit 241-AW-02A (J) \\
\hline $\mathrm{L} 2$ & $3^{\prime \prime}$ & 3"SN-220 & To Valve Pit 241-A-A (L2) \\
\hline L3 & 2" & 2"SL-168 & To Evap. Bldg. 242-A (18) \\
\hline L4 & 2" & 2"SL-510 & To Valve Pit 241-AP (2) \\
\hline$L 7$ & 2 & 2"SL-163 & To Pump Pit 241-AW-03A (B) \\
\hline L9 & 2 & 2"SL-165 & To Pump Pit 241-AW-05A (B) \\
\hline L11 & $3^{\prime \prime}$ & & Isolation blank \\
\hline L12 & $3^{\prime \prime}$ & & Isolation blank \\
\hline L14 & $3^{\prime}$ & 3"SN-263 & To Pump Pit 241-AW-03A (A) \\
\hline L15 & $3^{\prime}$ & 3"SN-265 & To Pump Pit 241-AW-05A (A) \\
\hline L16 & $3^{\prime}$ & 3"SN-261 & To Pump Pit 241-AW-01A (A) \\
\hline L17 & $3^{\prime}$ & 3"Flush & Flush \\
\hline L18 & $2^{\prime \prime}$ & & Process blank \\
\hline L19 & $3 "$ & & Process blank \\
\hline \multicolumn{4}{|c|}{ Location: 241-AW-B Valve Pit } \\
\hline R1 & $3^{\prime \prime}$ & 3"SN-268 & To Pump Pit 241-AW-02A \\
\hline R2 & $3^{\prime \prime}$ & & Isolation blank \\
\hline R3 & $2 "$ & 2"SL-167 & To Evap. Bldg. 242-A (19) \\
\hline R4 & $2^{\prime \prime}$ & $2 " S L-509$ & To Valve Pit 241-AP (1) \\
\hline R7 & $2 "$ & 2"SL-164 & To Pump Pit 241-AW-04A (B) \\
\hline R9 & $2 "$ & 2"SL-166 & To Pump Pit 241-AW-06A (B) \\
\hline R11 & 3" & & Isolation blank \\
\hline R12 & 3" & & Isolation blank \\
\hline R14 & $3^{\prime \prime}$ & 3"SN-264 & To Pump Pit 241-AW-04A (A) \\
\hline
\end{tabular}




\begin{tabular}{|c|c|c|c|}
\hline Nozzle No. & Size & Pipe No. & Descriptions \\
\hline R15 & $3 "$ & 3"SN-266 & To Pump Pit 241-AW-06A (A) \\
\hline R16 & 3" & 3"SN-262 & To Pump Pit 241-AW-02A (A) \\
\hline R17 & 3" & 3"Flush & Flush \\
\hline R18 & $2 "$ & & Process blank \\
\hline R19 & $3 "$ & & Process blank \\
\hline \multicolumn{4}{|c|}{ Location: 241-AP Valve Pit } \\
\hline 14 & 3" & 3"SN-609 & To Pump Pit 241-AW-02A (v) \\
\hline 16 & 3" & New 3"SN-634 & To 241-AZ-VP Valve Pit \\
\hline \multicolumn{4}{|c|}{ Location: 241-AN-01A Central Pump Pit } \\
\hline$A$ & $3 "$ & SN-261 & To Valve Pit 241-AN-B (R15) \\
\hline$H$ & $3 "$ & SNL-3150 & From cross-site tie-in (new) \\
\hline c & $2 "$ & 2" DR & New SNL-3150 Drain \\
\hline D & $3 "$ & SN-630 & From 241-AZ-VP Valve Pit (A) (new) \\
\hline J & $2^{\prime \prime}$ & 2" DR & New SN-630 Drain \\
\hline E & $2 "$ & & Process blank \\
\hline $\mathbf{F}$ & 2" & & Process blank \\
\hline $3 \mathrm{~A}$ & 3" & & To Transfer Pump \\
\hline \multicolumn{4}{|c|}{ Location: 241-AN-04A Central Pump Pit } \\
\hline c & $2 "$ & & Isolation blank \\
\hline \multirow[t]{2}{*}{$\mathrm{D}$} & $3 "$ & & Isolation blank \\
\hline & $2 "$ & & New SN-636 drain \\
\hline E & $2 "$ & & Process blank \\
\hline $\mathrm{F}$ & $2 "$ & & Process blank \\
\hline \multicolumn{4}{|c|}{ 241-AZ-VP Valve Pit } \\
\hline A & $3^{\prime \prime}$ & SN-630 & To Pump Pit 241-AN-01A (D) \\
\hline B & $2 "$ & SN-637 ENC DR & New Encasement Drain \\
\hline c & 3" & SN-637 & To HLW/PC Interface (See note below) \\
\hline $\mathrm{D}$ & $2 "$ & SN-634 ENC DR & New Encasement Drain \\
\hline E & 3" & $\mathrm{SN}-634$ & To 241-AP Valve Pit (16) \\
\hline
\end{tabular}




\begin{tabular}{|l|l|l|l|}
\hline \multicolumn{3}{|c|}{ Table 3.1-1 Manifold Jumper Configuration Details } \\
\hline Nozzle No. & Size & Pipe No. & Descriptions \\
\hline F & 3" & SN-633 & To Pump Pit 241-AY-02A (U5) \\
\hline G & 2" & SN-633 ENC DR & New Encasement Drain \\
\hline H & 3" & SN-632 & To Pump Pit 241-AZ-01A (U12) \\
\hline
\end{tabular}

Note: For nozzle $C$ in the New 241-AZ-VP Valve Pit, provide and install an isolation blank until the Privatization Contractor is ready to use line SN-637. In the description, block numbers and/or letters in parenthesis $(x)$ indicate the nozzle location in the referenced pit.

\subsubsection{Confine Waste}

After the transfer pump has started, the piping system shall confine the waste during transfers.

3.2.1.2.1 The piping system components shall support a corrosion/ erosion allowance of $0.01 \mathrm{~mm}$ per year ( 0.4 mil per year) for the life of the system.

Verification: (Analysis) The valve manifold consists of piping system components such as valves, bends, and tees. The components are modeled and the corrosion allowance is entered into the Autopipe program. The requirement is verified by Calculation W314-P-042, Jumper Pipe Stress Analysis, 241-AN-01. The stress analysis results show that even with a reduced pipe wall thickness due to this corrosion/erosion allowance the piping system is still within the allowables of ASME B31.3.

In addition, the requirement is verified by incorporating it in the Procurement Specification W-314-P1 Ball Valves, para 3.4.2.3. Therefore, the valves will be required to meet all applicable codes and standards with a reduced thickness equivalent to this corrosion/erosion allowance.

3.2.1.2.2 The piping system components shall be capable of transferring the waste at a Reynolds number greater than or equal to 20,000 .

Verification: (Analysis) This requirement depends on the transfer pump capacity, the transfer route pressure drop, the viscosity, and the specific gravity of the waste to be transferred. With the new 3-in transfer lines, a transfer from the AN-Farm to the AP-Farm would meet this requirement with a flow rate of $140 \mathrm{gpm}$ for waste with a specific gravity of 1.4 and viscosity of 10 centipoise (Ref. WHC-SD-WM-TI-750, page A-212). These parameters are used as the design point for Project W-314. However, Calculation W314-P-101 verifies this requirement for several other transfer routes and corresponding flow parameters. 
3.2.1.2.3 The valve manifoldljumper piping system shall have a head loss no greater than 10 meters per 100 meters (10 feet per 100 feet) of equivalent length of 3 in Sch 40 pipe.

Verification: (Analysis) The valve manifold consists of components such as valves, bends, and tees. The "resistance coefficients $\mathrm{K}$ " for these items are used in calculating the equivalent length of straight pipe according to Crane Technical Paper No. 410, Flow of Fluids (Crane). The above requirement is for the equivalent length that includes valves, tees etc. Pressure drop per equivalent length 100 feet of 3 inch, sch. 40 steel pipe according to Crane is 2.24 psi for a $150 \mathrm{gpm}$ flow rate of water. The prorated pressure drop for a design flow rate of 140 $\mathrm{gpm}$ and corrected for a fluid of specific gravity 1.4 is $2.78 \mathrm{psi}$. This is equivalent to a head loss of 6.44 feet of water per 100 feet of 3 inch pipe which meets the above requirements.

3.2.1.2.4 The piping system components shall be capable of supporting a design pressure of $400 \mathrm{psig}$. For interconnecting piping that have design pressures exceeding $400 \mathrm{psig}$, it is the owner/operator responsibility to verify that the most severe condition of coincident internal pressure and temperature expected during service does not exceed the design conditions of the valve manifold.

Verification: (Analysis) The valve manifold piping system consists of components such as valves, bends, and tees. The components are modeled and the pressure value is entered into the Autopipe program. The requirement is verified by Calculation W314-P-042, Jumper Pipe Stress Analysis 241-AN-01. The stress analysis results show that with a design pressure of 400 psig the piping system is still within the allowables of ASME B31.3.

In addition, this requirement will be verified by hydrostatically testing the completed jumper assembly according to ASME B31.3 at 600 psig (Reference Drawings $\mathrm{H}-14-103337$ through $\mathrm{H}-14-1033341$ and Construction Specification W-314-C5, Section 15493, (Appendix A).

Also, this requirement is verified by incorporating it in the Procurement Specification W-314-P1 Ball Valves, para 3.4.2.1. Therefore, the valves will be required to meet all applicable codes and standards for a design pressure of 400 psig.

3.2.1.2.5 The connection of WT-SLL-3160 to Riser 10 on tank 241-AN-104 shall be capable of supporting a design pressure of $10.27 \mathrm{Mpa}$ (1490 psi) up to and including the last point of isolation prior to entry into the riser. 
Verification: (Analysis) This requirement is documented by Calculation W314-P-053, Pressure Design for Transfer Piping and Encasements and Procurement Specifications W-314-P3, W314-P4, W-314-P5 and Construction Specification W-314-C5.

3.2.1.2.6 The WT-SLL-3160 line encasement shall have a design pressure of 50 psig and a design temperature of $180^{\circ} \mathrm{F}$.

Verification: (Analysis) The WT-SLL-3160 line encasement has a design pressure of 50 psig and a design temperature of $180^{\circ} \mathrm{F}$ as specified in Procurement Specification W-314$\mathrm{P3}$ and Construction Specifications W-314-C5.

3.2.1.2.7 The piping system components, as part of the waste transfer system, shall be capable of maintaining the temperature of the contents such that the temperature drop in the manifold does not exceed $2^{\circ} \mathrm{C}\left(3^{\circ} \mathrm{F}\right)$ during a waste transfer.

Verification: (Analysis) Verified by Calculation W314-P-006, Inside Pit and Buried Pipeline Heat Loss Calculation. The calculation shows that for the project design conditions the temperature drop for an equivalent length of $200 \mathrm{ft}$ of pipe is $2.3^{\circ} \mathrm{F}$. The equivalent length of piping in the manifold is well below $200 \mathrm{ft}$, therefore, the requirement is met.

3.2.1.2.8 The piping system components shall be capable of withstanding the liquid waste chemical composition ranges listed in Table 3-1 and the waste radionuclide concentrations listed under the $W-314$ column in Table 3-2.

Verification: (Analysis) This requirement is verified by the use of ASTM A312 TP 304L Stainless Steel (ss) as the material of construction for the valve manifold components. The 304L ss has a history of successful use and testing with the Hanford Site waste chemistry and was recommended as the material for the primary pipe according to Internal Memo, 7F540-94-019, dated, June 10, 1994, Projects W-058/W-028 Material of Construction Position Paper. The waste composition listed in WHC-SD-W058-FDC-001, Rev. 4 is the worst case inventory composition for the TWRS transfer system. The W-058 FDC specifies 304L ss as the primary pipe material of construction. Therefore, $304 \mathrm{~L}$ ss will meet the requirement for waste chemical composition.

In addition, this requirement is verified by incorporating it in the Procurement Specifications W-314-P1, Ball Valves, and W-314-P5, Block Valve. Therefore, the valves will be required to withstand the waste chemical composition ranges. 


\subsubsection{Confine Flush}

During the flush of the waste transfer system, the piping system shall confine the flush water.

3.2.1.3.1 The piping system components shall be capable of confining flush water with the following properties:

- Volumetric flow rate of $151-530 \mathrm{~L} / \mathrm{min}(40-140 \mathrm{gpm})$

- Temperature of $12.8-66^{\circ} \mathrm{C}\left(55-150^{\circ} \mathrm{F}\right)$

- $\quad \mathrm{pH}$ range of no less than 7 and a maximum of 14 .

Verification: (Analysis) The 3 inch sch. 40 steel pipes were shown to be capable of handling $210 \mathrm{gpm}$ (see para. 3.2.1.2.6).

The valve manifold piping system is rated for the maximum design temperature $200^{\circ} \mathrm{F}$ and the compliance for this requirement is the same as under para 3.2.1.2.7. The $\mathrm{pH}$ value $z 7$ is within the waste property $\mathrm{pH}$ range and the compliance for this requirement is the same as under para 3.2.5.2.3.

\subsubsection{Physical Characteristics}

3.2.2.1 The valve pit piping system shall have the following features:

a. Manual valve actuation from above the cover blocks, (except for the encasement rupture disk isolation valve in 241-AN-04D Slurry Receiver Pit)

b. Valves shall be capable of being locked in position, (except the WTS-SLL-3160 block valve at Riser 10).

Verification: (Analysis) Manual operation of the valves was previously addressed (see para. 3.2.1.1.1). The locking capabilities of the valves are shown on Drawing $\mathrm{H}-14$ 103351, (Notes 9 and 10).

3.2.2.2 The pit valves shall be manually operated with valve operating extension rods extending through the pit cover blocks, (except for the encasement rupture disk isolation valve in 241-AN-04D Slurry Receiver Pit).

Verification: (Analysis) This requirement is verified by Drawings $\mathrm{H}-14-103333$ and $\mathrm{H}-14-103334$, Jumper Arrangement Sections, which show the extension rods extending above the pit cover blocks. In addition, the manual operators are shown on Drawings $\mathrm{H}-14-103349, \mathrm{H}-14$ 103350, and H-14-103351, Valve Actuator Details.

(Exam) This requirement will also be verified by examination at the completion of construction. 
3.2.2.3 The PUREX jumper connector assembly design will be in accordance with Drawings $\mathrm{H}-2-32430$ and $\mathrm{H}-2-32420$. The pit nozzle shall be PUREX type design (Reference Drawings H-2-90185 and 90186).

Verification: (Analysis) The parts list of Drawings H-14-103337 through H-14-103341, Jumper Assembly calls out the required connector assembly drawings for fabrication. The required pit nozzle drawings are called out on the face of Drawings H-14-103347 and H-14-103348 Modification Details.

3.2.2.4 Each jumper manifold shall have a valved nozzle to facilitate interface with the existing transfer piping system via flexible jumpers ( Valve Pit 241-AP and the 241-AZ-VP Valve Pit are excluded from this requirement).

Verification: (Analysis) Not applicable to this package.

3.2.2.5 The valve position indication system shall provide sufficient accuracy with respect to the actual valve position such that the selected flow path configuration is leak tight.

Verification: (Analysis) Each of the valves has a manual operator equipped with mechanical stops as specified on Drawing $\mathrm{H}-14-103351$, Notes 9 and 10.

(Exam) This requirement will be verified and documented by examination per Construction Specification W-314C5, Section 15493.

Not Used

3.2.2.7 Indication of the valves position shall be visible when extension handles are removed.

Verification: (Analysis) Valve position is visible through the sleeve opening by observing the black stripe on the funnel, see Drawing $\mathrm{H}-14-103345$.

(Exam) This requirement will be verified and documented per Construction Specification W-314-C5, Section 15493.

3.2.2.8 The valve operators shall be capable of being locked in place by a padlock that has a bail diameter of $5 / 16^{\prime \prime}$ and a minimum closed length of 1.5 inches.

Verification: (Analysis) Each valve operator was specified to have locking capability per Drawing H-14-103351. See verification for 3.2.2.1.

(Test) This requirement will be verified and documented per ATP. 
Table 3-1. Chemical Composition Range (Sheet 1 of 2)

\begin{tabular}{|c|c|c|c|c|}
\hline \multicolumn{5}{|c|}{ Retrieved waste } \\
\hline \multirow[t]{3}{*}{ Species } & \multicolumn{2}{|c|}{ DST } & \multicolumn{2}{|c|}{ SST } \\
\hline & \multicolumn{2}{|c|}{ Anion/cation } & \multicolumn{2}{|c|}{ Anion/cation } \\
\hline & $\min \mathrm{mol} / \mathrm{L}$ & $\max \mathrm{mol} / \mathrm{L}$ & $\min \mathrm{mol} / \mathrm{L}$ & $\max \mathrm{mol} / \mathrm{L}$ \\
\hline $\mathrm{Ag}$ & 0 & 0.0013 & - & - \\
\hline $\mathrm{Al}$ & 0.05 & 1.1 & 0.029 & 0.5 \\
\hline As & 0 & 0.0066 & - & - \\
\hline$B$ & 0 & 0.013 & - & - \\
\hline $\mathrm{Ba}$ & 0 & 0.0004 & 0 & 0.0014 \\
\hline $\mathrm{Bi}$ & - & - & 0 & 0.076 \\
\hline $\mathrm{Ca}$ & 0.0014 & 0.1 & 0 & 0.17 \\
\hline $\mathrm{Cd}$ & 0 & 0.0074 & 0 & 0.0007 \\
\hline $\mathrm{Cr}$ & 0.0067 & 0.28 & 0.0001 & 0.091 \\
\hline $\mathrm{Cu}$ & 0 & 0.02 & - & - \\
\hline $\mathrm{Fe}$ & 0.0004 & 0.26 & 0.0057 & 0.89 \\
\hline $\mathrm{Hg}$ & 0 & $2.8 \mathrm{E}-05$ & 0 & 0.0001 \\
\hline K & 0.044 & 0.55 & 0.0002 & 0.0095 \\
\hline $\mathrm{La}, \mathrm{Nd}$ & 0 & 0.0066 & 0 & 0.001 \\
\hline $\mathrm{Mg}$ & 0.0004 & 0.046 & - & - \\
\hline $\mathrm{Mn}$ & 0.0003 & 0.16 & 0.0009 & 0.41 \\
\hline Mo & 0 & 0.0029 & - & - \\
\hline $\mathrm{Na}$ & 1.6 & 10.7 & 1.6 & 7.1 \\
\hline $\mathrm{Ni}$ & 0.0002 & 0.008 & 0 & 0.042 \\
\hline $\mathrm{Pb}$ & 0 & 0.004 & 0 & 0.12 \\
\hline $\mathrm{Pd}, \mathrm{Rh}$ & 0 & 0.0063 & - & - \\
\hline $\mathrm{Si}\left(\mathrm{SiO}_{2}\right)$ & 0.0024 & 0.028 & 0.0004 & 0.46 \\
\hline $\mathrm{Ti}$ & 0 & 0.002 & - & - \\
\hline
\end{tabular}


Table 3-1. Chemical Composition Range (Sheet 2 of 2)

\begin{tabular}{|c|c|c|c|c|}
\hline \multicolumn{5}{|c|}{ Retrieved waste } \\
\hline \multirow[t]{3}{*}{ Species } & \multicolumn{2}{|c|}{ DST } & \multicolumn{2}{|c|}{ SST } \\
\hline & \multicolumn{2}{|c|}{ Anion/cation } & \multicolumn{2}{|c|}{ Anion/cation } \\
\hline & $\min \mathrm{mol} / \mathrm{L}$ & $\max \mathrm{mol} / \mathrm{L}$ & $\min \mathrm{mol} / \mathrm{L}$ & $\max \mathrm{mol} / \mathrm{L}$ \\
\hline$u$ & 0 & 0.0092 & - & - \\
\hline $\mathrm{Zr}\left(\mathrm{ZrO}_{2}\right)$ & 0 & 0.3 & 0 & 0.065 \\
\hline Acetate & - & - & 0 & 0.0055 \\
\hline Citrate & 0 & 0.03 & 0.0042 & 0.06 \\
\hline EDTA & 0 & 0.016 & 0 & 0.011 \\
\hline HEDTA & 0 & 0.021 & - & - \\
\hline $\mathrm{Fe}(\mathrm{CN})_{6}$ & - & - & 0 & 0.025 \\
\hline $\mathrm{Cl}$ & 0.003 & 0.17 & 0 & 0.022 \\
\hline $\mathrm{CO}_{3}$ & 0.03 & 0.69 & 0.014 & 0.38 \\
\hline $\mathrm{F}$ & 0.014 & 1 & 0.001 & 0.71 \\
\hline $\begin{array}{l}\text { Fission } \\
\text { product }\end{array}$ & 0 & 0.0001 & - & - \\
\hline $\mathrm{NO}_{2}$ & 0.1 & 1.8 & 0.0086 & 0.83 \\
\hline $\mathrm{NO}_{x}\left(\mathrm{NO}_{3}\right)$ & 0.15 & 3.6 & 0.64 & 5.1 \\
\hline $\mathrm{OH}$ & 0.24 & 4.4 & 0.25 & 6.9 \\
\hline $\mathrm{PO}_{4}$ & 0 & 0.4 & 0.0007 & 3.8 \\
\hline $\mathrm{SO}_{4}$ & 0.003 & 0.16 & 0.01 & 0.22 \\
\hline TOC & 0 & 2 & - & - \\
\hline $\begin{array}{l}\text { DST } \\
\text { EDTA } \\
\text { HEDTA } \\
\text { SST } \\
\text { TOC }\end{array}$ & $\begin{array}{l}=\text { Double-she } \\
=\text { Ethylenedi } \\
=N \text {-(hydrox } \\
=\text { Single-shel } \\
=\text { Total orgal }\end{array}$ & $\begin{array}{l}\text { k } \\
\text { etraacetic ac } \\
\text { 1)-ethylenedi } \\
\text { arbon }\end{array}$ & triacetic acic & \\
\hline
\end{tabular}


Table 3-2. Radionuclide Concentrations

\begin{tabular}{|c|c|c|c|}
\hline \multirow{2}{*}{ Nuclide } & \multicolumn{3}{|c|}{ Nuclide concentrations (Bq/L) } \\
\hline & "All liquids & "All solids & W-314 \\
\hline${ }^{14} \mathrm{C}$ & $2.3 E+05$ & $1.6 \mathrm{E}+05$ & $2.3 E+05$ \\
\hline${ }^{60} \mathrm{Co}$ & $9.5 E+06$ & $4.9 E+08$ & $1.7 E+08$ \\
\hline${ }^{79} \mathrm{Se}$ & c & $1.7 E+04$ & $1.7 E+04$ \\
\hline${ }^{90} \mathrm{Sr}$ & $1.1 E+10$ & $2.9 E+12$ & $9.6 E+11$ \\
\hline${ }^{90} \mathrm{Y}$ & $1.1 E+10$ & $2.9 \mathrm{E}+12$ & $9.6 \mathrm{E}+11$ \\
\hline${ }^{99} \mathrm{Tc}$ & $1.7 E+07$ & $1.2 \mathrm{E}+10$ & $4.0 E+09$ \\
\hline${ }^{106} \mathrm{Ru}$ & $9.9 E+02$ & $7.2 \mathrm{E}+04$ & $2.4 E+04$ \\
\hline${ }^{125} \mathrm{Sb}$ & $3.4 E+04$ & $1.8 E+08$ & $5.9 E+07$ \\
\hline $129 \mathrm{I}$ & $2.0 \mathrm{E}+04$ & $6.4 E+06$ & $2.1 E+06$ \\
\hline${ }^{134} \mathrm{Cs}$ & $6.1 E+06$ & $9.4 E+06$ & $7.2 \mathrm{E}+06$ \\
\hline${ }^{137} \mathrm{Cs}$ & $8.8 E+10$ & $1.0 E+11$ & $9.2 E+10$ \\
\hline${ }^{144} \mathrm{Ce}$ & $9.1 E+00$ & $3.4 E+02$ & $1.2 \mathrm{E}+02$ \\
\hline${ }^{147} \mathrm{Pm}$ & $3.6 E+07$ & c & $3.6 E+07$ \\
\hline${ }^{154} \mathrm{Eu}$ & $2.4 E+09$ & $1.1 E+10$ & $5.2 \mathrm{E}+09$ \\
\hline${ }^{155} \mathrm{Eu}$ & $5.9 E+07$ & $5.0 E+06$ & $5.9 E+07$ \\
\hline${ }^{237} \mathrm{~Np}$ & $2.3 E+05$ & $9.9 E+08$ & $3.3 E+08$ \\
\hline${ }^{238} \mathrm{Pu}$ & $1.8 E+06$ & $1.9 E+08$ & $6.4 E+07$ \\
\hline${ }^{239} \mathrm{Pu}^{\mathrm{d}}$ & $3.6 \mathrm{E}+07$ & $1.6 \mathrm{E}+09$ & $5.5 E+08$ \\
\hline${ }^{241} \mathrm{Pu}$ & $2.6 E+08$ & $3.8 E+09$ & $1.4 E+09$ \\
\hline${ }^{241} \mathrm{Am}$ & $4.2 \mathrm{E}+07$ & $1.1 E+10$ & $3.7 E+09$ \\
\hline${ }^{242} \mathrm{Cm}$ & $1.1 E+01$ & $2.0 E+02$ & $7.3 \mathrm{E}+01$ \\
\hline${ }^{244} \mathrm{Cm}$ & $4.2 E+05$ & $6.1 E+07$ & $2.0 E+07$ \\
\hline
\end{tabular}

'From Table 1a., Van Keuren, J. C., 1996, Tank Waste Compositions and Atmospheric Dispersion Coefficients for use in Safety Analysis Consequence Assessments, WHC-SD-WM-SARR-016, Rev. 2, Westinghouse Hanford Company, Richland, Washington.

${ }^{\mathrm{b}} \mathrm{W}-314$ values represent a bounding mixture for design of $67 \%$ liquid and $33 \%$ solid, except for ${ }^{14} \mathrm{C}$ and ${ }^{155} \mathrm{Eu}$ where the maximum liquid value was used as it is higher than the mix and for ${ }^{79} \mathrm{Se}$ and ${ }^{147} \mathrm{Pm}$ where data is not available.

"No available data.

${ }^{d}$ The ${ }^{239} \mathrm{Pu}$ activity concentration also includes ${ }^{240} \mathrm{Pu}$. 


\subsubsection{Reliability}

3.2.3.1 The design life of the valve manifoldljumper piping system components shall be 12 years. The design life of the WT-SLL-3160 piping system components shall be 40 years

Verification: (Analysis) This requirement is verified by Calculation W314-P-042, Jumper Pipe Stress Analysis and Procurement Specification W-314-P1 Ball Valves, para 3.4.2.3. The total corrosion allowance is calculated for the design life and entered into the Autopipe program for calculating stresses. The procurement specification stipulates the 12 year design life of the valves.

3.2.3.2 The design life of the cover blocks shall be 35 years.

Verification: (Analysis) Cover blocks are reinforced concrete designed according to $\mathrm{ACl}$ specifications and will be constructed according to $\mathrm{ACl}-301$ and $\mathrm{ACl}-318$ (see Construction Specification W-314-C5, Section 03300 and Calculations W314-C-029 and W314-C-034). These requirements are expected to ensure a design life beyond 35 years. In addition, these cover blocks are similar to existing cover blocks which have been in place for up to 40 years.

3.2.3.3 The design life of the Slurry Receiver Pit, 241-AN-O4D shall be 40 years.

Verification: (Analysis) Pit is reinforced concrete designed according to $\mathrm{ACl}$ Specifications and will be constructed according to $\mathrm{ACl}-301$ and $\mathrm{ACl} 318$ (see Construction Specification W-314-C5, Section 03300 and Calculation W314-C034). These requirements are expected to ensure a design life of 40 years. In addition, pits similar to this pit have been in place for up to 40 years.

3.2.3.4 Valves shall be designed to operate properly following stagnant periods of up to one year.

Verification: (Analysis) The design requirement is verified by the Procurement Specification W-314-P1, Ball Valves, para. 3.4.1.4. The specification stipulates that valves remain in operation for a minimum period of one thousand complete cycles and be designed to operate properly following periods of stagnant position of up to one year. This fact, along with the fact that the fluid composition and properties are provided in the procurement specification (para. 3.1 ), provides adequate assurance that this reliability requirement will be met. 
In addition, this requirement is verified for the valve position sensor switches by requiring the switches to have a Mean Time Between Failure (MTBF) of at least 100,000 cycles (Ref. Drawing H-14-103351, Notes 11 and 12). This is well above the estimated 10,000 operations over the life of the equipment. As far as the periods of stagnant position, the position switches are non contact type and, therefore, are not subject to stagnant position failures.

3.2.3.5 Valves shall be capable of being operated up to 1000 cycles over its design life.

Verification: (Analysis) The design requirement is verified by the Procurement Specification W-314-P1, Ball Valves, para. 3.4.1.4. The specification stipulates that valves remain in operation for a minimum period of one thousand complete cycles and be designed to operate properly following periods of stagnant position of up to one year. This fact, along with the fact that the fluid composition and properties are provided in the procurement specification (para. 3.1), provides adequate assurance that this reliability requirement will be met.

In addition, this requirement is verified for the valve position sensor switches by requiring the switches to have a Mean Time Between Failure (MTBF) of at least 100,000 cycles (Ref. Drawing H-14-103351 Notes 11 and 12). This is well above the estimated 10,000 operations over the life of the equipment. As far as the periods of stagnant position, the position switches are non contact type and, therefore, are not subject to stagnant position failures.

\subsubsection{Fault Detection/Fault Isolation}

Designs shall provide for the detection and isolation of faults to systems, structures, and components as necessary in order to minimize the risks associated with faulty operation to plant, personnel and environment. Protection systems and associated instrumentation and controls shall be designed in accordance with DOE 6430.1a, Section 1660-99.0.2.

Verification: (Analysis) Section 1660-99.0.2 deals with Safety Class protection systems and Safety Class instrumentation and control systems. The valve pit manifold consists of piping, valve position sensors, and manual operators. None of these components are Safety Class, and, therefore, this requirement is not applicable. 


\subsubsection{Maintainability}

\subsubsection{Corrective Maintenance}

The repair or replacement of a failed component on the valve manifold jumper shall be performed within 25 days.

Verification: (Analysis) All components of the valve manifold that require preventive maintenance or operator access are located above the cover blocks, or are accessible without having to remove the cover blocks. This fact, along with the fact that the components are all standard off-the-shelf items, provides adequate assurance that the repair or replacement can be done within the 25-day requirement. The repair and replacement of components requiring cover block removal (e.g., valves and connectors) are all integral parts of a jumper. Jumpers are treated as throwaway items and are not repaired. Therefore, a new jumper would be required. Although the components within the pits are designed and expected to last for the design life (see para. 3.2.4.2), if corrective maintenance is required within 25 days, a spare jumper would need to be on hand. The jumper could not be fabricated, tested and installed within the 25-day requirement. Per conversations with operations personnel, entry into a pit can require up to 14 days just to fill out the required paper work. Approximately 7 days would be needed to remove/replace the cover blocks and install a new jumper. Therefore, based on past experience with cover block removal and assuming that a spare jumper is available the 25 -day requirement can be met.

\subsubsection{Preventive Maintenance}

The design of the valve manifold jumper system shall ensure no preventive maintenance requiring pit entry.

Verification: (Analysis) The jumpers for the valve manifold system are designed for installation with a remote operated impact wrench. In addition, the manifold valves are designed for actuation from above the cover blocks. These facts, along with the fact that the jumper components are designed to last the design life without any required preventive maintenance (see Procurement Specification $W-314-P 1$, para. 3.4.1.7) provide adequate assurance that pit entry will not be required for preventive maintenance.

\subsubsection{Environmental Conditions}

The systems and components covered by this specification shall be compatible with the environmental conditions listed below, as applicable. Performance Category (PC) 
3 is assigned to Safety Class systems and PC1 is assigned to general service systems. The design and analysis of loads associated with existing systems shall, as a minimum, be performed to the design requirements of the existing system.

3.2.5.1 Natural Environments

3.2.5.1.1 Ambient Air Temperature

The ambient air (outside the pit) temperature range is $48.9^{\circ} \mathrm{C}\left(120^{\circ} \mathrm{F}\right)$ to $-35.5^{\circ} \mathrm{C}\left(-32^{\circ} \mathrm{F}\right)$, and with a maximum 24 hour differential of $28.9^{\circ} \mathrm{C}\left(52^{\circ} \mathrm{F}\right)$.

Verification: (Analysis) The gear operator is designed to operate within the required temperature range as shown on Drawing $\mathrm{H}-14-103351$ (Notes 9 and 10). In addition, the requirement is incorporated in the Procurement Specification W-314-P1 Ball Valves, para 3.3. The gasket for the PUREX connector is made of Kynar which can handle temperatures as low as $-40^{\circ} \mathrm{F}$ and as high as $300^{\circ} \mathrm{F}$.

The allowable ambient air temperature range of the position sensor switches is $-40^{\circ} \mathrm{F}$ to $185^{\circ} \mathrm{F}$ per vendor data. This temperature range does satisfy the above requirement.

The concrete cover blocks and metallic components are not affected by this requirement as they are not restrained, thus free to move.

\subsection{Soil Temperature}

The minimum soil temperatures below ground surface is:

$1.3 \mathrm{~cm}(0.5 \mathrm{in}): \quad-19.5^{\circ} \mathrm{C}\left(-3.0^{\circ} \mathrm{F}\right)$

$38 \mathrm{~cm}(15 \mathrm{in}): \quad-8.8^{\circ} \mathrm{C}\left(16.1^{\circ} \mathrm{F}\right)$

$92 \mathrm{~cm}(36 \mathrm{in}): \quad 0.8^{\circ} \mathrm{C}\left(33.5^{\circ} \mathrm{F}\right)$

Verification: (Analysis) The manifold piping system is located below grade in the valve pits. The minimum expected temperature in the valve pit with the cover blocks installed is the minimum soil temperature $0.8^{\circ} \mathrm{C}$ $\left(33.5^{\circ} \mathrm{F}\right)$. The only place that this temperature is a factor is in determining the expansion stresses in the jumper assemblies. The stress analysis is verified in Calculation W314-P-042, Jumper Pipe Stress Analysis.

\subsection{Seismic Loads}

\section{PC1 structures, systems, and components}

Earthquake load design of PC1 SSCs shall comply with the UBC, Seismic Zone 2B, for standard occupancy facilities. 


\section{PC3 structures, systems, and components}

Earthquake load design of PC3 SSCs shall comply with DOE-STD-1020 by using dynamic analysis and site-specific design response spectra listed in Table 3-3.

New process pit and new cover blocks shall be designed, analyzed, procured, and constructed to $\mathrm{PC} 3$ requirements.

Calculate elastic seismic response, $D_{s}$, by dynamic analysis using Response Level 2 damping values from Table 3-4.

Verification: (Analysis) This requirement is verified by Calculations W314-P-042, Jumper Pipe Stress Analysis, W314-C029, Pump Pits 01A and 04A Structural Evaluation, W314-C-030, Pump Pit Wall Evaluation, W314-C-034, Riser 10, i.e. Slurry Receiver, Pit Design and W314-C008, AN Misc. Equipment Supports, which show that the seismic induced loads result in stresses within the code allowables.

\subsection{Wind Loads}

For PC3 systems:

"Fastest Mile" wind velocity:

"Three Second Gust" wind velocity:

Missile (horizontal):

\author{
$36 \mathrm{~m} / \mathrm{s}(80 \mathrm{mi} / \mathrm{h})$ \\ $44 \mathrm{~m} / \mathrm{s}(100 \mathrm{mi} / \mathrm{h})$ \\ $50 \times 100 \mathrm{~mm}(2 \times 4$ in.) \\ Timber plank weighing $7 \mathrm{~kg}$ \\ (15 lb)@ $22 \mathrm{~m} / \mathrm{s}(50 \mathrm{mi} / \mathrm{h})$. \\ Maximum trajectory \\ height $=9 \mathrm{~m}(30 \mathrm{ft})$.
}

For PC1 systems:

"Fastest Mile" wind velocity:

$31 \mathrm{~m} / \mathrm{s}(70 \mathrm{mi} / \mathrm{h})$

"Three Second Gust" wind velocity: $38 \mathrm{~m} / \mathrm{s}(85 \mathrm{mi} / \mathrm{h})$

Verification: (Analysis) This requirement is verified by Calculation W314-C-008, AN Misc. Equipment Supports for the valve extension handle and gear operator. The calculation shows that since the surface areas of the operator and handle are small, the resulting load due to wind is negligible. This requirement does not affect the design of cover blocks and all inside pit components. 
Table 3-3 - Response Spectra

\begin{tabular}{|c|c|c|c|c|c|c|}
\hline \multicolumn{7}{|c|}{ Horizontal Response Spectra "g" } \\
\hline \multirow{2}{*}{$\begin{array}{c}\text { Frequency } \\
\text { (Hertz) }\end{array}$} & \multicolumn{6}{|c|}{ Damping } \\
\hline & $0.50 \%$ & $2 \%$ & $5 \%$ & $7 \%$ & $10 \%$ & $12 \%$ \\
\hline 100 & 0.26 & 0.26 & 0.26 & 0.26 & 0.26 & 0.26 \\
\hline 33.3 & 0.26 & 0.26 & 0.26 & 0.26 & 0.26 & 0.26 \\
\hline 13.3 & 0.57 & 0.48 & 0.41 & 0.38 & 0.36 & 0.35 \\
\hline 10 & 0.77 & 0.59 & 0.47 & 0.43 & 0.38 & 0.36 \\
\hline 5 & 1.04 & 0.76 & 0.58 & 0.52 & 0.45 & 0.42 \\
\hline 3.3 & 0.98 & 0.72 & 0.54 & 0.48 & 0.42 & 0.39 \\
\hline 2 & 0.74 & 0.55 & 0.41 & 0.37 & 0.33 & 0.30 \\
\hline 1 & 0.45 & 0.34 & 0.26 & 0.23 & 0.21 & 0.19 \\
\hline 0.5 & 0.22 & 0.17 & 0.13 & 0.12 & 0.11 & 0.10 \\
\hline 0.25 & 0.08 & 0.06 & 0.05 & 0.05 & 0.04 & 0.04 \\
\hline \multicolumn{7}{|c|}{ Vertical Response Spectra "g" } \\
\hline \multirow{2}{*}{$\begin{array}{l}\text { Frequency } \\
\text { (Hertz) }\end{array}$} & \multicolumn{6}{|c|}{ Damping } \\
\hline & $0.50 \%$ & $2 \%$ & $5 \%$ & $7 \%$ & $10 \%$ & $12 \%$ \\
\hline 100 & 0.18 & 0.18 & 0.18 & 0.18 & 0.18 & 0.18 \\
\hline 33.3 & 0.18 & 0.18 & 0.18 & 0.18 & 0.18 & 0.18 \\
\hline 13.3 & 0.60 & 0.46 & 0.37 & 0.33 & 0.30 & 0.28 \\
\hline 10 & 0.66 & 0.49 & 0.37 & 0.33 & 0.29 & 0.27 \\
\hline 5 & 0.60 & 0.44 & 0.33 & 0.30 & 0.26 & 0.24 \\
\hline 3.3 & 0.48 & 0.36 & 0.27 & 0.24 & 0.21 & 0.19 \\
\hline 2 & 0.32 & 0.24 & 0.18 & 0.16 & 0.14 & 0.13 \\
\hline 1 & 0.19 & 0.14 & 0.11 & 0.10 & 0.09 & 0.08 \\
\hline 0.5 & 0.14 & 0.11 & 0.08 & 0.07 & 0.07 & 0.06 \\
\hline 0.25 & 0.06 & 0.05 & 0.04 & 0.03 & 0.03 & 0.03 \\
\hline
\end{tabular}


Table 3-4 - Response Level

\begin{tabular}{|l|c|}
\hline & Damping (\% of critical) \\
\cline { 2 - 2 } & Response Level \\
\hline Demand/capacity ratio & 0.5 to 1.0 \\
\hline Welded and friction bolted metal structures & 4 \\
\hline Bearing-bolted metal structures & 7 \\
\hline $\begin{array}{l}\text { Prestressed concrete structures without } \\
\text { complete loss of prestress }\end{array}$ & 5 \\
\hline Reinforced concrete structures & 7 \\
\hline Masonry shear walls & 7 \\
\hline Wood structures with nailed joints & 10 \\
\hline Distribution systems & 5 \\
\hline $\begin{array}{l}\text { Massive low stressed components (pumps, } \\
\text { motors, etc.) }\end{array}$ & 3 \\
\hline Light welded instrument racks & 3 \\
\hline Electrical cabinets and other equipment & 3 \\
\hline $\begin{array}{l}\text { Liquid containing metal tanks } \\
\text { Implusive mode }\end{array}$ & 3 \\
\hline $\begin{array}{l}\text { Liquid containing metal tanks } \\
\text { Sloshing mode }\end{array}$ & 0.5 \\
\hline
\end{tabular}

\subsection{Snow Loads}

The ground snow loads are: $720 \mathrm{~Pa}\left(15 \mathrm{lb} / \mathrm{ft}^{2}\right)$

Verification: (Analysis) This requirement is verified by Calculations W314-C-029, Pump Pits 01A and 04A Pit Structural Evaluation and W314-C-034, Riser 10, i.e. Slurry Receiver, Pit Design where $20 \mathrm{lb} / \mathrm{ft}^{2}$ is input as a design load on the cover blocks. The valve extension handle and gear operator assembly have insignificant horizontal area and, therefore, snow loads would be negligible. Inside pit components are not affected by this requirement.

\subsection{Relative Humidity}

The relative humidity range is 0 to $100 \%$ (Rate of change is negligible). 
Verification: (Analysis) This requirement is verified by incorporating it in the Procurement Specification W-314-P1 Ball Valves, para 3.3.

The gear operator is encased in a totally enclosed housing, filled with heavy duty high temperature grease to give lifetime lubrication. The seals keep the lubrication in and foreign matter out and provide weather resistant performance.

The valve position sensor switches are in a hermetically sealed capsule, which is in a NEMA 4 rated enclosure. With no chance for corrosion, the effects of moisture or humidity are not a design consideration. This requirement does not affect the design of the cover blocks or the metallic components inside the pit.

\subsection{Surface Precipitation}

The surface precipitation is $4 \mathrm{~cm}(1.56 \mathrm{in})$ in a 24 hour period.

Verification: (Analysis) This requirement is verified by sloping the valve pit cover blocks to provide adequate drainage of any precipitation (Ref. Drawing H-14-100932).

The gear operator and valve position sensor switches are above the surface approximately $3 \mathrm{ft}$ and are housed in weather-tight and NEMA 4 rated enclosures (respectively). Therefore, surface precipitation will not affect the operation of the gear operator or position sensor switches.

\subsection{Hail Events}

The hail diameter is less than or equal to $1.9 \mathrm{~cm}(0.75 \mathrm{in})$.

Verification: (Analysis) This requirement is verified by the fact that this size of a hail event will have no affect on the concrete cover blocks (Ref. Drawings H-14-103318. $103319,103323)$. In addition, the gear operator is enclosed in a cast metal housing and the valve position sensors are in a NEMA 4 rated enclosure. These enclosures will provide adequate protection against the hail event. The components within the pit are not affected by this requirement.

\subsection{Sand and Dust}

The sand/dust concentration is $0.177 \mathrm{gm} / \mathrm{m}^{3}$ with a typical size of 350 $\mu \mathrm{m}$.

Verification: (Analysis) This requirement is verified by designing the valve actuators for a desert environment (Ref. Drawing 
$\mathrm{H}-14-103351$, Notes 9 and 10 l. In addition, the valve position sensor NEMA 4 enclosure is rated for the protection against dust, dirt, oil and water. This requirement does not affect the design of cover blocks and all inside pit components.

\subsection{Solar Radiation}

The solar radiation range is between $4 \mathrm{Watts} / \mathrm{m}^{2}$ and $406 \mathrm{Watts} / \mathrm{m}^{2}$.

Verification: (Analysis) This requirement is verified by Calculation W314-J-005 for the solar radiation affects on the valve position switch enclosure. This calculation shows that at the maximum ambient temperature of $120^{\circ} \mathrm{F}$, the increased temperature due to solar radiation will not exceed the enclosure's rated temperature (ref. para. 3.2.5.1.1). In addition, based on their materials of construction and/or their location this requirement will not affect the design of the cover blocks, the valve extension handles, the gear operators, and all inside pit components.

\subsection{Glaze (See definition in Section 5.1)}

The glaze is $2.54 \mathrm{~cm}(1 \mathrm{in.})$.

Verification: (Analysis) As far as a design load, this requirement does not affect the design of the cover blocks, the valve extension handles, the gear operators, valve position sensors, and all inside pit components. However, operation personnel would have problems walking on the cover blocks and operating the gear operators.

\subsection{Ashfall Events}

A total combination load of snow fall and ash fall of $960 \mathrm{~Pa}\left(20 \mathrm{lb} / \mathrm{ft}^{2}\right)$ shall be used.

Verification: (Analysis) This requirement is verified in the Pump Pits Structural Evaluation (Calculations W314-C-029) and Riser 10, i.e. Slurry Receiver, Pit Design(Calculation W314-C-034). This analysis increased the live load by $100 \mathrm{lb} / \mathrm{ft}^{2}$ to account for miscellaneous loading such as an ashfall event $\left(20 \mathrm{lb} / \mathrm{ft}^{2}\right)$. The valve extension handles and gear operator assemblies have insignificant horizontal area and, therefore, ashfall loads would be negligible. In addition, the inside pit components are not affected by this requirement. Calculations W314-C-008, AN Misc. Equipment Supports and W314-C-033 AN and WTS Wind Missile Shield, includes this requirement in the analysis. 


\subsection{Dead loads}

Dead loads include the weights of all permanent materials and equipment, including the structure's own weight. Design dead loads shall include the weight of all permanent service equipment. Load calculations shall include an allowance for any loadings anticipated to be added at a later date. Initially assumed loads shall be revised so that the final design reflects the configuration shown on the drawings.

The unit weights of materials and construction assemblies for buildings and other structures shall be those given in ASCE 7-95. Where unit weights are neither established in that standard nor determined by test or analysis, the weights shall be determined from data in manufacturer drawings or catalogs.

Verification: (Analysis) This requirement is verified by Calculations W314-P-042, Jumper Pipe Stress Analysis and Calculation No. W314-C-029, Pump Pits 01A and 04A Structural Evaluation and W314-C-034, Riser 10, i.e. Slurry Receiver, Pit Design. The jumper stress analysis includes the weight of the fluid and all support dunnage besides the pipe and components. The pit structural evaluation only includes the weight of the concrete since the support steel weight is small compared with that of the concrete.

\subsection{Thermal Forces}

The design of structures shall include the effects of stresses and movements resulting from variations in temperature. Structures shall be designed for movements resulting from the maximum seasonal temperature change. The design shall provide for the lags between air temperatures and the interior temperatures of massive concrete members or structures. Consideration shall be given to passive soil loading resulting from thermal growth of subgrade structures.

Verification: (Analysis) The cover block design provides for this movement by providing clearances between the pit walls and cover blocks and between the cover blocks as shown on Drawings $\mathrm{H}-14-103318, \mathrm{H}-14-103319$, and $\mathrm{H}-14-103323$. The cover blocks will move at the same rate as the pit walls.

\subsection{Creep and Shrinkage Forces}

Concrete and masonry structures shall be investigated for stresses and deformations induced by creep and shrinkage. For concrete and masonry structures, the minimum linear coefficient of shrinkage shall be assumed to be $0.0002 \mathrm{~mm} / \mathrm{mm}$, unless a detailed analysis is undertaken. The theoretical shrinkage displacement shall be computed as the product of the linear coefficient and the length of the member. 
Verification: (Analysis) This requirement is verified in the Pump Pits 01A and 04A Structural Evaluation (Calculation W314C-029) and Riser 10, i.e. Slurry Receiver, Pit Design (Calculation W314-C-034) and provided for by the reinforcing steel.

\subsection{Load Combinations and Allowable Stresses}

Load combinations, allowable stresses, and strength requirements for load conditions that include live load, dead load, snow load, and normal operating loads for all SSCs shall comply with the UBC or applicable system national codes and standards.

Load combinations, allowable stresses, and strength requirements for load conditions that include live load; dead load ; snow load; normal operating loads; and NPH loads of extreme wind, earthquake, flood, and ashfall for all SSCs shall comply with DOE-STD-1020.

Load factors and load combinations for PC1 structures, systems, and components

Combine response from various loadings to determine the structural demand by using the UBC-specified load combination rules (e.g., load factors for ultimate strength design and unit load factors for allowable stress design).

Where:

DL = DEAD LOAD

LL $\quad=\quad$ LIVE LOAD

RL $\quad=\quad$ ROOF LIVE LOAD

$S=$ SNOW LOAD

$\mathrm{W}=$ WIND LOAD

E $=$ EARTHQUAKE

$T=$ THERMAL

C $=$ CREEP/SHRINKAGE

Allowable Stress (AS) Design: All Construction

$A S=D L+L L+R L$ (or $S$ )

$A S=0.75[D L+L L+W($ or $E)]$

$A S=0.75[D L+L L+W+S / 2]$

$A S=0.75[D L+L L+S+W / 2]$

Ultimate Strength (U) Design: Reinforced Concrete

$U=1.4 D L+1.7 L L+1.7 R L$ (or 1.7S)

$U=0.75[1.4 \mathrm{DL}+1.7 \mathrm{LL}+1.7 \mathrm{~W}]$

$U=1.05[\mathrm{DL}+\mathrm{LL}+\mathrm{E}]$

$U=0.9 \mathrm{DL}+1.3 \mathrm{~W}$ (or $1.4 \mathrm{E}$ )

$\mathrm{U} \quad=1.4[\mathrm{DL}+\mathrm{T}($ or $\mathrm{C})]$

$U=0.75[1.4 \mathrm{DL}+1.7 \mathrm{LL}+1.4 \mathrm{~T}$ (or $1.4 \mathrm{C}$ ) $]$

Strength (S) Design: Steel (Load \& Resistance Factor Design)

$\mathrm{S}=1.4 \mathrm{DL}$

$S=1.2 \mathrm{DL}+1.6 \mathrm{LL}+0.5(\mathrm{RL}$ or $\mathrm{S})$ 


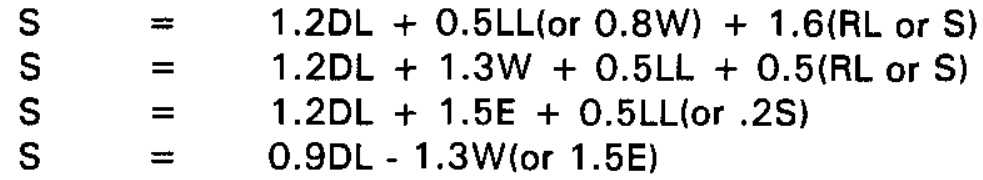

Load factors and load combination for PC3 structures, systems, and components

Combine response from various loadings to determine structural demand as follows.

Where:

$\mathrm{DL} \quad=$

LL = LIVE LOAD

$\mathrm{RL} \quad=\quad$ ROOF LIVE LOAD

$\mathrm{S}=$ SNOW LOAD

$W=$ WIND LOAD

$\mathrm{E} \quad=$ EARTHQUAKE

$A=$ ASHFALL

$\mathrm{T}=$ THERMAL

C $=$ CREEP/SHRINKAGE

Allowable Stress (AS) Design:

$A S=D L+L L+R L(o r S)$

$A S=0.62[\mathrm{DL}+\mathrm{LL}+\mathrm{RL}$ (or $\mathrm{S})+\mathrm{W}+\mathrm{T}$ (or $\mathrm{C})]$

for shear stress

$A S=0.71[\mathrm{DL}+\mathrm{LL}+\mathrm{RL}($ or $\mathrm{S})+\mathrm{E}($ or $\mathrm{A})+\mathrm{T}($ or $\mathrm{C})]$

for all stress other than shear stress

$A S=0.59[D L+L L+R L($ or $S)+E($ or $A)+T$ (or $C)]$

Ultimate Strength (U) Design:

$\mathrm{U}=1.4 \mathrm{DL}+1.7 \mathrm{LL}+1.7 \mathrm{RL}$ (or $1.7 \mathrm{~S}$ )

$U=1.4[D L+T$ (or $C)]$

$U=D L+L L+R L($ or $S)+W($ or $E$ or $A)+T($ or $C)$

Strength (S) Design: Steel (Load \& Resistance Factor Design)

$\mathrm{S}=1.4 \mathrm{DL}$

$\mathrm{S}=1.2 \mathrm{DL}+1.6 \mathrm{LL}+0.5(\mathrm{RL}$ or $\mathrm{S})$

$S=1.2 \mathrm{DL}+0.5 \mathrm{LL}+1.6(\mathrm{RL}$ or $\mathrm{S})$

$S=D L+L L+R L($ or $S)+W($ or $E$ or $A)+T$

Verification: (Analysis) This requirement is verified by Calculations W314-P-042, Jumper Pipe Stress Analysis and W314-C029, Pump Pits 01A and 04A Structural Evaluation and W314-C-034, Riser 10, i.e. Slurry Receiver, Pit Design and meets the requirements. 


\subsubsection{Induced Environments}

\subsection{Waste Properties}

Materials used that come in contact with the waste be capable of safely handling waste with the following properties:

$\begin{array}{ll}\text { Specific Gravity } & 1 \text { to } 1.5 \\ \text { Viscosity } & 1 \text { to } 30 \text { centipoise (Newtonian) } \\ \text { Miller Number } & 100 \text { maximum } \\ \text { pH } & 7 \text { to } 14 \\ \text { Temperature } & 10 \text { to } 93^{\circ} \mathrm{C}\left(50 \text { to } 200^{\circ} \mathrm{F}\right) \\ \text { Solids Content } & 30 \mathrm{Vol} . \% \\ \text { Particle Size } & 0.5 \text { to } 4000 \text { microns } \\ \text { Note: } 95 \% \text { of total particles } 0 \text { to } 50 \text { microns } \\ <5 \text { percent of total particles } 50 \text { to } 500 \text { microns } \\ <1 \text { percent of total particles } 500 \text { to } 4000 \text { microns }\end{array}$

Verification: (Analysis) The material of construction of the valve manifold components is ASTM A312 TP 304L Stainless Steel (ss). The 304L ss has a history of successful use and testing with the Hanford Site waste chemistry and was recommended as the material for the primary pipe according to the Internal Memo 7F540-94-019, June 10, 1994, Projects W-058/W-028 Material of Construction Position Paper. The waste properties listed above are identical to those of Project W-058 and are the worst case for the W-314 transfer.

In addition, this requirement is incorporated in the Procurement Specification W-314-P1 Ball Valves, para 3.1.

The cover blocks are protected with special protective coating. The special protective coatings ability to resist the above requirements will be verified by vendor data submittals. The pit is lined with stainless steel; type 304L.

\subsection{Radiation Tolerance}

\subsection{Inside Pit Radiation Level}

Materials used that are located inside a pit shall be capable of operating in the following radiation environment:

total accumulated dose: $\quad 6 \times 10^{7}$ rads

dose rate:

$1 \times 10^{7} \mathrm{mr} / \mathrm{hr}$

Verification: (Analysis) This requirement is verified by incorporating it in the Procurement Specifications W-314-P1 Ball Valves, para 3.1 and W-314-P2 Impact Wrench, para 
3.2.3. The valves seats will need to meet the total accumulated dose, however, the impact wrench is only used for installing/removing the jumpers and, therefore will not need to meet the total accumulated dose requirement. Metallic components of the manifold system are not affected by the inside pit radiation level.

The valve seats/seals and gasket on the PUREX connector assemblies will be fabricated from Kynar that has a radiation resistance of up to $1 \times 10^{9}$ rads. (Reference Elfatochem Technical Brochure).

The cover blocks are protected with special protective coating. The special protective coatings ability to resist the above requirements will be verified by vendor data submittals.

\subsection{Background Radiation Level}

Materials used that are located outside a pit shall be capable of operating in the following radiation environment:
total accumulated dose:
$0.5 \mathrm{rad} /$ year
dose rate:
$0.25 \mathrm{mr} / \mathrm{hr}$

Verification: (Analysis) All equipment outside the pit is protected in a metal enclosure and based on representative manufacturer information, will not break down at this radiation level. In addition, the equipment is similar to equipment that has previously been used in the tank farms without any adverse affects.

\subsubsection{Transportability}

This paragraph is not applicable to the document.

\subsubsection{Flexibility and Expansion}

Each system design shall, to the maximum extent practable, provide sufficient flexibility to accommodate for programmatic changes or operation modifications.

Verification: (Analysis) The valve pit manifold system allows transfers to and from selected DST.

The valve operators can be readily replaced if a future change is made to add motor-operators. In addition, the conduit runs embedded in the cover blocks have been oversized and shielded wire has been used on the instrument wiring. This was done to allow power to be run in the same conduit if the change is made to motor operators for the valves. 


\subsection{Design and Construction}

\subsubsection{Materials, Processes, and Parts}

3.3.1.1 The pit piping system shall meet the applicable design and construction requirements contained in DOE Order 6430.1A, HS-BS0084, ASME B31.3, and UCRL-15910.

Verification: (Analysis) Allowable stresses per B31.3 and loading per UCRL-15910 are verified by Calculation W314-P-042, Jumper Pipe Stress Analysis. In this calculation, the resulting stresses are compared to the allowables in B31.3. The design requirements of ASME B31.3 are verified by incorporating these into the Construction Specification W-314-C5, Section 15493, Appendix A, and the Procurement Specification W-314-P1, Ball $V$ alves. The requirements of HS-BS-0084, Jumper Fabrication, are verified by incorporating the relevant sections of this document into Appendix $A$ of the Construction Specification, W-314-C5. Compliance with the DOE Order $6430.1 \mathrm{~A}$ is verified by FDNW DOE 6430.1A Checklist, W314-DOE6430-AN200E-P-1.

3.3.1.2 The new pits and cover blocks shall meet the applicable design and construction requirements contained in DOE Order 6430.1A, ACl-318, ACl-349, UCRL-15910, AISC, and ASCE 7.

Verification: (Analysis) Since the cover blocks are Safety Class, DOE Order 6430.1A establishes the listed codes as the basis for design and construction of the cover blocks. Therefore, the use of these codes in Calculations W314C-029, Pump Pits 01A and 04A Structural Evaluation, W314-C-034, Riser 10, i.e. Slurry Receiver, Pit Design and Construction Specification W-314-C5, Section 03300 satisfies this requirement. Specifically, $\mathrm{ACl}-318$, $\mathrm{ACl}-349$, and UCRL-15910 are referenced in Calculations W314-C-029 and W314-C-034. In addition, the snow and live loads are from ASCE 7 as referenced on page 2 of the same calculation. No structural steel on the cover blocks is Safety Class, therefore, there is no specific reference to AISC in the calculation. Finally, compliance with all of the requirements of DOE 6430.1A is verified by FDNW DOE 6430.1A Checklist.

3.3.1.3 The valve position sensor systems shall comply with NFPA 70 in accordance with DOE Manual 6430.1A, Section 1600.

Verification: (Analysis) The valve position sensors are required to be installed as specified in NFPA 70. The valve position sensor systems are required to be UL, FM, or other nationally recognized testing lab approved as per DOE $6430.1 \mathrm{a}$. The compliance of the system is verified by 
FDNW DOE 6430.1 a checklist, and by incorporating these requirements in the Construction Specification $W$ 314-C5, Section 16400, para. 1.3.1, 3.2.1.1, and 3.4.1.

3.3.1.4 Electrical materials and equipment shall be UL or FM tested, with label attached, for the purpose intended, whenever such products are available. Where there are no UL or FM listed products of the type, testing and certification by another nationally recognized testing agency may be acceptable.

Verification: (Analysis) This requirement is verified by FDNW DOE 6430.1A Checklist, and by incorporating this requirement in the Construction Specification W-314-C5, Section 13440, para. 1.3.2 and Section 16400, para. 1.3.1 and Procurement Specification W-314-P6, Section 4.2.

3.3.1.5 Field control equipment shall comply with the NEMA ICS standards and UL 508A in accordance with DOE Order 6430.1A, Section 1640-2.5.

Verification: (Analysis) This requirement is verified by incorporating it in the Construction Specification W-314-C5, Section 13440, para. 2.2.7 and Procurement Specification W314-P6, para. 3.5 .5 requires compliance to UL 508A instead of UL 508 because UL 508 as referenced in DOE 6430.1a, Section 1640-2.5 applies to motor controllers only. The design engineer applied UL 508A to this design package. For compliance with DOE Order 6430.1a, Div. 16, refer to FDNW DOE Order 6430.1a, Div. 16 checklist.

3.3.1.6 All components of the valve manifold piping system including manifold supports, but excluding the PUREX connector assemblies, should be exterior corrosion resistant (e.g., coated with suitable corrosion resistant materials).

Verification: (Analysis) Except the PUREX connector assemblies, all components of the valve manifold piping system including manifold supports are made of stainless steel and do not require additional coating for corrosion protection. This is verified on the jumper fabrication Drawings $\mathrm{H}-14-103337$ through $\mathrm{H}-14-103341$. Jumper Fabrication specification, HS-BS-0084 states that the carbon steel components of the connector assemblies shall not be painted. This is because the connector assembly consists of several components such as threads and pins whose functions would be affected by the painting.

3.3.1.7 Two-way valves shall be full ported and designed for isolation service in accordance with ANSI B16.34. 
Verification: (Analysis) This requirement is verified by incorporating it in the Procurement Specification W-314-P1, Ball Valves, para 3.4.4.1 and 3.9.

3.3.1.8 Three-way valves shall be full ported, designed in accordance with ANSI B16.34 and seat closure tested per MSS-SP-61 or API 598. For seat closure test there shall be no leakage from the flow side to the isolated port for each flow position.

Verification: (Analysis) This requirement is verified by incorporating it in the Procurement Specification W-314-P1, Ball Valves, para 3.4.4.1 and 3.9. The valves are certified by the vendor to meet ANSI B16.34 and are tested per MSSSP-61. The test results are documented in the vendor information file.

3.3.1.9 During the design of facilities, optimization principles, as discussed in ICRP Publication 37, shall be utilized in developing and justifying facility design and physical controls.

Verification: (Analysis) ICRP Publication 37 addresses techniques for use in the optimization of radiation protection based on cost-benefit analysis to various radiation levels. Project W-314 is upgrading existing facilities where the architecture is constrained, the operational practices are already in place, and the acceptable risk and detriment to individuals is already provided and the applicable radiation levels are listed as separate requirements in this specification.

\subsubsection{Electromagnetic Radiation}

3.3.2.1 Hand held radio and cell phone wattage frequency shall not interfere with electrical/electronic components at a distance of one meter.

Verification: (Analysis) The electrical/electronic components are located in NEMA rated enclosure. Based on prior operational experience and the voltage of the valve position sensors, it is anticipated the shielding provided by the enclosure will be sufficient to protect the system from interference due to hand held radios or cell phones.

(Demo) This requirement will also be verified by demonstration during the ATP.

3.3.2.2 The valve position system shall not be adversely affected by outside electromagnetic forces generated by a 60 horse power, $480 \mathrm{Vac}$, induction type motor operating at frequencies between 0 and 60 hertz and located 1 meter away from the leak detection system.

Verification: (Analysis) The motor will be located above the pit cover blocks. 
Any EMI to the signals located outside the pit above the cover blocks next to the motor are shielded either by a grounded metal enclosure or conduit. In addition the cabling is shielded with metal (aluminum) foil which is also grounded to the electrical system ground in the 241-AN-271 building.

The grounded shielding drains away any stray induced currents caused by the motor electromagnetic field.

\subsubsection{Identification and Marking}

3.3.3.1 New equipment and/or modifications to existing equipment shall be labeled in a standardized format in accordance HNF-IP-0842, Volume II, Section 6.1, Rev. 0.

Verification: (Analysis) This requirement is verified by the fact that the new $\mathrm{H}-14$ drawings were prepared using equipment numbering formats provided by LMHC. In addition, Construction Specification W-314-C5, Section 13440, para. 2.2.4 specifies labeling will be by LMHC OCM per their existing procedures.

(Exam) This requirement will also be verified by examination at the end of construction.

3.3.3.2 A master equipment list consisting of electronic data base for structures, systems, and components shall be generated in accordance with HNF-IP-0842, Volume II, Section 6.1, Rev. 0. The list contains such information as: unique equipment label, drawing reference, procedures, vendor information, Safety Classification, nameplate data etc.

Verification: (Analysis) This requirement will be met by providing the information into an electronic database.

3.3.3.3 Operations and Maintenance Drawings (As-built H-14 essential drawings) shall be prepared as the system master drawings showing as built configuration changes in accordance with HNF-IP-0842, Volume II. Section 6.1, Rev. 0.

Verification: (Analysis) The compliance with this requirement will take place and be verified at the end of construction.

3.3.3.4 Valve extension handles shall be uniquely identified.

Verification: (Analysis) Valve extension handle marking is specified on Drawing H-14-103351.

(Exam) This requirement will be verified and documented per Construction Specification W-314-C5, Section 15493. 


\subsubsection{Workmanship}

3.3.4.1 The design of the valve pit piping system shall determine and specify appropriate levels of workmanship for the fabrication and installation of the manifold according to the requirements of ASME B31.3, except PUREX connectors.

Verification: (Analysis) This requirement is verified by incorporating it in the Construction Specification W-314-C5, Section 15493.

3.3.4.2 The design of the cover blocks and new pits shall determine and specify appropriate levels of workmanship for the fabrication and installation of the cover blocks and new pits according to the requirements of $\mathrm{ACl}-301$, Section 1 through 5 and $\mathrm{ACl}-318$, Part 3.

Verification: (Analysis) This requirement is verified by Drawings $\mathrm{H}-14-103323$ and Construction Specification W-314-C5, Section 03300, Part 3.

\subsubsection{Interchangeability}

All like equipment (valves, position sensors, etc.) shall have interchangeable parts.

Verification: (Analysis) This requirement is verified by the fact that all like equipment in this design package and other design packages for $W$ 314 will be of identical make and model and, therefore, have interchangeable parts.

\subsubsection{Safety}

\subsubsection{Nuclear Safety}

\subsection{Safety Classification}

The cover blocks and new pits are identified as Safety Class items for the safety structures, systems, and components (SSCs). The Safety Class function of the cover blocks and new pits is to knockdown spray and limit the release of aerosols to the atmosphere.

Verification: (Analysis) This requirement is verified by Calculations W314-C-029, Pump Pits 01A and 04A Structural Evaluation, W314-C-030, Pump Pit Wall Evaluation, and W314-C-034, Riser 10, i.e. Slurry Receiver, Pit Design that incorporate safety design criteria per DOE $6430,1 \mathrm{~A}$ (Ref. para. 3.3.1.2). In addition, the concrete and reinforcing steel for the cover blocks will be purchased from a qualified supplier or as a commercial grade item per Construction Specification W-314-C5, Section 03300, para. 1.5.1 and 1.5.2 and Calculation 
W314-C-035, Commercial Grade Evaluation of Concrete and Rebar, respectively.

\subsection{Flammable Gas Hazardous Environment}

The components of the valve position sensor systems installed in the tank intrusive locations, shall be intrinsically safe, designed to meet NFPA 70 Class 1, Division 1, Group B criteria for hazardous locations.

Verification: (Analysis) This requirement is not applicable as there are no valve position sensor systems installed in tank intrusive locations.

\subsubsection{Human Performance/Human Engineering}

3.3.7.1 Each control device shall be in accordance with NUREG 0700, Section 6.4 and MIL-STD-1472E, Section 5.4 in accordance with DOE 6430.1A, Section 1300-12.4.7.

Verification: (Analysis) This requirement is not applicable to this design package since the valve pit manifold does not have any control devices.

3.3.7.2 Each display device shall be in accordance with NUREG 0700, Section 6.5 and MIL-STD-1472E, Section 5.2 in accordance with DOE 6430.1A, Section 1300-12.4.6.

Verification: (Analysis) This requirement is not applicable to this design package since the valve pit manifold does not have any display devices.

3.3.7.3 Each valve actuator shall be designed to produce the required operating torque with a maximum rim pull of $80 \mathrm{lbs}$ on the handwheel.

Verification: (Analysis) The valve actuators are specified to have a maximum rim pull of 80 ibs, reference Drawing $\mathrm{H}-14$ 103265 , notes 7 and 8 .

(Demo) Maximum rim pull forces will be verified in the CWP.

\subsection{Documentation}

3.4.1 Records, documents, and document control pertinent to design functions shall be in accordance with HNF-PRO-224 and HNF-PRO-233.

Verification: (Analysis) The overall record management for identification and storage of drawings, calculations, and specifications pertinent to design functions were performed in accordance with HNF-PRO-224 and HNF-PRO-233.

(Exam) This requirement will also be verified by $O A$ assessment of the documents. 
3.4.2 Drawings shall be prepared according to the formats set forth in "HNF-PRO-242, Rev. 0 . Engineering Drawing Requirements", for documents produced prior to June 15, 1999 and "HNF-PRO-709, Rev. 1, Preparation and Control Standards for Engineering Drawings", for documents produced after June 15, 1999.

Verification: (Analysis) H-Series Drawings were prepared and will be released according to the guidelines set forth in HNF-PRO-709, Rev 1.

\subsection{Logistics}

\subsubsection{Maintenance}

3.5.1.1 Fully Remote Maintenance and Operation. Each system or portion of a system having radiation levels greater than $50 \mathrm{mrem} / \mathrm{hr}$ contact exposure shall be designed to be remotely maintained and operated or designed to require no maintenance and be remotely operated.

Verification: (Analysis) The jumpers for the valve manifold system are designed for installation with a remote operated impact wrench. In addition, the manifold valves are designed for actuation from above the cover blocks. Also, the components within the pit are designed to require no preventive maintenance (Ref. para. 3.2.4.2).

3.5.1.2 Limited Contact Maintenance and Operation. Each system or portion of a system having radiation levels greater than $0.1 \mathrm{mrem} / \mathrm{hr}$ to less than or equal to $50 \mathrm{mrem} / \mathrm{hr}$ shall be designed for limited contact maintenance and operation.

Verification: (Analysis) The jumpers for the valve manifold system are designed for installation with a remote operated impact wrench. In addition, the manifold valves are designed for actuation from above the cover blocks. Also, the components within the pit are designed to require no preventive maintenance (Ref. para. 3.2.4.2).

3.5.1.3 Full Contact Maintenance and Operation. Each system or portion of a system having radiation levels less than or equal to $0.1 \mathrm{mrem} / \mathrm{hr}$ shall be designed for full contact maintenance and operation.

Verification: (Analysis) The only portion of the system that has these radiation levels is above the cover blocks. All components above the cover block are accessible for full contact maintenance and operation.

3.5.1.4 The equipment used for installation and maintenance must comply with the DST dome loading constraints.

Verification: (Analysis) If equipment is located outside a 20' exclusion zone around the DST, dome loading effects are mitigated. Compliance with this requirement will be verified by the calculation and by the issuing of dome 
loading permits for locating the equipment from Tank Farm Engineering and Operations.

3.5.1.5 Valves shall be maintenance free with up to 1000 cycles over a design life of 12 years.

Verification: (Analysis) The design requirement is verified by the Procurement Specification W-314-P1, Ball Valves, para. 3.4.1.4. The specification stipulates that valves remain in operation for a minimum period of one thousand complete cycles and be designed to operate properly following periods of stagnant position of up to one year. This fact, along with the fact that the fluid composition and properties are provided in the procurement specification (para. 3.1), provides adequate assurance that this reliability requirement will be met.

In addition, this requirement is verified for the valve position sensor switches by requiring the switches to have a Mean Time Between Failure (MTBF) of at least 100,000 cycles (Ref. Drawing H-14-100976 Notes 11 and 12). This is well above the estimated 10,000 operations over the life of the equipment. As far as the periods of stagnant position, the position switches are non contact type and, therefore, are not subject to stagnant position failures.

\subsubsection{Supply}

3.5.2.1 The system design shall, to the greatest extent practicable, use readily available parts and components.

Verification: (Analysis) To the greatest extent practicable, the parts and components used are standard off-the-shelf items. It is not anticipated that such items cannot be found to fulfill the requirements.

\subsubsection{Facilities and Facility Equipment}

New Hanford Site remote operation impact wrenches shall be developed for installation/removal of the PUREX Jumper Connector Assembly.

Verification: (Analysis) This requirement is verified by requiring a torque rating of $550 \mathrm{ft}-\mathrm{lb}$ for the impact wrench (Ref. Procurement Specification W314-P2, Impact Wrench).

\subsection{Personnel and Training}

The valve pit piping system, cover blocks, and valve position sensor systems shall be designed for operation by personnel possessing qualifications in accordance with DOE 5480.20, Chapter IV, and trained in accordance with Chapter 1. 
Verification: (Analysis) The design package was prepared with the assumption that the operating personnel are qualified according to DOE 5480.20. The package includes equipment, fittings, and materials similar to those already installed and operated throughout the tank farms. No new material or technology was introduced which would require additional training or special skill of the operating personnel.

\subsection{Major Component Characteristics}

\subsubsection{New Process Pits and Cover blocks}

\subsubsection{Performance Characteristics}

3.7.1.1.1 The process pit(s) shall support transfer line equipment located in and above the pits, nozzles where transfer lines terminate at the pit sidewalls, and the cover blocks.

Verification: (Analysis) This requirement is verified by Calculations W314-C-029, Pump Pit Wall Evaluation and W314-C034, Riser 10, i.e. Slurry Receiver, Pit Design evaluations that investigates the piping loads supported by the pit walls.

3.7.1.1.2 The process pit(s) and cover blocks shall enclose the valve pit piping system and pit leak detection equipment.

Verification: (Analysis) This requirement is verified by nature of the design of the new pit and cover blocks shown on Drawings $\mathrm{H}-14-103318, \mathrm{H}-14-103319, \mathrm{H}-14-103323$

3.7.1.1.3 The process pit(s) with liners/special protective coatings shall provide leak tight secondary confinement.

Verification: (Analysis) For existing pits this requirement will be verified by LMHC Quality Control. Required repairs for existing pits and installation in new pits of SPC will be in accordance with Construction Specification W-314C5, Section 09855.

3.7.1.1.4 The process pit(s) and cover blocks shall confine release of any aerosol spray of a product leak from the valve manifold within the valve or pump pit. Compressible gasket shall be used between cover block and top of pit to prevent leakage.

Verification: (Analysis) This requirement is verified by Drawing $\mathrm{H}-14-$ 103323.

3.7.1.1.5 The process pit(s) shall provide a low-point location in the floor for the pit leak detection equipment.

Verification: (Analysis) This requirement is verified by Drawing $\mathrm{H}-14$ 103322 and existing Drawing H-2-71912. 
3.7.1.1.6 The process pit(s) shall provide a low-point drain system to return accumulated liquids, leakage from the primary confinement system, and wash-down liquids to a Double-Shell Tank.

Verification: (Analysis) This requirement is verified by Drawing $\mathrm{H}-14$ 103322 and existing Drawing H-2-71912.

3.7.1.1.6.1 The drain system shall have the ability for drain accumulated leakage within 24 hours.

Verification: (Analysis) The drain has a check valve for automatic drainage at a certain liquid level and a removable plug for complete drainage. Complete drainage of the pit within 24 hours is achieved by operator response to the pit leak detector and operating the drain plug. Reference Drawing H-14-103352.

3.7.1.1.7 The process pit(s) and cover blocks, including penetrations, shall provide adequate shielding for facility workers located on top of the cover blocks and adjacent to the process pits during normal operations and maintenance. The radiation shielding shall meet the design objective to maintain exposure levels below an average of $0.5 \mathrm{mrem}$ ( 5 microsieverts) per hour and as far below this average as is reasonably achievable. The goal for reasonably achievable is $0.05 \mathrm{mrem} 10.5$ microsieverts) per hour or less.

Verification: (Analysis) This requirement is verified by Calculation W314-P-050, Shielding Analysis. The shielding meets the 0.5 mrem requirement for the new 241-AN-04D Slurry Receiver Pit. Since under normal transfer conditions, an operator is not standing $30 \mathrm{~cm}$ from the pits. Based on engineering judgement, it was determined that meeting the $0.5 \mathrm{mrem}$ requirement is conservative due to the source term being worst case and the exposure time being limited to transfers only. In addition, the 0.05 mrem goal will be met for the majority of the waste that will be transferred in the future (per discussions with the Design Authority). The 241-AN$01 \mathrm{~A}$ and $04 \mathrm{~A}$ pump pits are existing and per Calculation W314-P-050 will exceed the $0.5 \mathrm{mrem} / \mathrm{hr}$ criteria.

3.7.1.1.8 The cover blocks shall be designed to limit intrusion of rain water or snow melt into the process pits.

Verification: (Analysis) This requirement is verified by Drawing $\mathrm{H}-14-103323$.

3.7.1.1.9 New process pit(s) shall be equipped with stainless steel liners that extend to the bottom of the cover blocks. All other exposed surfaces and the cover blocks shall have a special protective coating to protect the structural secondary confinement by providing a barrier between the interior exposed surfaces of the pits and cover blocks and any 
waste present in the pit due to leaks, spill, or intrusion. 241-AN-04D Slurry Receiver Pit shall be protected by SPC on exposed surfaces.

Verification: (Analysis) For new cover blocks SPC requirement is included in Construction Specification W-314-C5, Section 09855. New pit, 241-AN-04D, has been excluded from this requirement per customer direction due to encasement around primary pipe.

(Exam) Stainless steel liner and SPC requirement will be verified by examination during construction and documented in the CWP.

\subsubsection{Physical Characteristics}

3.7.1.2.1 New process pits and cover blocks shall be constructed of reinforced concrete pits shall be below grade. Edges of the cover blocks shall be stepped to preclude radiation streaming.

Verification: (Analysis) The requirement for the cover blocks to be stepped is verified by Drawing $\mathrm{H}-14-103323$.

(Exam) Will be verified and documented in the CWP.

3.7.1.2.2 Process pits shall be equipped with sleeves for wall nozzles as required. Wall nozzles shall be PUREX type design (Reference Drawings $\mathrm{H}-2-90185$ and $\mathrm{H}-2-90186$ ).

Verification: (Analysis) New nozzles are specified on Drawings $\mathrm{H}-14$ 103347 and $\mathrm{H}-14-103348$. The valves provided in the new 241-AN-04D Slurry Receiver Pit will require pit entry for maintenance. The process piping in this pit is encased and can be flushed so that pit entries can be made.

(Exam) The new nozzles will be verified and documented per Construction Specification W-314-C5, Section 15493.

3.7.1.2.3 Sleeves for spare nozzles shall be installed in any new process pit, except for the new 241-AN-04D Slurry Receiver Pit.

Verification: (Analysis) This requirement is not applicable to this package as the only new pit is 241-AN-O4D Slurry Receiver Pit.

(Exam) This requirement is not applicable to this package.

3.7.1.2.4 A grounding system shall be furnished for electrical equipment, structural components, valve pit liners, reinforcing steel, nozzles and other metallic equipment. This grounding system shall be interfaced to the appropriate tank farm grounding and cathodic protection systems. 
Verification: (Analysis) This requirement is verified by Drawing $\mathrm{H}-14-$ 103380.

3.7.1.2.5 New cover blocks and existing cover blocks to be modified (see 3.1) shall be equipped with penetrations to facilitate operations and/or maintenance of manifold valves, pit drains, pit leak detection devices and transfer leak detection devices. Additionally, the penetrations shall provide for access to any other equipment in the pits requiring maintenance, pit wash down, gas sampling ports, and installation of support equipment (e.g., video cameras, etc.). A sufficient number of penetrations shall be provided to allow full visual inspection of the interior of the pits.

Verification: (Analysis) This requirement is verified by Drawings $\mathrm{H}-14-103318, \mathrm{H}-14-103319$, and $\mathrm{H}-14-103323$.

(Exam) This requirement will also be verified by examination and documented in the CWP.

3.7.1.2.6 Cover blocks shall be sloped to drain water off the top of the blocks and shall extend over the outside of the pit walls.

Verification: (Analysis) The 241-AN-04D Slurry Receiver Pit cover block is a single unit and is flat to limit the weight of the cover block. It does overhang the pit walls, as shown on Drawing $\mathrm{H}-14-103323$.

3.7.1.2.7 The cover blocks for 241-AZ-02A, 241-AZ-01A, 241-AY-01A, and 241-AY-02A Central Pump Pits, including penetrations shall be sealed to limit air infiltrations.

Verification: (Analysis) This requirement is not applicable to this package since no work is done in these Pump Pits.

3.7.1.2.8 Gas sampling ports shall be greater than 0.7 inch and less than 1.0 inch in diameter, located above the drain or center of the pit, flared on the bottom to minimize snagging of sample line during removal, and equipped with two bonding lugs for attachment to the portable sampler.

Verification: (Analysis) This requirement is verified by Drawings $\mathrm{H}-14-103318, \mathrm{H}-14-103319$, and $\mathrm{H}-14-103323$.

(Exam) This requirement will be verified and documented in the CWP.

3.7.1.2.9 Gas sampling ports shall be constructed of low sparking, electrically conductive material, and shall be electrically bonded.

Verification: (Analysis) This requirement is verified by Drawings $\mathrm{H}-14-103318, \mathrm{H}-14-103319$, and $\mathrm{H}-14-103323$. 
3.7.1.2.10 Gas sampling ports shall have an electrically conductive, non-screw type cover that is electrically bonded to the port with a noninsulated conductor strong enough to act as a cover keeper.

Verification: (Analysis) This requirement is verified by Drawings $\mathrm{H}-14-103318, \mathrm{H}-14-103319$, and $\mathrm{H}-14-103323$.

3.7.1.2.11 Cover blocks shall be supplied with lifting mechanisms on the top surface to facilitate handling with a crane. The maximum weight of new cover block shall be 16.5 ton.

Verification: (Analysis) The location of the lifting bails is verified by Drawing H-14-103323. The weight of the cover block is estimated to be approximately 9.4 tons, much less than the 16.5 , tons.

(Exam) This requirement will be verified by examination during construction.

3.7.1.2.12 Cover blocks and pit walls shall be marked to facilitate alignment of the cover blocks.

Verification: (Analysis) This requirement is redundant with only one cover block on 241-AN-04D, Slurry Receiver Pit, thus not applicable.

(Exam) Not applicable to this package.

\subsubsection{Valve Position Sensor Systems}

\subsubsection{Performance Characteristics}

\subsection{Monitor Valve Position}

After the transfer system route has been setup, the transfer system shall monitor the limit positions of the valves on the valve jumpers manifolds in the transfer route. This requirement does not apply to 241-AN-04D Slurry Receiver Pit.

3.7.2.1.1.1 The waste transfer system jumper/manifold valves shall indicate valve limit position.

Verification: (Analysis) The valve limit position indication is provided by a non-contact sensor switch. This switch provides feedback (an electric signal) to the local PLC to be installed under a separate W-314 design/construction package. The PLC monitors and updates the HMI (human machine interface) display and position of the valve limit by use of the switch. In addition, visual valve indication is provided locally by an indicating disc attached to the valve extension handle shaft (Ref. Drawings $\mathrm{H}-14-100972$ and $\mathrm{H}-14-100976)$. 
3.7.2.1.1.2 Each separate valve limit position shall be actively indicated.

Verification: (Analysis) A sensor is provided for each valve limit position. Each sensor is activated by a magnet mounted to a cam mounted directly to the gear operator drive shaft. When the magnet is in the proximity of the sensor, a valve is said to be in that position as programmed by the PLC for an electric signal from that position switch. This signal is fed back to the HMI by the same means as 3.7.2.1.1.1. Additionally, there is local indication of the valve position indicated on the gear operator assembly (Ref. Drawings H-14-100972 and $\mathrm{H}$-14-100976).

3.7.2.1.1.3 The valve position shall be transmitted to the Master Pump Shutdown system.

Verification: (Analysis) The transmission of the valve position signals is as stated in 3.7.2.1.1.1. Wires will be used to transmit the actual valve position signal to the PLC installed as part of W-314's MPS system upgrades.

3.7.2.1.1.4 The valve position indication system shall provide sufficient accuracy with respect to the actual valve position such that the selected flow path configuration is leak tight.

Verification: (Analysis) The requirement is concerned with the valve port being in the correct position. It does not apply to the actual tolerance for locating the valve within the jumper. The primary method of indicating the port position is provided by an indicating disc attached to the valve extension handle shaft (Ref. Drawings $\mathrm{H}-14$ 100972 and $H-14-100976)$. The operator will line up the decal on the disc with the required painted flow path of the jumper manifold. With a 7-inch disc, the operator must make sure that the painting diagram lines up within the red area of the decal to ensure that valve position is leak tight. This requirement is associated with the manual position indicator and not the electrical position sensor.

3.7.2.2 Physical Characteristics

This requirement does not apply to 241-AN-04D Slurry Receiver Pit.

3.7.2.2.1 The valve position sensing hardware, display, and transmitter as applicable shall be able to withstand the insertion and removal, turning, and overturning of the valve actuator handle and still operate properly.

Verification: (Analysis) The actual valve position sensor does not come in contact with the adjustable cams. Since physical contact does not occur to provide the electric 
signal of a valve position change, the contact life and operation are much more dependable.

(Test) This requirement will also be verified by examination during the ATP.

3.7.2.2.2 The valve position hardware, display, and transmitter, as applicable, shall be designed to perform in the environment on top of the cover block and withstand inadvertent physical abuse.

Verification: (Analysis) The valve position sensor hardware is protected by a metal NEMA 4 enclosure. This enclosure provides both physical and environmental protection. The NEMA 4 enclosure is mounted directly above the gear operator on the valve position sensor assembly. See Drawing H-14-100980 for details, In addition, the valve position sensor wires are run through a rigid conduit along the side of the gear operator assembly and in the cover blocks.

3.7.2.2.3 The valve position hardware, display, and transmitter, as applicable, shall be designed to facilitate quick mechanical/electrical disconnect for ease of cover block removal and replacement.

Verification: (Analysis) The valve position sensor wires are run through a rigid conduit along the side of the gear operator assembly. At the base of the assembly is a receptacle with an environmentally rated quick disconnect cord set. By removing the cord set, the entire assembly is ready to be removed from the cover block (see Drawing H-14-100980).

3.7.2.2.4 The valve position hardware to detect, display, and transmit valve position shall be located outside the pit.

Verification: (Analysis) This requirement is verified by Drawing $\mathrm{H}$-14-100980 which shows the location of the valve position gear operators above the cover block, outside the pit.

\subsubsection{Site Work - New Pits}

\subsubsection{Performance Characteristics}

3.7.3.1.1 The site soils shall support the major components of the new valve pits.

Verification: (Analysis) This requirement is verified by the Dames and Moore Soils Report.

3.7.3.1.2 Access control to radiological and hazardous waste areas shall be provided by fencing consistent with existing fencing for RPP operations. 
Verification: (Analysis) This requirement is verified by Construction Specification $\mathrm{W}-314-\mathrm{C} 5$ and Drawings $\mathrm{H}-14-103233$ and H-14-103242.

3.7.3.1.3 The existing area lighting system at the 241-AZ tank farm shall be extended to provide an adequate level of illumination for night-time operations at the new 241-AZ valve pit. The lighting system shall provide a minimum average illumination of 54 lux $(5 \mathrm{fc})$ with a maximum uniformity ratio of $5: 1$ average to minimum.

Verification: (Analysis) Not applicable to this scope of work.

(Exam) Not applicable to this scope of work.

3.7.3.1.4 Lighting control shall be furnished with a photocell override to ensure that lights are turned off during the day.

Verification: (Analysis) Not applicable to this scope of work.

(Exam) Not applicable to this scope of work.

\subsubsection{Physical Characteristics}

3.7.3.2.1 All areas disturbed by construction shall be stabilized subsequent to construction.

Verification: (Analysis) This requirement is verified by Construction Specification W-314-C5, Section 02220.

(Exam) This requirement will be verified by examination during construction and documented in the CWP.

3.7.3.2.2 Pole-mounted banks of luminaries shall be used. Fixture lowering devices shall be provided for poles over $18 \mathrm{~m}$ high. Existing electrical distribution system in the area shall be utilized to provide necessary power.

Verification: (Analysis) Not applicable to this scope of work.

(Exam) Not applicable to this scope of work.

3.7.3.2.3 Luminaries shall be shielded mercury vapor, or metal halide directed to minimize upward glare.

Verification: (Analysis) Not applicable to this scope of work.

(Exam) Not applicable to this scope of work. 


\subsection{QUALITY ASSURANCE PROVISIONS}

There are no requirements identified in this section.

\subsection{NOTES}

\subsection{Definitions}

\subsubsection{Manifold}

Remotely installed rigid piping systems inside a pit that transfer waste and flush water between nozzles.

\subsubsection{Pit Nozzle}

Rigid male connector anchored in the pit wall that provides a leak tight connection with the integral seal block attached to a manifold.

\subsubsection{Equivalent Length}

The actual length of piping plus the friction loss of all valves and fittings in the system expressed in terms of equivalent feet of piping.

\subsubsection{Glaze}

Coating of ice formed when rain or drizzle freezes on contact with any surface having a temperature that is below freezing. 


\section{APPENDIX C}

\section{Requirements Verification}

For

\section{PDS-003}

Pit Leak Detection 
HNF-4533

Rev. 0

\title{
REQUIREMENTS VERIFICATION
}

FOR

\author{
PIT LEAK DETECTION
}

\subsection{SCOPE}

This appendix documents how the requirements that are listed in the Project Development Specification (PDS) for the Pit Leak Detection system (HNF-SD-W314PDS-003) are satisfied for the new pit leak detection systems that will be installed by Project W-314 for Valve Pits 241-AN-A and 241-AN-B and 241-AN-04D, Slurry Receiver Pit.

\subsection{APPLICABLE DOCUMENTS}

For a list of applicable documents, refer to the appropriate PDS.

\subsection{REQUIREMENTS ANALYSIS}

\subsection{Item Definition}

No requirements are listed in this section.

\subsection{Characteristics}

\subsubsection{Performance}

\subsubsection{Monitor for Leaks (FFBD Function 3.1)}

After the waste transfer system is up and operating and after the administrative lock has been removed, the pit leak detection system shall monitor for leaks from the primary piping system.

3.2.1.1.1 The pit leak detection system shall detect the presence of a leak within twenty-four hours. (See Section 5.1 for definition of leak)

Verification: (Analysis) The upgraded pit leak detection system is designed such that a conductivity probe is installed in the low point of the pit to detect the presence of liquid when it reaches the probes. There has been an informal agreement between $\mathrm{LMHC}$ and the Washington State Department of Ecology that the maximum allowable quantity of leakage that is necessary to detect in 24hours is 10 gallons or less. Calculation W314-I-045 shows that the placement of the probes at 0.370 inch above the pit floor will detect a quantity of 10 gallons for Central Pump Pits 241-AN-01A and 241-AN-04A. Calculation W314-I-047 shows that placement of the 
probes at 1 inch above the pit floor will detect a quantity of 10 gallons for slurry receiver pit 241-AN04D. The 10 gallons in 24-hours corresponds to a leak rate of 0.0069 gallons/minute. Any leak rate less than that will not be detected in the 24-hour time period. This requirement is also verified by Acceptance Test Report for Leak Detection Mock-up, TWR-4663.

3.2.1.1.2 The pit leak detection system shall monitor for liquids during a waste transfer and shall provide a signal when a leak is detected.

Verification: (Analysis) The Pit Leak Detection System monitors for liquids continuously, both when there a transfer is in progress and when there is no transfer in progress, as long as power is applied to the system. Any liquid that enters the pit will flow to the lowest point (the drain) and be held up by the drain plug. When the liquid reaches the height of the probes the electrical circuit is completed and the alarm light (ANO1A-WT-LDA-201A or AN04A-WT-LDA-203A or ANO4D-WT-LDA-152A) is activated by the leak detection relay (ANO1A-WT-LDK201 or AN04A-WT-LDK-203 or AN04D-WT-LDK-152) and the automatic MPS shutdown signal is initiated. The MPS shutdown signal will first be connected into the existing MPS shutdown system and later connected into the new MPS system when installed at a later date. The leak detection circuitry is shown on Drawings $\mathrm{H}-14$ 103357, $\mathrm{H}-14-103362$ and $\mathrm{H}-14-103370$. This requirement is also verified by Acceptance Test Report for Leak Detection Mock-up, TWR-4663.

3.2.1.1.3 Pit leak detection system sensors shall be positioned no higher than two inch above the floor in the lowest part of the pit or in a sump in the pit.

Verification: (Analysis) The pit leak detection probes (ANO1A-WTLDE-201A/B, AN04A-WT-LDE-203A/B, and ANO4D-WTLDE-152A/B) are not located directly over the low point of the pit (interference from the pit drain) but are located adjacent to the low point. The probes are to be located at a height of approximately $1 / 16$ inch from the pit floor. See Drawings $\mathrm{H}-14-103355, \mathrm{H}-14-103361$ and $\mathrm{H}-14-$ 103366 for more details on probe placement. This requirement is also verified by Acceptance Test Report for Leak Detection Mock-up, TWR-4663.

(Test) This requirement will also be verified by test during the ATP.

3.2.1.1.4 The monitoring frequency of the pit leak detection system shall be continuous. (See Section 5.1 for definition of continuous) 
Verification: (Analysis) The pit leak detection system monitors for leaks within the valve pit. This is accomplished with the use of a continuously energized leak detection relay (AN01A-WT-LDK-201, AN04A-WT-LDK-203 and AN04D-WT-LDK-152) and conductivity probes (ANO1AWT-LDE-201A/B, AN04A-WT-LDE-203A/B and ANO4DWT-LDE-152A/B). Upon failure of power to the leak detection relay or probe circuit, an alarm is activated so operators can respond. The leak detection circuitry is shown on Drawings $\mathrm{H}-14-103357, \mathrm{H}-14-103362$ and $\mathrm{H}-$ 14-103370.

3.2.1.1.5 The required response time of the pit leak detection system shall be instantaneous. (See Section 5.1 for definition of instantaneous)

Verification: (Analysis) The leak detection system is continuously monitoring for leaks. When a leak is detected, the contacts of the leak detection relay (AN01A-WT-LDK201, ANO4A-WT-LDK-203, and ANO4D-WT-LDK-152) will close and instantaneously initiate the local alarm light (ANO1A-WT-LDA-201A, AN04A-WT-LDA-203A, and ANO4D-WT-LDA-152A). The active components that would primarily contribute to the response time are the components that change state, i.e., the leak detection relay and the latching coil relay (ANO1A-WTLDA-201-1, ANO4A-WT-LDA-203-1 or ANO4D-WT-LDK152-1 and AN-1A-WT-K-201D, ANO4A-WT-K-203D or ANO4D-WT-K-152D). Calculation W314-I-054 verified leak detection system response time to be 0.525 seconds. The leak detection circuitry is shown on Drawings $\mathrm{H}-14-103357, \mathrm{H}-14-103362$ and $\mathrm{H}-14-$ 103370.

3.2.1.1.6 The wiring between the leak detection system sensor and control panel shall be electrically supervised.

Verification: (Analysis) Supervision for the wiring between the probes and the leak detection control panel is performed by the trip amplifier (ANO1A-WT-EY-201, ANO4A-WT-EY-203 and ANO4D-WT-EY-152). This device monitors the voltage (at the probes) and is located in the leak detection control panel. Upon loss of probe voltage or wire failure, the trip amplifier will activate the local alarm (AN01A-WT-LDA-201A, AN04A-WT-LDA-203A, and ANO4D-WT-LDA-152A) and initiate the master pump shutdown system. The leak detection circuitry is shown on Drawings $\mathrm{H}-14-103357, \mathrm{H}-14-103362$ and $\mathrm{H}-14-$ 103370. This requirement is also verified by Acceptance Test Report for Leak Detection Mock-up, TWR-4663.

(Test) This requirement will also be verified by test during the ATP of the leak detection system. 


\subsubsection{Monitor for Leak Detector Malfunction (FFBD Function 3.2)}

After the waste transfer system is up and operating and after the administrative lock has been removed, the MPS system shall monitor for a leak detector malfunction. The MPS shall notify the operator(s) when a leak detector malfunction occurs.

3.2.1.2.1 Loss of power to the leak detection probes, shall provide an output signal to the local alarm and MPS.

Verification: (Analysis) The leak detection relay cabinet was designed with two general purpose relays used for testing (AN01A-WT-K-301A\&B, AN04A-WT-K-203A\&B, or AN04D-WT-K-152A\&B). The selector switch (AN01AWT-SS-201, AN04-WT-SS-203 or ANO4D-WT-SS-152) is used for two operations. The first operation is for testing the leak detection relay by simulating a leak in the pit with the addition of a $8.2 \mathrm{kohm}$ resistor between the probes from the leak detection relay cabinet. The second test is to interrupt (open) the leak detection sensing circuit at the leak detection relay cabinet and verify the leak detection failsafe circuit is operational. The leak detection circuitry is shown on Drawings $\mathrm{H}$ 14103357, $\mathrm{H}-14-103362$ and $\mathrm{H}-14-103370$. This requirement is also verified by Acceptance Test Report for Leak Detection Mock-up, TWR-4663.

(Test) This requirement will also be verified by test during the ATP of the leak detection system.

3.2.1.2.2 A detected failure in the leak detection system shall provide an output signal to the local alarm and MPS.

Verification: (Analysis) The leak detection system is designed to initiate the local alarm and master pump shutdown given the following failures. The first failure is the leak detection relay (AN01A-WT-LDK-201, AN04A-WT-LDK203, or ANO4D-WT-LDK-152) failure. Upon failure of the leak detection relay, the probe voltage will no longer be present and the shutdown signal will be generated from the trip amplifier as verified by section 3.2.1.1.6. The second failure is the probe wire and wire connectors failing. Upon failure of any leak detection probe wire or connector, the local alarm and the master pump shutdown is activated. In addition to these failures, the local warning light and the master pump shutdown system will also activate upon failure of the trip amplifier (AN01A-WT-EY-201, ANO4A-WT-EY-203, or ANO4DWT-EY-152) and the failsafe relay (ANO1A-WT-K-201C, AN04A-WT-K-203C, or ANO4D-WT-K-152C). The leak detection circuitry is shown on Drawings $\mathrm{H}-14-103357$, 
$\mathrm{H}-14-103362$ and $\mathrm{H}-14-103370$. This requirement is also verified by Acceptance Test Report for Leak Detection Mock-up, TWR-4663.

(Test) This requirement will also be verified by test during the ATP of the leak detection system.

3.2.1.2.3 The leak detection system shall perform an operational test of itself when commanded by the MPS. The test shall include alarm, circuitry, and sensor functions of the leak detection system.

Verification: (Analysis) The leak detection relay cabinet was designed with two general purpose relays used for testing (AN01A-WT-K-301 A/B, AN04A-WT-K-203A/B, or AN04D-WT-K-152A/B). The selector switch (ANO1AWT-SS-201, ANO4A-WT-SS-203, or ANO4D-WT-SS152) is used for two operations. The first operation is for testing the leak detection relay by simulating a leak in the pit with the addition of a $8.2 \mathrm{kohm}$ resistor between the probes from the leak detection relay cabinet. The second test is to interrupt (open) the leak detection sensing circuit at the leak detection relay cabinet and verify the leak detection failsafe circuit is operational. The leak detection circuitry is shown on Drawings $\mathrm{H}-14-103357, \mathrm{H}-14-103362$ and $\mathrm{H}-14-$ 103370 . This requirement is also verified by Acceptance Test Report for Leak Detection Mock-up, TWR-4663.

(Test) This requirement will also be verified by test during the ATP of the leak detection system.

\subsubsection{Activate Local Alarm (FFBD Function 3.3)}

After a leak or leak detector malfunction is detected, the leak detection system shall activate a local alarm. The local alarm shall stay activated until acknowledged by the operator(s). (See Section 5.1 Definitions)

3.2.1.3.1 The local alarm shall be a warning light. The light shall identify the pit where the leak or malfunction occurred. Each warning light location shall be determined from Human Factors Analysis.

Verification: (Analysis) The design provides a warning light located on top of the leak detection relay cabinet. Calculation W314-I-002 analyses the human factors considerations that were used to determine the location of the light. For placement of the leak detection local alarm (strobe light), refer to Drawing H-14-100983. For reference of where the leak detection systems are located in relationship to the pits, see Drawings $\mathrm{H}-14-103354, \mathrm{H}-$ 14-103360 and H-14-103366.

(Test) This requirement will also be verified by test during the ATP of the leak detection system. 
3.2.1.3.2 The reset/acknowledgment of the local alarm shall be either from a MPS system Human-Machine Interface (HMI) location or the local leak detector station.

Verification: (Analysis) The reset/acknowledgment of the local alarm can be activated locally at the leak detector station and from HMI locations. This is accomplished by operating the reset switch (AN01A-WT-PB-201C, AN04A-WT-PB$203 \mathrm{C}$ or ANO4D-WT-PB-152C). The local alarm can also be reset by the MPS system (installed at a later date). This is accomplished from a PLC (Programmable Logic Controller) output generated from the $\mathrm{HMI}$ at terminal block No. 15 in the leak detection relay cabinet. The leak detection circuitry is shown on Drawings $\mathrm{H}-14-$ 103357, $\mathrm{H}-14-103362$ and $\mathrm{H}-14-103370$. This requirement is also verified by Acceptance Test Report for Leak Detection Mock-up, TWR-4663.

(Test) This requirement will also be verified by test during the ATP of the leak detection system.

3.2.1.3.3 The local alarm shall operate as follows:

- Immediately upon detecting a leak or malfunction, the local alarm shall flash and the MPS System shall produce an audible alarm.

- After the local alarm is acknowledged by an operator located at either the MPS System HMI or the local alarm cabinet, the local alarm shall remain flashing until recovery occurs.

- After the alarm is acknowledged at the MPS System HMI, the MPS System audible signal shall be silenced.

- When recovery occurs (the leak or malfunction has been corrected) and after the local alarm is acknowledged, the local alarm shall cease illuminating.

Verification: (Analysis) As stated in the analysis of section requirement 3.2.1.1.5, the local alarm consisting of a local flashing (strobe) light and a horn operated by the MPS system is instantaneously activated. For the second requirement, the local warning light will remain flashing until the latch coil of the latch relay (ANO1AWT-K-201D, ANO4A-WT-K-203D or ANO4D-WT-K$152 D$ ) is reset. The reset coil can be activated from the $\mathrm{HMI}$ by generating a signal to the leak detection relay cabinet on terminal block No. 15 . The latching relay will only reset providing contacts on the leak detector are in a state not representing a leak condition within the valve pit. If liquid is still present within the valve pit, the local warning light will continue to flash even if the reset coil is energized from the HMI. The third requirement, after the alarm is acknowledged at the MPS system HMI, the MPS System audible signal shall be silenced, is not currently applicable to this package. For the last 
requirement, the local alarm light will cease to illuminate only upon recovery of the leaking condition within the valve pit and resetting the latch coil. The leak detection circuitry is shown on Drawings $\mathrm{H}-14-103357, \mathrm{H}-14$ 103362 or $\mathrm{H}-14-103370$. This requirement is also verified by Acceptance Test Report for Leak Detection Mock-up, TWR-4663.

(Test) This requirement will also be verified by test during the ATP of the leak detection system.

After the waste transfer system is up and operating and after the administrative lock has been removed, the pit leak detection system shall monitor for intrusions, sources can be spills, rain, washdown, etc. from liquid sources outside the pit.

3.2.1.4.1 The pit leak detection system shall monitor for liquid sources outside the pit and shall provide a signal when an Intrusion is detected.

Verification: (Analysis) The Pit Leak Detection System monitors for liquid intrusion continuously, both when a transfer is in progress and when there is no transfer in progress, as long as power is applied to the system. Any liquid that enters the pit will flow to the lowest point (the drain) and be held up by the drain plug. When the liquid reaches the height of the probes the electrical circuit is completed and the alarm light (ANO1A-WT-LDA-201A or AN04A-WT-LDA-203A or AN04D-WT-LDA-152A) is activate by the leak detection relay (ANO1A-WT-LDK201 or AN04A-WT-LDK-203 or ANO4D-WT-LDK-152) and the automatic MPS shutdown signal is initiated. The MPS shutdown signal will first be connected into the existing MPS shutdown system and later connected into the new MPS system when installed at a later date. The leak detection circuitry is shown on Drawings $\mathrm{H}-14$ 103357, $\mathrm{H}-14-103362$ and $\mathrm{H}-14-103370$. This requirement is also verified by Acceptance Test Report for Leak Detection Mock-up, TWR-4663.

3.2.1.4.2 Pit leak detection system sensors shall be positioned below the level where the floor drain allows drainage from the pit into the waste tank.

Verification: (Analysis) The pit leak detection probes (ANO1A-WTLDE-201A/B, AN04A-WT-LDE-203A/B, and ANO4D-WTLDE-152A1B) are not located directly over the low point of the pit (interference from the pit drain) but are located adjacent to the low point. The probes are to be located at a height of approximately $1 / 16$ inch from the pit floor. See Drawings $\mathrm{H}-14-103355, \mathrm{H}-14-103361$ and $\mathrm{H}-14$ 103366 for more details on probe placement. 
(Test) This requirement will also be verified by test during the ATP.

3.2.1.4.3 The monitoring frequency of the pit leak detection system shall be continuous. (See Section $\mathbf{5 . 1}$ for definition of continuous)

Verification: (Analysis) The pit leak detection system monitors for leaks within the valve pit. This is accomplished with the use of a continuously energized leak detection relay (AN01A-WT-LDK-201, AN04A-WT-LDK-203 and ANO4D-WT-LDK-152) and conductivity probes (ANO1AWT-LDE-201A/B, ANO4A-WT-LDE-203A/B and ANO4DWT-LDE-152A/B). Upon failure of power to the leak detection relay or probe circuit, an alarm is activated so operators can respond. The leak detection circuitry is shown on Drawings $\mathrm{H}-14-103357, \mathrm{H}-14-103362$ and $\mathrm{H}-$ 14-103370.

3.2.1.4.4 The required response time of the pit leak detection system shall be instantaneous. (See Section 5.1 for definition of instantaneous)

Verification: (Analysis) The leak detection system is continuously monitoring for intrusion. When an intrusion is detected, the contacts of the leak detection relay (ANO1A-WTLDK-201, AN04A-WT-LDK-203, and ANO4D-WT-LDK152) will close and instantaneously initiate the local alarm light (ANO1A-WT-LDA-201A, ANO4A-WT-LDA203A, and ANO4D-WT-LDA-152A). The active components that would primarily contribute to the response time are the components that change state, i.e., the leak detection relay and the latching coil relay (AN01A-WT-LDA-201-1, AN04A-WT-LDA-203-1 or ANO4D-WT-LDK-152-1 and AN-1A-WT-K-201D, ANO4AWT-K-203D or ANO4D-WT-K-152D). Calculation W314I-054 verified leak detection system response time to be 0.525 seconds. A signal is also sent to the master pump shutdown system by opening contacts (ANO1AWT-LDK-201-2, ANO4A-WT-LDK-203-2 or ANO4D-WTLDK-152-2) and de-energizing the first of a series of trip relays within the master pump shutdown logics. The leak detection circuitry is shown on Drawings $\mathrm{H}-14-$ 103357, $\mathrm{H}-14-103362$ and $\mathrm{H}-14-103370$.

3.2.1.4.5 The wiring between the leak detection system sensor and control panel shall be electrically supervised.

Verification: (Analysis) (Analysis) Supervision for the wiring between the probes and the leak detection control panel is performed by the trip amplifier (ANO1A-WT-EY-201, ANO4A-WT-EY-203 and ANO4D-WT-EY-152). This device monitors the voltage (at the probes) and is located in the leak detection control panel. Upon loss of probe voltage or wire failure, the trip amplifier will 
activate the local alarm (AN01A-WT-LDA-201A, ANO4AWT-LDA-203A, and ANO4D-WT-LDA-152A) and initiate the master pump shutdown system. The leak detection circuitry is shown on Drawings $\mathrm{H}-14-103357, \mathrm{H}-14$ 103362 and $\mathrm{H}-14-103370$.

(Test) This requirement will also be verified by test during the ATP of the leak detection system.

\subsubsection{Physical Characteristics}

3.2.2.1 Weight limit: Not applicable to this specification.

\subsubsection{Access for Maintenance}

The portion of the pit leak detection system located in the pit shall be replaceable without removing the pit cover block.

Verification: (Analysis) The probes located under the cover block can be extracted through the 3 in. riser designated for pit leak detection assembly. By removing the pit leak detection riser radiation shielding plug (Refer to Drawing $\mathrm{H}-14-100981$, sht $1 \&$ 2) the probes can easily be extracted from the valve pit. In addition, the probe height can be adjusted from above the cover block in the electrode holder to determine the height of liquid within the pit. This requirement is also verified by Acceptance Test Report for Leak Detection Mock-up, TWR-4663.

(Test) This requirement will also be verified by test during the ATP of the leak detection system.

3.2.2.3 Requirements for transport and storage: Not applicable to this specification.

3.2.2.4 Durability factors: Not applicable to this specification.

3.2.2.5 Health and Safety criteria:

The alarm and control panel portions of the pit leak detection system shall be located outside of the pit and shielded by the pit's cover block.

Verification: (Analysis) The pit leak detector stations are located above the cover block and away from the pit. Refer to Drawings $\mathrm{H}-14-103354, \mathrm{H}-14-103360$, and $\mathrm{H}-14-$ 103366 for placement of the leak detector stations. For reference of radiation limits above the cover block, see section 3.2.5.2.2.2 for analysis.

3.2.2.6 Security criteria: Not applicable to this specification.

3.2.2.7 Vulnerability factors: Not applicable to this specification 


\subsubsection{Reliability}

3.2.3.1 Each pit leak detection system's buried conduit shall have a design life of 35 years. Replaceable components in each system shall have a design life of 12 years.

Verification: (Analysis) Construction Specification W-314-C5, Section 16400 specifies PVC coated rigid steel conduit or PVC non-metallic conduit, as shown in drawings, for underground applications. The drawings indicate use of PVC Coated rigid steel conduit inside the tank farms and PVC non-metallic conduit outside the tank farms. The PVC coated rigid steel conduit is the best available industrial category conduit for use inside the tank farms, which will provide both mechanical and chemical protection for the wiring inside the conduit. PVC nonmetallic conduit is the most cost effective direct burial raceway system for use outside the tank farms, based upon application and burial depths. This type of raceway system will also provide both mechanical and chemical protection for the wiring inside the conduit. These conduit systems will be installed per manufacturer's instruction as specified in Construction Specification W-314-C5, Section 16400, para 3.2.3.9 which will provide maximum service life. There is no technical data available for conduit design life under the anticipated installation and environmental conditions both inside or outside the tank farms.

3.2.3.2 Pit leak detection systems shall be capable of detecting the leak with a probability of detection of 0.95 and a probability of false alarm of 0.05 .

Verification: (Analysis) The leak detection system availability based on a mean-time-to-repair of 4 hours and a mission time of 5 years is 0.9965 based on Calculation W314-I-055. The probability of a false alarm for the leak detection in a period of one year is 0.0135 per Calculation W314-I058.

Designs shall provide for the detection and isolation of faults to systems, structures, and components as necessary in order to minimize the risks associated with faulty operation to plant, personnel and environment. Protection systems and associated instrumentation and controls shall be designed in accordance with DOE 6430.1a, Section 1660-99.0.2.

Verification: (Analysis) Isolation: Each leak detection relay cabinet enclosure is equipped with a disconnect switch. This mechanical device will terminate power when activated 
manually. Each cabinet is also equipped with an internal dc power supply. This supply is energized from the enclosure power which terminates when the disconnect is operated. Detection: The pit leak detection relay cabinets are supplied 120 volts from a circuit breaker panel. In the event a fault occurs anywhere in this circuit, the breaker would isolate all pit leak detectors feed from this circuit. The design complies with DOE Order 6430.1a, Div 16, section 1660-99.0.2 requirements (see FDNW DOE 6430.1a, Div. 16 checklist).

\subsubsection{Maintainability}

3.2.4.1 The time to repair the pit leak detection system, excluding craft time to mobilize and enter tank farms, shall be equal to or less than 4 hours.

Verification: (Analysis) All components of the leak detection system, with the exception of the leak detection probes and probe wire, are commercially available, off-the-shelf items. It is assumed that spare components will be maintained on-site to support maintenance requirements. The design of the system allows for easy access to all components outside the pit. The probes inside the pits are also design to allow for removal without taking the cover blocks being removed. With the current design and after setup time, the components can be repaired within a 3.9 hour time period as documented in Calculation W314-I-056.

3.2.4.2 The frequency of preventive maintenance shall be no less than annually.

Verification: (Analysis) Based on a review of vendor information, it is anticipated that the specified components will require no more than annual preventative maintenance which is cleaning the probes otherwise all other maintenance is corrective.

3.2.4.3 The leak detection system sensor assembly and electrical connections shall not interfere with removal of the pit cover blocks.

Verification: (Analysis) The probes are capable of being removed from the top of the cover block prior to or without the removal of the cover block. See Drawing H-14-100981 for details of this design.

3.2.4.4 The leak detection system sensors that are located in the pits shall be testable in place by the addition of water to the pit or any solution with a conductivity nominally equivalent to the waste solution.

Verification: (Analysis) By introducing approximately 10 gallons of water into the valve pit (beyond the minimum required 
for detecting a leak), the leak detection warning light will activate. The water may be introduced into the pits from one of the observation ports. For details on how the leak detection system is activated, refer to section 3.2.1.1.2. This requirement is also verified by Acceptance Test Report for Leak Detection Mock-up, TWR-4663.

(Test) This requirement will also be verified by ATP.

\subsubsection{Environmental Conditions}

The systems and components covered by this specification shall be compatible with the environmental conditions listed below, as applicable. Performance Category (PC) 3 is assigned to Safety Class systems and PC1 is assigned to general service systems. The design and analysis of loads associated with existing systems shall, as a minimum, be performed to the design requirements of the existing system.

\subsubsection{Natural Environments}

\subsection{Ambient Air Temperature}

The ambient air temperature range is $48.9^{\circ} \mathrm{C}\left(120^{\circ} \mathrm{F}\right)$ to $-35.5^{\circ} \mathrm{C}$ ($\left.32^{\circ} \mathrm{F}\right)$, and with a maximum 24 hour differential of $28.9^{\circ} \mathrm{C}\left(52^{\circ} \mathrm{F}\right)$.

Verification: (Analysis) Vendor data for the leak detection systems active components are as follows:

Potter Brumfield - General Purpose Relay Type KRPA $\left(-45^{\circ} \mathrm{C}\right.$ to $\left.70^{\circ} \mathrm{C}\right)$

Potter Brumfield - Dual Coil Latch Relay Type KBP $\left(-45^{\circ} \mathrm{C}\right.$ to $\left.85^{\circ} \mathrm{C}\right)$

B/W Controls - Intrinsically Safe Relay Series $5300\left(-30^{\circ} \mathrm{F}\right.$ to $\left.175^{\circ} \mathrm{F}\right)$

MTL - Trip Amplifier, General Purpose MTL2313A $\left(-20^{\circ} \mathrm{C}\right.$ to $\left.60^{\circ} \mathrm{C}\right)$

Edwards - Strobe Light 94DV2 $\left(-35^{\circ} \mathrm{F}\right.$ to $\left.150^{\circ} \mathrm{F}\right)$

Disconnect switch was verified to operate between $0^{\circ}$ and $140^{\circ} \mathrm{F}$ documented by CGI Data Transmittal W-314-C1-29.2B, Section 2.2.2.4.

Wiring inside the cabinet is type MTW as required by UL508. The high temperature rating or type MTW is $195^{\circ} \mathrm{F}$ per NEC and UL1063. Insulation for MTW is PVC per UL1063. The low temperature rating of PVC insulation is $-5^{\circ} \mathrm{F}$.

Based on this design criteria, a heating element was needed to assure that the temperature inside of the enclosure will not drop lower than $20^{\circ} \mathrm{C}$. The heater (AN01A-WT-HTR-201, ANO4A-WT-HTR-203 and ANO4D-WT-HTR-152) is primarily for the trip amplifier (ANO1A-WT-EY201, ANO4A-WT-EY-203, and ANO4D-WT-EY-152). If the inside of the enclosure were to drop below $-20^{\circ} \mathrm{C}$., the trip amplifier would not 
be operating in the temperature zone specified by the manufacturer. This problem was resolved with the addition of the thermostatically controlled heater.

Hoffman - Heater, General Purpose D-AH1001A $\left(-18^{\circ} \mathrm{F}\right.$ to $\left.158^{\circ} \mathrm{F}\right)$. Note that heater operation shall maintain environmental temperature above $-20^{\circ} \mathrm{C}$.

Passive components such as wire, fittings, disconnect switch and other metallic non-moving devices used in this design will operate within the ambient air temperature limits.

Further analysis will be performed when Vendor information is received prior to installation.

\subsection{Soil Temperature}

The minimum soil temperatures below ground surface is:
$1.3 \mathrm{~cm}(0.5 \mathrm{in}):$
$-19.5^{\circ} \mathrm{C}\left(-3.0^{\circ} \mathrm{F}\right)$
$38 \mathrm{~cm}(15 \mathrm{in}):$
$-8.8^{\circ} \mathrm{C}\left(16.1^{\circ} \mathrm{F}\right)$
$92 \mathrm{~cm}$ (36 in):
$0.8^{\circ} \mathrm{C}\left(33.5^{\circ} \mathrm{F}\right)$

Verification: (Analysis) Due to the design of instrumentation for this project being above ground, the soil temperature does not apply. The conduit will be buried at varying depths between $12^{\prime \prime}$ and $48^{\prime \prime}$. The limiting temperature is $-7.1^{\circ} \mathrm{C}\left(19.2^{\circ} \mathrm{F}\right)$. The conduit is coated with PVC which is rated $-20^{\circ} \mathrm{C}$ to $80^{\circ} \mathrm{C}$ according to manufacturer's data. The wire routed through the conduit has TFN (Teflon) insulation rated at $-70^{\circ} \mathrm{C}$ to $260^{\circ} \mathrm{C}$ according to manufacturer's data. The insulation quality of the materials specified in this design meet the design requirements.

\subsection{Seismic Loads}

\section{PC1 structures, systems, and components}

Earthquake load design of PC1 SSCs shall comply with the UBC, Seismic Zone 2B, for standard occupancy facilities.

\section{PC3 structures, systems, and compenents}

Earthquake load design of PC3 SSCs shall comply with DOE-STD-1020 by using dynamic analysis and site-specific design response spectra listed in Table 3-1.

Calculate elastic seismic response, $D_{\mathrm{s}}$, by dynamic analysis using Response Level 2 damping values from Table 3-2.

Verification: (Analysis) Civil Calculation W314-C-008 analyzes the structures associated with the instrumentation installed 
by this design package using UBC earthquake loads and meets the requirements. Even though the pit leak detection system is designated as Safety Class, the system does not have to operate after a DBA (as per BIO and design direction, given in Letter No. 9750215, W.W. Rutherford, Numatec Hanford Corporation, to K.J. Dempsey, Fluor Daniel Northwest, Inc., Dated January 17,1997 ) and thus, does not have to be designed and analyzed to the higher earthquake loads.

\subsection{Wind Loads}

For PC3 systems:

"Fastest Mile" wind velocity: "Three Second Gust" wind velocity: Missile (horizontal):

For PC1 systems:

"Fastest Mile" wind velocity:

"Three Second Gust" wind velocity:
$36 \mathrm{~m} / \mathrm{s}(80 \mathrm{mi} / \mathrm{h})$
$44 \mathrm{~m} / \mathrm{s}(100 \mathrm{mi} / \mathrm{h})$
$50 \times 100 \mathrm{~mm}(2$
Timber plank weig
(15 lb)
$@ 22 \mathrm{~m} / \mathrm{s}(50 \mathrm{~m} /$
Maximum traject
height = $9 \mathrm{~m} \mathrm{(30)}$
$31 \mathrm{~m} / \mathrm{s}(70 \mathrm{mi} / \mathrm{h})$
$38 \mathrm{~m} / \mathrm{s}(85 \mathrm{mi} / \mathrm{h})$

Verification: (Analysis) The pit leak detection relay cabinets meets the requirements for the wind velocity specified as shown in Calculations W314-C-008 and W314-C-033. A protective grate that meets the requirements, is provided to protect the leak detection relay cabinet and alarm light from the specified wind blown missile hazard. See Drawing H-14-103247 for details of the protective grating.

\subsection{Snow Loads}

The ground snow loads are: $720 \mathrm{~Pa}\left(15 \mathrm{lb} / \mathrm{ft}^{2}\right)$

Verification: (Analysis) Civil Calculation W314-C-008 and W314-C033 details the snow loading as being minimal on the horizontal surfaces of the leak detection relay cabinets compared to the structural strength of the relay cabinet material and supporting frame assembly. 
Table 3-1 - Response Spectra

\begin{tabular}{|c|c|c|c|c|c|c|}
\hline \multicolumn{7}{|c|}{ Horizontal Response Spectra "g" } \\
\hline \multirow{2}{*}{$\begin{array}{c}\text { Frequency } \\
\text { (Hertz) }\end{array}$} & \multicolumn{6}{|c|}{ Damping } \\
\hline & $0.50 \%$ & $2 \%$ & $5 \%$ & $7 \%$ & $10 \%$ & $12 \%$ \\
\hline 100 & 0.26 & 0.26 & 0.26 & 0.26 & 0.26 & 0.26 \\
\hline 33.3 & 0.26 & 0.26 & 0.26 & 0.26 & 0.26 & 0.26 \\
\hline 13.3 & 0.57 & 0.48 & 0.41 & 0.38 & 0.36 & 0.35 \\
\hline 10 & 0.77 & 0.59 & 0.47 & 0.43 & 0.38 & 0.36 \\
\hline 5 & 1.04 & 0.76 & 0.58 & 0.52 & 0.45 & 0.42 \\
\hline 3.3 & 0.98 & 0.72 & 0.54 & 0.48 & 0.42 & 0.39 \\
\hline 2 & 0.74 & 0.55 & 0.41 & 0.37 & 0.33 & 0.30 \\
\hline 1 & 0.45 & 0.34 & 0.26 & 0.23 & 0.21 & 0.19 \\
\hline 0.5 & 0.22 & 0.17 & 0.13 & 0.12 & 0.11 & 0.10 \\
\hline 0.25 & 0.08 & 0.06 & 0.05 & 0.05 & 0.04 & 0.04 \\
\hline \multicolumn{7}{|c|}{ Vertical Response Spectra " $g$ " } \\
\hline \multirow{2}{*}{$\begin{array}{c}\text { Frequency } \\
\text { (Hertz) }\end{array}$} & \multicolumn{6}{|c|}{ Damping } \\
\hline & $0.50 \%$ & $2 \%$ & $5 \%$ & $7 \%$ & $10 \%$ & $12 \%$ \\
\hline 100 & 0.18 & 0.18 & 0.18 & 0.18 & 0.18 & 0.18 \\
\hline 33.3 & 0.18 & 0.18 & 0.18 & 0.18 & 0.18 & 0.18 \\
\hline 13.3 & 0.60 & 0.46 & 0.37 & 0.33 & 0.30 & 0.28 \\
\hline 10 & 0.66 & 0.49 & 0.37 & 0.33 & 0.29 & 0.27 \\
\hline 5 & 0.60 & 0.44 & 0.33 & 0.30 & 0.26 & 0.24 \\
\hline 3.3 & 0.48 & 0.36 & 0.27 & 0.24 & 0.21 & 0.19 \\
\hline 2 & 0.32 & 0.24 & 0.18 & 0.16 & 0.14 & 0.13 \\
\hline 1 & 0.19 & 0.14 & 0.11 & 0.10 & 0.09 & 0.08 \\
\hline 0.5 & 0.14 & 0.11 & 0.08 & 0.07 & 0.07 & 0.06 \\
\hline 0.25 & 0.06 & 0.05 & 0.04 & 0.03 & 0.03 & 0.03 \\
\hline
\end{tabular}


Table 3-2 - Response Level

\begin{tabular}{|l|c|}
\hline & Damping (\% of critical) \\
\cline { 2 - 2 } & Response Level \\
\hline Demand/capacity ratio & $\sim 0.5$ to 1.0 \\
\hline Welded and friction bolted metal structures & 4 \\
\hline Bearing-bolted metal structures & 7 \\
\hline $\begin{array}{l}\text { Prestressed concrete structures without } \\
\text { complete loss of prestress }\end{array}$ & 5 \\
\hline Reinforced concrete structures & 7 \\
\hline Masonry shear walls & 7 \\
\hline Wood structures with nailed joints & 10 \\
\hline Distribution systems & 5 \\
\hline $\begin{array}{l}\text { Massive low stressed components (pumps, } \\
\text { motors, etc.) }\end{array}$ & 3 \\
\hline Light welded instrument racks & 3 \\
\hline Electrical cabinets and other equipment & 4 \\
\hline $\begin{array}{l}\text { Liquid containing metal tanks } \\
\text { Implusive mode }\end{array}$ & 3 \\
\hline $\begin{array}{l}\text { Liquid containing metal tanks } \\
\text { Sloshing mode }\end{array}$ & \\
\hline
\end{tabular}

\subsection{Relative Humidity}

The relative humidity range is 0 to $100 \%$ (Rate of change is negligible).

Verification: (Analysis) All devices affected by relative humidity are located in a NEMA $4 X$ rated enclosure as shown on Drawing H-14-100983. The enclosure will be sealed and rated for rain, sleet, dust $\&$ hail. In addition, the operating limits of the trip amplifier and the switch operated relay are $5-95 \% \mathrm{RH}$. The humidity inside the enclosure is governed by the pressure and temperature inside and outside the enclosure. With the addition of a combination breather and drain (refer to Drawing $\mathrm{H}-14-$ 100983), the temperature and pressure inside the enclosure will equalize. Any additional build-up of condensation will drain out of the enclosure. Although the addition of the breather/drain can not quantify what 
the humidity would be inside the enclosure if the humidity outside the enclosure was $100 \%$, it should be less than $100 \%$ due to the heat produced inside the cabinet from components that are normally energized equipment.

In the case where the humidity inside the enciosure falls below $5 \% \mathrm{RH}$, the breather will allow moisture absorption from the outside environment which will raise the relative humidity inside the enclosure.

Engineering judgement with regards to relative humidity induced failure, is that electronic components would fail in a safe condition.

\subsection{Surface Precipitation}

The surface precipitation is $4 \mathrm{~cm}(1.56 \mathrm{in})$ in a 24 hour period.

Verification: (Analysis) The instrumentation components located outside the valve pits that would be affected by surface precipitation are protected by the leak detection relay enclosure and the electrode holder. The leak detection relay cabinet enclosure is designed as a NEMA type $4 X$ with gaskets to protect the components inside from dust, dirt, oil and water. The electrode holder has service rating of watertight, heavy duty outdoor. The electrical junction boxes have been specified NEMA 4 to provide the necessary protection against dust and water. Watertight fittings have been specified for conduits terminating in the junction boxes. The hand holes that are used for the conduit runs have been provided with drain holes to avoid water accumulation. Refer to Construction Specification W-314-C5 section 1600 for details.

\subsection{Hail Events}

The hail diameter is less than or equal to $1.9 \mathrm{~cm}(0.75 \mathrm{in})$.

Verification: (Analysis) The enclosures discussed in section 3.2.5.1.7 also protect against the damages due to hail. The NEMA rated enclosure and electrode holder are made of stainless steel and will not be damaged by hail to the extent that the components within the enclosure would be damaged.

\subsection{Sand and Dust}

The sand/dust concentration is $0.177 \mathrm{gm} / \mathrm{m}^{3}$ with a typical size of 350 $\mu \mathrm{m}$. 
Verification: (Analysis) The enclosures covered in section 3.2.5.1.7 also protect the components internal operations from sand and dust.

\subsection{Solar Radiation}

The solar radiation range is between $4 \mathrm{Watts} / \mathrm{m}^{2}$ and $406 \mathrm{Watts} / \mathrm{m}^{2}$.

Verification: (Analysis) The leak detection relay cabinet and electrode holder are the only two components directly exposed to solar radiation. The inside temperature of the leak detection relay cabinet is limited by the maximum operating temperature limit of the trip amplifier set at $60^{\circ} \mathrm{C}$. At a maximum solar radiation of 406 Watts $/ \mathrm{m}^{2}$, the temperature of this enclosure will increase significantly. Calculation W314-I-004 shows that with a maximum solar radiation of $406 \mathrm{Watts} / \mathrm{m}^{2}$ and a maximum ambient air temperature of $120^{\circ} \mathrm{F}$, the inside temperature of the enclosure will not raise above the maximum operating temperature of the trip amplifier. This calculation has considered the heat generated inside the relay cabinet from normally energized components and concludes that the enclosure is below the operating maximum of $60^{\circ} \mathrm{C}$ without the use of forced air moving through the cabinet. The probe wiring and cord grips located inside the electrode holder have breakdown temperatures much higher than the solar radiation and maximum ambient temperature.

\subsection{Glaze (See definition in Section 5.1)}

The glaze is $2.54 \mathrm{~cm}(1 \mathrm{in}$.$) .$

Verification: (Analysis) Glaze is not considered to affect the leak detection system. All active components that glaze would affect are inside the relay cabinet enclosure which is rated to protect against ice formation. Civil Calculation W314-C-008 identifies the ice as not being a considerable weight factor in the structural analysis for loading.

\subsection{Ashfall Events}

A total combination load of snow fall and ash fall of $960 \mathrm{~Pa}\left(20 \mathrm{lb} / \mathrm{ft}^{2}\right)$ shall be used.

Verification: (Analysis) Civil Calculations W314-C-008 and W314-C033 identifies weight loading due to an ashfall event has negligible effect on the structure. 


\subsection{Dead loads}

Dead loads include the weights of all permanent materials and equipment, including the structure's own weight. Design dead loads shall include the weight of all permanent service equipment. Load calculations shall include an allowance for any loadings anticipated to be added at a later date. Initially assumed loads shall be revised so that the final design reflects the configuration shown on the drawings.

The unit weights of materials and construction assemblies for buildings and other structures shall be those given in ASCE 7-95. Where unit weights are neither established in that standard nor determined by test or analysis, the weights shall be determined from data in manufacturer drawings or catalogs.

Verification: (Analysis) This requirement is verified by Calculations W314-C-008 and W314-C-033 as meeting the requirements.

\subsection{Thermal Forces}

The design of structures shall include the effects of stresses and movements resulting from variations in temperature. Structures shall be designed for movements resulting from the maximum seasonal temperature change. The design shall provide for the lags between air temperatures and the interior temperatures of massive concrete members or structures. Consideration shall be given to passive soil loading resulting from thermal growth of subgrade structures.

Verification: (Analysis) This requirement is not applicable to this design package.

\subsection{Creep and Shrinkage Forces}

Concrete and masonry structures shall be investigated for stresses and deformations induced by creep and shrinkage. For concrete and masonry structures, the minimum linear coefficient of shrinkage shall be assumed to be $0.0002 \mathrm{~mm} / \mathrm{mm}$, unless a detailed analysis is undertaken. The theoretical shrinkage displacement shall be computed as the product of the linear coefficient and the length of the member.

Verification: (Analysis) This requirement is not applicable to this design package.

\subsection{Load Combinations and Allowable Stresses}

Load combinations, allowable stresses, and strength requirements for load conditions that include live load, dead load, snow load, and normal operating loads for all SSCs shall comply with the UBC or applicable system national codes and standards.

Load combinations, allowable stresses, and strength requirements for load conditions that include live load; dead load; snow load; normal 
operating loads; and NPH loads of extreme wind, earthquake, flood, and ashfall for all SSCs shall comply with DOE-STD-1020.

Load factors and load combinations for PC1 structures, systems, and components

Combine response from various loadings to determine the structural demand by using the UBC-specified load combination rules (e.g., load factors for ultimate strength design and unit load factors for allowable stress design).

Where:

$\begin{array}{lll}\mathrm{DL} & = & \text { DEAD LOAD } \\ \mathrm{LL} & = & \text { LIVE LOAD } \\ \mathrm{RL} & = & \text { ROOF LIVE LOAD } \\ \mathrm{S} & = & \text { SNOW LOAD } \\ W & = & \text { WIND LOAD } \\ \mathrm{E} & = & \text { EARTHQUAKE } \\ T & = & \text { THERMAL } \\ \mathrm{C} & = & \text { CREEP/SHRINKAGE }\end{array}$

Allowable Stress (AS) Design: All Construction

$\begin{array}{lll}A S & = & D L+L L+R L(o r S) \\ A S & = & 0.75[D L+L L+W(o r E)] \\ A S & = & 0.75[D L+L L+W+S / 2] \\ A S & = & 0.75[D L+L L+S+W / 2]\end{array}$

Ultimate Strength (U) Design: Reinforced Concrete

$\begin{array}{lll}U & = & 1.4 D L+1.7 L L+1.7 R L(o r) 1.7 S) \\ U & = & 0.75[1.4 D L+1.7 L L+1.7 W] \\ U & = & 1.05[D L+L L+E] \\ U & = & 0.9 D L+1.3 W(\text { or } 1.4 E) \\ U & = & 1.4[D L+T \text { (or } C)] \\ U & = & 0.75[1.4 D L+1.7 L L+1.4 T \text { (or } 1.4 C \text { ) }]\end{array}$

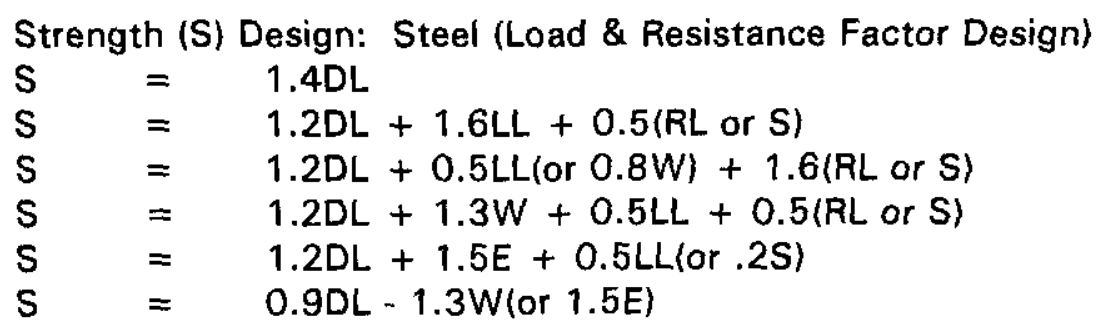

Load factors and load combination for PC3 structures, systems, and components

Combine response from various loadings to determine structural demand as follows.

Where:

$\begin{array}{lll}D L & = & \text { DEAD LOAD } \\ \mathrm{LL} & = & \text { LIVE LOAD }\end{array}$ 


$\begin{array}{lll}\mathrm{RL} & = & \text { ROOF LIVE LOAD } \\ \mathrm{S} & = & \text { SNOW LOAD } \\ \mathrm{W} & = & \text { WIND LOAD } \\ \mathrm{E} & = & \text { EARTHQUAKE } \\ \mathrm{A} & = & \text { ASHFALL } \\ \mathrm{T} & = & \text { THERMAL } \\ \mathrm{C} & = & \text { CREEP/SHRINKAGE }\end{array}$

Allowable Stress (AS) Design:

$A S=D L+L L+R L$ (or $S)$
$A S=0.62[D L+L L+R L($ or $S)+W+T$ (or $C)]$

for shear stress

$A S=0.71[D L+L L+R L($ or $S)+E($ or $A)+T($ or $C)]$

for all stress other than shear stress

$A S=0.59[D L+L L+R L($ or $S)+E($ or $A)+T$ (or $C)]$

Ultimate Strength (U) Design:

$U=1.4 D L+1.7 L L+1.7$ RL(or 1.7S)

$U=1.4[\mathrm{DL}+\mathrm{T}$ (or $\mathrm{C})]$

$U=D L+L L+R L($ or $S)+W($ or $E$ or $A)+T$ (or $C)$

Strength (S) Design: Steel (Load \& Resistance Factor Design)

$\mathrm{S}=1.4 \mathrm{DL}$

$S=1.2 \mathrm{DL}+1.6 \mathrm{LL}+0.5(\mathrm{RL}$ or $\mathrm{S})$

$S=1.2 \mathrm{DL}+0.5 \mathrm{LL}+1.6(\mathrm{RL}$ or $\mathrm{S})$

$S=D L+L L+R L($ or $S)+W($ or $E$ or $A)+T$

Verification: (Analysis) Civil Calculation W314-C-008 identifies that a combination of loads due to a natural environmental effect would not impact the structural strength of the frame assembly of the leak detection relay cabinet enclosure.

3.2.5.2 Induced Environments

\subsection{Waste Properties}

Materials used that come in contact with the waste shall be capable of safely handling waste with the following properties:

$\begin{array}{ll}\text { Specific Gravity } & 1 \text { to } 1.5 \\ \text { Viscosity } & 1 \text { to } 30 \text { centipoise (Newtonian) } \\ \text { Miller Number } & 100 \text { maximum } \\ \text { pH } & 7 \text { to } 14 \\ \text { Temperature } & 10 \text { to } 93^{\circ} \mathrm{C}\left(50 \text { to } 200^{\circ} \mathrm{F}\right) \\ \text { Solids Content } & 30 \mathrm{Vol} \% \\ \text { Particle Size } & 0.5 \text { to } 4000 \text { microns } \\ \text { Note: } 95 \% \text { of total particles } 0 \text { to } 50 \text { microns } \\ \\ \quad<5 \text { percent of total particies } 50 \text { to } 500 \text { microns } \\ <1 \text { percent of total particles } 500 \text { to } 4000 \text { microns }\end{array}$


Verification: (Analysis) The only pit leak detection components subject to the effects of waste are the probe, probe cover and wire coating. The probe cover is made of PEEK (poly ether ketone) filled with glass and graphite. PEEK is a high performance thermoplastic that resists continuous temperatures of up to $480^{\circ} \mathrm{F}$. It features excellent chemical resistance, plus high tensile strength and wear resistance. In addition, PEEK resists abrasion, radiation and exhibits low moisture absorption. Due to the application of the probe and probe cover, the only relevant requirements that need to be addressed are the waste $\mathrm{pH}$ levels and the waste temperature. PEEK withstands a wide $\mathrm{pH}$ range, from 60 percent sulfuric acid to 40 percent sodium hydroxide, and at high temperatures. With this percentage range, PEEK meets the $\mathrm{pH}$ requirement. The waste temperature is far below that of PEEK breakdown temperatures (at $480^{\circ} \mathrm{F}$ ). For this design, PEEK is the most suitable material with radiation tolerances well above that required to be used in this application, while remaining to be machinable. The probe cover is considered to be an insulator and will protect the probes from unnecessary contact of metallic devices.

The probe wire coating is made of Tefzel 280 or HT2183 (Dupont) which exhibits some of the same properties as the probe cover. The wire insulation is located approximately 5 inches from the pit floor. If a leak does occur, it will be detected when 10 gallons has accumulated at the pit floor. In order for the leaking fluid to come in direct contact with the probe wire insulation, more than 10 gallons would have to be located on the pit floor. For this design, the pit drain releases fluid to a tank well before it would come in contact with the wire insulation. In the event the waste does come in contact with the coated probe cable, Tefzel 280 will not break down with waste $\mathrm{pH}$ in this range as it is specified by the vendor to have a base and acidic resistance that meets this requirement. The temperature at which Tefzel breaks down is $270^{\circ} \mathrm{C}$, which is above the waste temperature requirement.

The probe is made of solid stainless steel that has stable metallic properties that will withstand all of the above requirements.

\subsection{Radiation Tolerance}

\subsection{Inside Pit Radiation Level}

Materials used that are located inside a pit shall be capable of operating in the following radiation environment: 
Total accumulated dose:

Dose rate:
$6 \times 10^{7} \mathrm{rads}$

$1 \times 10^{7} \mathrm{mr} / \mathrm{hr}$

Verification: (Analysis) There are three items located under the cover block and considered inside the pit; the probe, the probe cover and the probe wire $\&$ coating. The probe is made of stainless steel and is considered to withstand this radiation level and not be affected. The probe cover or insulator is made of PEEK, as stated in 3.2.5.2.1, and stated from the manufacturer to have a tolerance to radiation of $2 \times 10 \mathrm{E} 9$ rads. This is well above the range specified above. Tefzel 280 is designed to operate in the nuclear facilities with a total accumulated dose rate resistance of $2 \times 10 \mathrm{E} 8$ rads. This is also well within the tolerance levels above.

\subsection{Background Radiation Level}

Materials used that are located outside a pit, above grade, shall be capable of operating in the following radiation environment:
Total accumulated dose:
$0.5 \mathrm{rad} /$ year
Dose rate:
$0.25 \mathrm{mr} / \mathrm{hr}$

Verification: (Analysis) All equipment outside the pit is protected in a metal enclosure and based on representative manufacturer information, will not break down at this radiation level. In addition, the equipment is similar to equipment that has previously been used in the tank farms without any adverse affects.

\subsubsection{Transportability}

Not applicable to this specification.

\subsubsection{Flexibility and Expansion}

3.2.7.1 Each system design shall, to the maximum extent practable, provide sufficient flexibility to accommodate for programmatic changes or operation modifications.

Verification: (Analysis) The leak detection system design has the ability to adjust the height at which the probes are positioned above the pit floor. This feature will allow flexibility to meet changing operational requirements. See Drawing H-14-100981 for details of this feature.

\subsection{Design and Construction}

\subsubsection{Materials, Processes, and Parts}

3.3.1.1 All systems shall comply with DOE Order 6430.1a Div, 16, NFPA 70, and UL 508A. 
Verification: (Analysis) Compliance with UL508A and NFPA 70 are verified in Construction Specification W-314-C5, Section $16400,3.2 .1 .1$ and Procurement Specification W-314P6, para 3.5.4. The requirement of UL 508 comes from DOE $6430.1 \mathrm{a}$ and is applicable only to motor controllers. The design engineer applied UL 508A to this design package. For compliance with DOE Order 6430.1a, Div 16, refer to FDNW DOE Order 6430.1a, Div. 16 checklist.

(Exam) This requirement will also be verified by examination during construction.

3.3.1.2 Electrical materials and equipment shall be UL or FM tested, with label attached, for the purpose intended, whenever such products are available.

Verification: (Analysis) Construction Specification W-314-C5, Section 13440, Part 1, Paragraph 1.3.2 and 1.3.3 and Procurement Specification W-314-P6, Section 4.2 require components of the leak detection system to be UL or FM listed components. Additionally, if material or equipment is not UL or FM tested, other nationally recognized testing labs is allowed per DOE 6430.1a.

(Exam) This requirement will also be verified by examination during receiving inspection and/or construction.

3.3.1.3 As a minimum electrical equipment enclosures shall be NEMA Type 4.

Verification: (Analysis) The leak detection relay cabinets and pressure alarm relay cabinets on Drawings $\mathrm{H}-14-100983$ and $\mathrm{H}$ 14-103368, respectively, are both rated NEMA $4 X$. The Field Terminal Box (FTBX) enclosure on Drawing $\mathrm{H}$-14101341 is rated NEMA 4.

(Exam) This requirement will also be verified by examination during construction.

3.3.1.4 During the design of facilities, optimization principles, as discussed in ICRP Publication 37, shall be utilized in developing and justifying facility design and physical controls.

Verification: (Analysis) ICRP Publication 37 addresses techniques for use in the optimization of radiation protection based on cost-benefit analysis to various radiation levels. Project W-314 is upgrading existing facilities where the architecture is constrained, the operational practices are already in place, and the acceptable risk and detriment to individuals is already provided and the applicable 
radiation levels are listed as separate requirements in this specification.

3.3.1.5 The equipment used for installation and maintenance shall comply with the DST dome loading constraints.

Verification: (Analysis) If equipment is located outside a 20' exclusion zone around the DST, dome loading effects are mitigated. Compliance with this requirement will be verified by the calculation and by the issuing of dome loading permits for locating the equipment from Tank Farm Engineering and Operations.

\subsubsection{Electromagnetic Radiation}

3.3.2.1 Hand held radio and cell phone wattage frequency shall not interfere with electrical/electronic components at a distance of one meter.

Verification: (Analysis) The electrical/electronic components are located in a stainless steel NEMA rated enclosure. Based on prior operational experience and the voltages of the leak detection system, it is anticipated the shielding provided by the enclosure will be sufficient to protect the system from interference due to hand held radios or cell phones. This requirement is also verified by Acceptance Test Report for Leak Detection Mock-up, TWR-4663.

(Test) This requirement will also be verified by demonstration during the ATP of the leak detection system.

3.3.2.2 The pit leak detection system shall not be adversely affected by outside electromagnetic forces generated by a 60 horse power, 480 $\mathrm{Vac}$, induction type motor operating at frequencies between 0 and 60 hertz and located 1 meter away from the leak detection system.

Verification: (Analysis) The motor is assumed to be located above the pit cover blocks.

Any electromagnetic interference (EMI) to the signals located inside the pit below the cover blocks are assumed to be shielded by the cover blocks. The cover blocks contain a grid of grounded concrete reinforcing steel rods, steel sleeves, and steel conduit.

Any EMI to the signals located outside the pit above the cover blocks next to the motor are shielded either by a grounded metal enclosures or conduit. In addition the cabling is shielded with metal (aluminum) foil which is also grounded to the electrical system ground in the 241-AN-271 building. 
The grounded shielding drains away any stray induced currents caused by the motor electromagnetic field.

\subsubsection{Identification and Marking}

3.3.3.1 New equipment and/or modifications to existing equipment shall be labeled in a standardized format in accordance with the tank farm labeling program as specified in HNF-IP-0842, Volume II, Section 6.1, Rev. 0 .

Verification: (Analysis) Construction Specification W-314-C5, Section 13440, paragraph 2.2.7 specifies labeling will be by LMHC OCM per their existing procedures. New $\mathrm{H}$ 14 drawings identified on Drawing $\mathrm{H}-14-100929$ were prepared using equipment numbering formats provided by LMHC.

(Exam) This requirement will also be verified by examination at the end of construction.

3.3.3.2 A master equipment list consisting of electronic data base for structures, systems, and components shall be generated in accordance with HNF-IP-0842, Volume II, Section 6.1, Rev. 0. The list contains such information as: unique equipment label, drawing reference, procedures, vendor information, Safety Classification, nameplate data, and etc.

Verification: (Analysis) This requirement will be met by providing the information into an electronic database.

3.3.3.3 Operations and maintenance drawings (As-built $\mathrm{H}-14$ essential drawings) shall be prepared as the system master drawings showing as-built configuration changes in accordance with HNF-IP-0842, Volume II, Section 6.1, Rev. 0.

Verification: (Analysis) This requirement is planned as an activity during Title III stage of the project. Completion of this analysis will take place at the end of construction.

\subsubsection{Workmanship}

Not applicable to this specification

\subsubsection{Interchangeability}

3.3.5.1 All like equipment (e.g., sensors, alarm lights, etc.) shall have interchangeable parts.

Verification: (Analysis) This requirement is verified by the fact that all like equipment in this design package and other design packages for $\mathrm{W}-314$ will be of identical make and model 

equipment that are identical and identified as Safety Class can be used in a non-Safety Class application but a non-Safety Class item can not be used as a Safety Class item until special qualifications are performed on the item.

\subsubsection{Safety}

3.3.6.1 The Pit Leak Detection System is identified as safety-class for the safety structures, systems and components (SSCs), except 241-AN04D, Slurry Receiver Pit. The Safety Class functions of the Pit Leak Detection System are to detect leaks inside the pit to limit the volume of waste spilled to the pit and provide an interlock to the transfer pump or an alarm.

Verification: (Analysis) Per the TWRS BIO, the Safety Class functions of the Pit Leak Detection system is to detect a leak 1inch from the pit floor and provide a local alarm or pump interlock. The design will detect the leak within at least 1 -inch from the floor (see Drawings $\mathrm{H}-14-103362$ and $\mathrm{H}-14-103370)$ and provide a local alarm light see Drawing H-14-100983). The Safety Class function of this design is being fulfilled by the local alarm light. The design also includes a non-Safety Class feature of providing a pump interlock signal.

3.3.6.1.1 The 241-AN-04D, Slurry Receiver Pit leak detector shall be identified as General Services.

Verification: (Analysis) The 241-AN-04D, Slurry Receiver Pit leak detector shall be identified as General Services.

3.3.6.2 The Pit Leak Detection System components installed in ex-tank intrusive locations shall be designed to meet NFPA 70 Class I, Division 1 , Group B criteria for hazardous locations.

Verification: (Analysis) The only ex-tank intrusive components of the pit leak detection system are the probes (AN01A-WTLDE-201A/B, AN04A-WT-LDE-203A/B, and ANO4D-WTLDE-152A/B) and the connecting wiring. The leak detector probes meets the criteria for a Simple Apparatus as defined by the NEC and therefore needs no approval. A Simple Apparatus is a device that will neither generate nor store more than 1.2 volts, 0.1 ampere, 25 milliwatts, or 20 microjoules. The leak detection relay (AN01A-WT-LDK-201, ANO4A-WT-LDK203, and ANO4D-WT-LDK-152) connects to the probes and is FM approved as being intrinsically safe. Thus, this is an intrinsically safe circuit and is accepted by the NEC for use in a Class I, Division 1 or 2, Group B location. Refer to Drawings $\mathrm{H}-14-103357, \mathrm{H}-14-$ 
103362, and $\mathrm{H}-14-103370$ for details on how these components are wired.

\subsubsection{Human Performance/Human Engineering}

3.3.7.1 Each control device shall be in accordance with NUREG 0700, Section 6.4 and MIL-STD-1472E, Section 5.4.

Verification: (Analysis) Verified by Calculation W314-I-002, human factor analysis pit leak detection warning lights.

3.3.7.2 Warning systems shall be in accordance with the general guidelines found in MIL-STD-1472E, Section 5.3. Auditory signal guidelines shall be in accordance with NUREG 0700, Section 6.2.

Verification: (Analysis) Verified by Calculation W314-I-002, human factor analysis pit leak detection warning lights.

\subsection{Documentation}

3.4.1 Drawings shall be prepared according to the formats set forth in "HNF-PRO-242, Rev. 0 , Engineering Drawing Requirements", for documents produced prior to June 15, 1999 and "HNF-PRO-709, Rev. 1, Preparation and Control Standards for Engineering Drawings", for documents produced after June 15, 1999.

Verification: (Analysis) $H$ - Series Drawings will be released in accordance with the guidelines set forth in HNF-PRO-709, Rev 1.

3.4.2 Records, documents, and document control pertinent to design functions shall be in accordance with HNF-PRO-224 and HNF-PRO-233.

Verification: (Analysis) The overall record management for identification and storage of drawings, calculations, and specifications pertinent to design functions will be performed in accordance with HNF-PRO-224 and HNF-PRO-233.

(Exam) This requirement will also be verified by $\mathrm{OA}$ assessment of the documents.

\subsection{Logistics}

\subsubsection{Maintenance}

3.5.1.1 Fully remote maintenance and operation. Each system or portion of a system having radiation levels greater than $50 \mathrm{mrem} / \mathrm{hr}$ contact exposure shall be designed to be remotely maintained and operated or designed to require no maintenance and be remotely operated.

Verification: (Analysis:) This requirement applies only to equipment inside the pit. Probes located inside the pit can be washed down as they are extracted from the top of the cover block and maintained outside radioactive environments. Decontamination of the probes will be in 
accordance with ALARA. Areas outside the pit do not require protection from radiation levels greater than 50 $\mathrm{mrem} / \mathrm{hr}$ and therefore do not apply.

3.5.1.2 Limited contact maintenance and operation. Each system or portion of a system having radiation levels greater than $0.1 \mathrm{mrem} / \mathrm{hr}$ to less than or equal to $50 \mathrm{mrem} / \mathrm{hr}$ shall be designed for limited contact maintenance and operation.

Verification: (Analysis) See analysis in section 3.5.1.1.

3.5.1.3 Full contact maintenance and operation. Each system or portion of a system having radiation levels less than or equal to $0.1 \mathrm{mrem} / \mathrm{hr}$ shall be designed for full contact maintenance and operation.

Verification: (Analysis) See analysis in section 3.5.1.1. The operation of the valve pit leak detection system does not require full contact. Full contact maintenance, if required, will be performed only after decontamination in accordance with ALARA.

\subsubsection{Supply}

3.5.2.1 The system design shall, to the greatest extent practicable, use readily available parts and components.

Verification: (Analysis) All components in the leak detection systems, except the leak detection probes, are off the shelf items and can be readily purchased from off site suppliers.

\subsubsection{Facilities and Facility Equipment}

Not applicable to this specification.

\subsection{Personnel and Training}

\subsubsection{Personnel}

Not applicable to this specification.

\subsubsection{Training}

Not applicable to this specification.

\subsection{Major Component Characteristics}

Not applicable to this specification 


\subsection{Quality Assurance Provisions}

There are no requirements identified in this section.

\section{$5.0 \quad$ Notes}

\subsection{Definitions}

\subsubsection{Instantaneous Response Time}

The time allowed for the leak detection system to produce an output signal after it has detected a leak. Based on the design authority judgement that this time is less than or equal to one second.

\subsubsection{Local Alarm}

A local alarm is defined as an alarm located at or near the point of measurement. For example the leak detector local alarm would be at the pit leak detection system control panel, which would be at or near the pit where the leak detection sensor is located.

\subsubsection{Leak}

Leaks from waste transfer systems at the Hanford Site are established for each specific project. Each project demonstrates to the Washington Department of Ecology that the proposed system meets state regulations. The leak for the proposed system is established in this process. The leak for the pit leak detection system has been established at 10 gallons in a 24 hour period.

\subsubsection{Glaze}

Glaze is a coating of ice formed when rain or drizzle freezes on contact with any surface which has a temperature that is below freezing.

\subsubsection{Continuous Monitoring Frequency}

Continuous monitoring frequency is defined as monitoring for a leak without interruption as long as power is applied to the system which normally means that the sensing instrumentation is dedicated to a single measurement. 


\section{APPENDIX D}

Requirements Verification

For

PDS-005

Special Protective Coating 
HNF-4533

Rev. 0

\section{REQUIREMENTS VERIFICATION}

FOR

SPECIAL PROTECTIVE COATING

\subsection{SCOPE}

This appendix documents how the requirements that are listed in the Project Development Specification (PDS) for the Special Protective Coating (SPC) (HNF-SDW314-PDS-005) are satisfied for the SPC that will be installed in existing Pump Pits 241-AN-01A and 241-AN-04A and new 241-AN-04D, Slurry Receiver Pit.

\subsection{APPLICABLE DOCUMENTS}

For a list of the applicable documents, refer to the appropriate PDS.

\subsection{REQUIREMENTS VERIFICATION ANALYSIS}

\subsection{Item Definition}

There are no requirements specified in this section.

\subsection{Characteristics}

\subsubsection{Performance}

The performance requirements of the SPC system are as follows:

\subsubsection{Chemical Resistance}

The SPC system shall be capable of withstanding the liquid waste chemical composition ranges listed in Table 3-1.

Verification: (Analysis) This requirement is included in Construction Specification W-314-C5, Section 09855. This analysis will be completed when Vendor submittal data is received and prior to procurement.

\subsubsection{Decontaminabilty}

\subsection{Radionuclide Compatability}

The SPC system shall be compatible with the waste radionuclide concentrations listed under the W-314 column in Table 3-2. 
Verification: (Analysis) This requirement is included in Construction Specification W-314-C5, Section 09855. This analysis will be completed when Vendor submittal data is received and prior to procurement.

\subsection{Decontamination Factor}

The top coating of the SPC system shall demonstrate relative ease of decontamination with a minimum Decontamination Factor (DF) of 100. The DF after initial water wash shall be a minimum of 20 .

Verification: (Analysis) This requirement is included in Construction Specification W-314-C5, Section 09855. This analysis will be completed when Vendor submittal data is received and prior to procurement.

\subsubsection{Physical Characteristics}

3.2.2.1 Surface Application

The SPC system shall develop the ability to resist the development of holidays with time.

Verification: (Analysis) Construction Specification W-314-C5, Section 09855, specifies a rigid coating system consisting of four coats totaling 15 mils in thickness. Proper application of these high solids epoxies with multiple coats, will resist the development of holidays. Once the coating cures holidays will not form.

(Exam) This requirement will be verified by examination during construction.

\subsubsection{Thermal Stress Endurance}

The SPC system shall successfully fill or bridge cracks of $1.0-1.5 \mathrm{~mm}$ $(0.040-0.060$ inches) caused by thermal movement and stresses within concrete.

Verification: (Analysis) Construction Specification W-314-C5, Section 09855, requires elongation at break be at least $5 \%$ for rigid coatings. This requirement will assure cracks up to $1.5 \mathrm{~mm}$ ( 0.060 inches) can be bridged.

\subsubsection{Volatile Organic Content Compliance}

The SPC system shall be volatile organic content (VOC) compliant with a maximum $V O C$ of $2.9 \mathrm{lbs} /$ gallon ( $350 \mathrm{grams} / \mathrm{liter}$ ). 
Table 3-1. Chemical Composition Range (Sheet 1 of 2)

\begin{tabular}{|c|c|c|c|c|}
\hline \multicolumn{5}{|c|}{ Retrieved waste } \\
\hline \multirow[t]{3}{*}{ Species } & \multicolumn{2}{|c|}{ DST } & \multicolumn{2}{|c|}{ SST } \\
\hline & \multicolumn{2}{|c|}{ Anion/cation } & \multicolumn{2}{|c|}{ Anion/cation } \\
\hline & $\min \mathrm{mol} / \mathrm{L}$ & $\max \mathrm{mol} / \mathrm{L}$ & $\min \mathrm{mol} / \mathrm{L}$ & $\max \mathrm{mol} / \mathrm{L}$ \\
\hline $\mathrm{Ag}$ & 0 & 0.0013 & - & - \\
\hline $\mathrm{Al}$ & 0.05 & 1.1 & 0.029 & 0.5 \\
\hline As & 0 & 0.0066 & - & - \\
\hline B & 0 & 0.013 & - & - \\
\hline $\mathrm{Ba}$ & 0 & 0.0004 & 0 & 0.0014 \\
\hline $\mathrm{Bi}$ & - & - & 0 & 0.076 \\
\hline $\mathrm{Ca}$ & 0.0014 & 0.1 & 0 & 0.17 \\
\hline $\mathrm{Cd}$ & 0 & 0.0074 & 0 & 0.0007 \\
\hline $\mathrm{Cr}$ & 0.0067 & 0.28 & 0.0001 & 0.091 \\
\hline $\mathrm{Cu}$ & 0 & 0.02 & - & - \\
\hline $\mathrm{Fe}$ & 0.0004 & 0.26 & 0.0057 & 0.89 \\
\hline $\mathrm{Hg}$ & 0 & $2.8 \mathrm{E}-05$ & 0 & 0.0001 \\
\hline$K$ & 0.044 & 0.55 & 0.0002 & 0.0095 \\
\hline $\mathrm{La}, \mathrm{Nd}$ & 0 & 0.0066 & 0 & 0.001 \\
\hline $\mathrm{Mg}$ & 0.0004 & 0.046 & - & - \\
\hline Mn & 0.0003 & 0.16 & 0.0009 & 0.41 \\
\hline Mo & 0 & 0.0029 & - & - \\
\hline $\mathrm{Na}$ & 1.6 & 10.7 & 1.6 & 7.1 \\
\hline $\mathrm{Ni}$ & 0.0002 & 0.008 & 0 & 0.042 \\
\hline $\mathrm{Pb}$ & 0 & 0.004 & 0 & 0.12 \\
\hline $\mathrm{Pd}, \mathrm{Rh}$ & 0 & 0.0063 & - & - \\
\hline $\mathrm{Si}\left(\mathrm{SiO}_{2}\right)$ & 0.0024 & 0.028 & 0.0004 & 0.46 \\
\hline $\mathrm{Ti}$ & 0 & 0.002 & - & - \\
\hline
\end{tabular}


Table 3-1. Chemical Composition Range (Sheet 2 of 2)

\begin{tabular}{|c|c|c|c|c|}
\hline \multicolumn{5}{|c|}{ Retrieved waste } \\
\hline \multirow[t]{3}{*}{ Species } & \multicolumn{2}{|c|}{ DST } & \multicolumn{2}{|c|}{ SST } \\
\hline & \multicolumn{2}{|c|}{ Anion/cation } & \multicolumn{2}{|c|}{ Anion/cation } \\
\hline & $\min \mathrm{mol} / \mathrm{L}$ & $\max \mathrm{mol} / \mathrm{L}$ & $\min \mathrm{mol} / \mathrm{L}$ & $\max \mathrm{mol} / \mathrm{L}$ \\
\hline U & 0 & 0.0092 & - & - \\
\hline $\mathrm{Zr}\left(\mathrm{ZrO}_{2}\right)$ & 0 & 0.3 & 0 & 0.065 \\
\hline Acetate & - & - & 0 & 0.0055 \\
\hline Citrate & 0 & 0.03 & 0.0042 & 0.06 \\
\hline EDTA & 0 & 0.016 & 0 & 0.011 \\
\hline HEDTA & 0 & 0.021 & - & - \\
\hline $\mathrm{Fe}(\mathrm{CN})_{6}$ & - & - & 0 & 0.025 \\
\hline $\mathrm{Cl}$ & 0.003 & 0.17 & 0 & 0.022 \\
\hline $\mathrm{CO}_{3}$ & 0.03 & 0.69 & 0.014 & 0.38 \\
\hline $\mathbf{F}$ & 0.014 & 1 & 0.001 & 0.71 \\
\hline $\begin{array}{l}\text { Fission } \\
\text { product }\end{array}$ & 0 & 0.0001 & - & - \\
\hline $\mathrm{NO}_{2}$ & 0.1 & 1.8 & 0.0086 & 0.83 \\
\hline $\mathrm{NO}_{x}\left(\mathrm{NO}_{3}\right)$ & 0.15 & 3.6 & 0.64 & 5.1 \\
\hline $\mathrm{OH}$ & 0.24 & 4.4 & 0.25 & 6.9 \\
\hline $\mathrm{PO}_{4}$ & 0 & 0.4 & 0.0007 & 3.8 \\
\hline $\mathrm{SO}_{4}$ & 0.003 & 0.16 & 0.01 & 0.22 \\
\hline TOC & 0 & 2 & - & - \\
\hline
\end{tabular}

DST = Double-shell tank

EDTA = Ethylenediametetraacetic acid

HEDTA $=\mathrm{N}$-(hydroxyethyl)-ethylenediaminetriacetic acid

SST = Single-shell tank

TOC = Total organic carbon 
Table 3-2. Radionuclide Concentrations

\begin{tabular}{|c|c|c|c|}
\hline \multirow{2}{*}{ Nuclide } & \multicolumn{3}{|c|}{ Nuclide concentrations $(\mathrm{Bq} / \mathrm{L})$} \\
\hline & "All liquids & •All solids & b $W-314$ \\
\hline${ }^{14} \mathrm{C}$ & $2.3 E+05$ & $1.6 \mathrm{E}+05$ & $2.3 E+05$ \\
\hline${ }^{80} \mathrm{Co}$ & $9.5 E+06$ & $4.9 E+08$ & $1.7 E+08$ \\
\hline${ }^{79} \mathrm{Se}$ & c & $1.7 E+04$ & $1.7 E+04$ \\
\hline${ }^{90} \mathrm{Sr}$ & $1.1 E+10$ & $2.9 E+12$ & $9.6 \mathrm{E}+11$ \\
\hline${ }^{90} \mathrm{Y}$ & $1.1 E+10$ & $2.9 E+12$ & $9.6 E+11$ \\
\hline${ }^{99} \mathrm{TC}$ & $1.7 \mathrm{E}+07$ & $1.2 \mathrm{E}+10$ & $4.0 \mathrm{E}+09$ \\
\hline${ }^{108} \mathrm{Ru}$ & $9.9 \mathrm{E}+02$ & $7.2 E+04$ & $2.4 E+04$ \\
\hline${ }^{125} \mathrm{Sb}$ & $3.4 E+04$ & $1.8 E+08$ & $5.9 \mathrm{E}+07$ \\
\hline${ }^{129} \mid$ & $2.0 E+04$ & $6.4 E+06$ & $2.1 E+06$ \\
\hline${ }^{134} \mathrm{Cs}$ & $6.1 \mathrm{E}+06$ & $9.4 E+06$ & $7.2 E+06$ \\
\hline${ }^{137} \mathrm{Cs}$ & $8.8 E+10$ & $1.0 E+11$ & $9.2 E+10$ \\
\hline${ }^{144} \mathrm{Ce}$ & $9.1 E+00$ & $3.4 E+02$ & $1.2 \mathrm{E}+02$ \\
\hline${ }^{147} \mathrm{Pm}$ & $3.6 \mathrm{E}+07$ & c & $3.6 E+07$ \\
\hline${ }^{154} \mathrm{Eu}$ & $2.4 E+09$ & $1.1 E+10$ & $5.2 E+09$ \\
\hline${ }^{155} \mathrm{Eu}$ & $5.9 E+07$ & $5.0 E+06$ & $5.9 E+07$ \\
\hline${ }^{237} \mathrm{~Np}$ & $2.3 E+05$ & $9.9 E+08$ & $3.3 E+08$ \\
\hline${ }^{238} \mathrm{Pu}$ & $1.8 E+06$ & $1.9 E+08$ & $6.4 E+07$ \\
\hline${ }^{239} \mathrm{Pu}^{d}$ & $3.6 E+07$ & $1.6 E+09$ & $5.5 E+08$ \\
\hline${ }^{241} \mathrm{Pu}$ & $2.6 E+08$ & $3.8 \mathrm{E}+09$ & $1.4 E+09$ \\
\hline${ }^{241} \mathrm{Am}$ & $4.2 E+07$ & $1.1 E+10$ & $3.7 E+09$ \\
\hline${ }^{242} \mathrm{Cm}$ & $1.1 E+01$ & $2.0 E+02$ & $7.3 E+01$ \\
\hline${ }^{244} \mathrm{Cm}$ & $4.2 E+05$ & $6.1 E+07$ & $2.0 E+07$ \\
\hline
\end{tabular}

'From Table 1a., Van Keuren, J. C., 1996, Tank Waste Compositions and Atmospheric Dispersion Coefficients for use in Safety Analysis Consequence Assessments, WHC-SD-WM-SARR-016, Rev. 2, Westinghouse Hanford Company, Richland, Washington.

${ }^{b} \mathrm{~W}-314$ values represent a bounding mixture for design of $67 \%$ liquid and $33 \%$ solid, except for ${ }^{14} \mathrm{C}$ and ${ }^{155} \mathrm{Eu}$ where the maximum liquid value was used as it is higher than the mix and for ${ }^{79} \mathrm{Se}$ and ${ }^{147} \mathrm{Pm}$ where data is not available.

'No available data.

${ }^{d}$ The ${ }^{239} \mathrm{Pu}$ activity concentration also includes ${ }^{240} \mathrm{Pu}$. 
Verification: (Analysis) This requirement is included in Construction Specification W-314-C5, Section 09855. This analysis will be completed when Vendor submittal data is received and prior to procurement.

\subsubsection{Tensile Properties}

The SPC system shall have minimum acceptable tensile properties tabulated in Table $3-3,-4$, and -5 .

Table 3-3 Tensile Properties of Coatings

\begin{tabular}{||l|l|l||}
\hline Properties & Rigid Coating (Epoxy) & $\begin{array}{l}\text { Flexible Coating } \\
\text { (Elastomeric) }\end{array}$ \\
\hline Tensile Strength & N/A & $\begin{array}{l}\text { Minimum 20,700 KPa } \\
(3,000 \text { psi) at 30 days }\end{array}$ \\
\hline $\begin{array}{l}\text { Elongation at break at } \\
24^{\circ} \mathrm{C}\left(75^{\circ} \mathrm{F}\right)\end{array}$ & Minimum 5 percent & $\begin{array}{l}\text { Minimum 400 percent at } \\
30 \text { days }\end{array}$ \\
\hline
\end{tabular}

Table 3-4 Tensile Properties of Joint Sealants

\begin{tabular}{||l|l|l||}
\hline Properties & Flexibilized Epoxy & $\begin{array}{l}\text { Fluoroelastomer, } \\
\text { Polysulfide, Polyurethane }\end{array}$ \\
\hline Tensile Strength & $\begin{array}{l}\text { Minimum } 3,500 \mathrm{KPa}(500 \\
\text { psi) }\end{array}$ & $\begin{array}{l}\text { Minimum 10,400 } \mathrm{KPa} \\
(1,500 \mathrm{psi})\end{array}$ \\
\hline $\begin{array}{l}\text { Elongation at break at } \\
24^{\circ} \mathrm{C}\left(75^{\circ} \mathrm{F}\right)\end{array}$ & Minimum 100 percent & Minimum 100 percent \\
\hline
\end{tabular}

Table 3-5 Tensile Properties of Fillers

\begin{tabular}{||l|l|}
\hline Properties & Solid Epoxy Mastic \\
\hline Tensile Strength & Minimum 3,500 KPa (500 psi) \\
\hline Elongation at break at & Minimum 20 percent \\
$24^{\circ} \mathrm{C}\left(75^{\circ} \mathrm{F}\right)$ & \\
\hline
\end{tabular}

Verification: (Analysis) These requirements are required by Construction Specification W-314-C5, Sections 09855. This analysis will be completed when Vendor submittal data is received and prior to procurement.

\subsubsection{Abrasion Resistance}

The top coating shall demonstrate the abrasion resistance property. The acceptable abrasion resistance values of the installed coating are 
tabulated in Table 3-6. The weight loss values are for 1000 cycles when a CS-17 wheel is used with a $1000 \mathrm{~g}$ load in accordance with ASTM D 4060.

Table 3-6 Abrasion Resistance Properties of Coatings

\begin{tabular}{||l|l|l||}
\hline Properties & Rigid Coating (Epoxy) & $\begin{array}{l}\text { Flexible Coating } \\
\text { (Elastomeric) }\end{array}$ \\
\hline Abrasion Resistance & $\begin{array}{l}\text { Weight loss less than } \\
100 \mathrm{mg}\end{array}$ & $\begin{array}{l}\text { Weight loss less than } \\
10 \mathrm{mg}\end{array}$ \\
\hline
\end{tabular}

Verification: (Analysis) This requirement is included in Construction Specification W-314-C5, Section 09855. This analysis will be completed when Vendor submittal data is received and prior to procurement.

Permeability

The SPC system shall be capable of resisting the migration of liquid waste/water into the pit wall. The permeability shall be measured as follows:

- The maximum water vapor transmission (WVT) rate for a top coating shall be $8 \mathrm{gm} / \mathrm{m}^{2} / 24 \mathrm{hr}$.

- The maximum water absorption rate for a top coating and joint sealant shall be 0.5 percent per 24 hours.

Verification: (Analysis) This requirement is included in Construction Specification W-314-C5, Section 09855. This analysis will be completed when Vendor submittal data is received and prior to procurement.

3.2.2.7 Adhesion to Substrate

The SPC system shall display an adhesion property to the underlying concrete and previously coated surfaces. Minimum pull-off strength shall be $6,200 \mathrm{KPa}$ (900 psi).

Existing Pit Interior SPC Repairs are excluded from this requirement when ALARA considerations prevent surface preparation per manufacturer's recommendations.

Verification: (Analysis) This requirement is included in Construction Specification W-314-C5, Section 09855. This analysis will be completed when Vendor submittal data is received and prior to procurement. Specification calls for adhesion to steel of 900 psi for rigid coating only. Steel is used as the standard because of repeatability, 
but the test is a meaningful measure of adhesion to concrete.

3.2.8 Color

The color of the top coat shall be white or near white such that nozzle labels and markers can be painted over the top coat.

Verification: (Analysis) This requirement is included in Construction Specification W-314-C5, Section 09855.

(Exam) This requirement will also be verified by examination and documented in the CWP.

3.2.9 Labeling Paint

Paint (coating) use for identification marking on the SPC top coat shall be compatible with the SPC system.

Verification: (Analysis) This requirement is included in Construction Specification $W-314-C 5$, Section 09855 by requirements to use SPC coating materials. Thus no compatibility issues.

\subsubsection{Reliability}

The SPC system shall have a design life of 12 years when installed per the manufacturer's recommendation.

Verification: (Analysis) This requirement is included in Construction Specification W-314-C5, Section 09855. This analysis will be completed when Vendor submittal data is received and prior to procurement.

\subsubsection{Maintainability}

The SPC system shall be repairable for cracks appearing through the applied coated surface to the substrate or for chips and flaking on account of mechanical damage.

Verification: (Analysis) This requirement is included in Construction Specification, W-314- C5, Section 09855. This analysis will be completed when Vendor data is received and prior to procurement.

\subsubsection{Environmental Conditions}

The systems and components covered by this specification shall be compatible with the environmental conditions listed below, as applicable.

\subsubsection{Natural Environments}

\subsection{Ambient Air Temperature}

The ambient air temperature range is $48.9^{\circ} \mathrm{C}\left(120^{\circ} \mathrm{F}\right)$ to $-35.5^{\circ} \mathrm{C}$ ($\left.32^{\circ} \mathrm{F}\right)$, and with a maximum 24 hour differential of $28.9^{\circ} \mathrm{C}\left(52^{\circ} \mathrm{F}\right)$. 
Verification: (Analysis) Construction Specification W-314-C5, Section 09855, requires coatings be applied only when temperatures are within the range recommended by the coating manufacturer. This analysis will be completed when Vendor submittal data is received and prior to procurement.

\subsection{Soil Temperature N/A}

3.2.5.1.3 Seismic Loads N/A

3.2.5.1.4 Wind Loads N/A

3.2.5.1.5 Snow Loads N/A

3.2.5.1.6 Relative Humidity

The relative humidity range is 0 to $100 \%$ (Rate of change is negligible).

Verification: (Analysis) This requirement is required by Construction Specification W-314-C5, Section 09855. This analysis will be completed when Vendor submittal data is received and prior to procurement.

\subsection{Surface Precipitation}

The surface precipitation is $4 \mathrm{~cm}(1.56 \mathrm{in})$ in a 24 hour period.

Verification: (Analysis) Coating meeting requirements of Construction Specification W-314-C5 will not be affected by surface precipitation.

3.2.5.1.8 Hail Events

The hail diameter is less than or equal to $1.9 \mathrm{~cm}(0.75 \mathrm{in})$.

Verification: (Analysis) Wear resistance as specified in Construction specification W-314-C5, Section 09855, will help provide resistance to hail damage.

3.2.5.1.9 Sand and Dust

The sand/dust concentration is $0.177 \mathrm{gm} / \mathrm{m}^{3}$ with a typical size of 350 $\mu \mathrm{m}$.

Verification: (Analysis) Wear resistance as specified in Construction Specification W-314-C5, Section 09855 will help protect the SPC applied to the top of the cover blocks from sand/dust damage. 


\subsection{Solar Radiation}

The solar radiation range is between $4 \mathrm{Watts} / \mathrm{m}^{2}$ and $406 \mathrm{Watts} / \mathrm{m}^{2}$.

Verification: (Analysis) All coatings specified in the Construction Specification W-314-C5, Section 09855 are for use on surfaces exposed to solar radiation. Exposure to solar radiation may weather the surface of the coating, but not effect the integrity of the coating.

\subsection{Glaze (See definition in Section 5.1)}

The glaze is $2.54 \mathrm{~cm}(1 \mathrm{in}$.$) .$

Verification: (Analysis) Coating meeting requirements of Construction Specification W-314-C5, Section 09855 will resist glaze.

\subsection{Ashfall Events N/A}

\subsection{Load Combinations and Allowable Stresses N/A}

\subsubsection{Induced Environments}

\subsection{Waste Properties}

Materials used that come in contact with the waste shall be capable of safely handling waste with the following properties:

Specific Gravity
Viscosity
Miller Number
pH
Temperature
Solids Content

Particle Size

Note: $95 \%$

$<5$ percent of total particles 50 to 500 microns

$<1$ percent of total particles 500 to 4000 microns

Verification: (Analysis) Coating will be subject to only occasional splashes and spills and not to prolonged immersion. Conformance to requirements of the Construction Specifications W-314-C5, Section 09855, will assure resistance to the waste. This analysis will be completed when Vendor submittal data is received and prior to procurement.

\subsection{Radiation Tolerance}

\subsection{Inside Pit Radiation Level}

Materials used that are located inside a pit shall be capable of operating in the following radiation environment: 
total accumulated dose: $\quad 6 \times 10^{7}$ rads

dose rate:

$1 \times 10^{7} \mathrm{mr} / \mathrm{hr}$

Verification: (Analysis) Standard ASTM tests as specified in Construction Specification W-314-C5, Section 09855, will assure coating has resistance to radiation. This analysis was completed when Vendor submittal data was received.

\subsection{Background Radiation Level}

Materials used that are located outside a pit, above ground, shall be capable of operating in the following radiation environment:
total accumulated dose:
$0.5 \mathrm{rad} /$ year

dose rate:

$0.25 \mathrm{mr} / \mathrm{hr}$

Verification: (Analysis) The SPC is required to meet the Inside Pit Radiation Level and as such, it will fulfill this requirement.

\subsubsection{Transportability N/A}

\subsubsection{Flexibility and Expansion}

Each system design shall, to the maximum extent practicable, provide sufficient flexibility to accommodate for programmatic changes or operation modifications.

Verification: (Analysis) The use of the SPC for the valve pits will allow for easier decontamination of the pit prior to entry which will allow for timely changes and modification that may be required for support of future operations.

\subsection{Design and Construction}

\subsubsection{Materials, Processes, and Parts}

\subsubsection{Materials}

3.3.1.1.1 SPC System

\subsection{Service Area}

The SPC system shall be suitable for Service Level II Area.

Verification: (Analysis) This requirement, which is defined in ASTM D-5144, is included in Construction Specification W314-C1, Section 09855. This analysis will be completed when Vendor submittal data is received and prior to procurement. 


\subsection{SPC System Schedule}

A SPC system schedule shall be prepared during definitive design stage, based on manufacturer recommendations, published data for the SPC system and field ALARA conditions. The schedule shall provide descriptions of prime, base, intermediate, and finish coats as applicable; minimum dry film thickness in mils; and color.

Verification: (Analysis) Construction Specification W-314-C5, Section 09855 lists representative products with appropriate requirements that will meet this requirement. This analysis will be completed when Vendor submittal data is received.

\subsection{SPC System Accessory Materials}

Coating accessory materials such as joint sealants, fillers, primers, thinners, form release agents, and scrim cloth shall be as recommended by the manufacturer of the SPC system suitable for environmental conditions specified in this document.

Verification: (Analysis) Construction Specification W-314-C5, Section 09855, require compliance with these requirements. This analysis will be completed when vendor submittal data is received.

\subsubsection{Processes}

\subsection{Surface Preparation}

\subsection{Surface Preparation (Excluding Existing Pit Interior SPC Repairs)}

The design document will incorporate a surface preparation procedure prepared in consultation with the manufacturer of the SPC system. Acceptable substrate preparation method will be selected during the design phase.

Verification: (Analysis) Construction Specification W-314-C5, Section 09855, includes a general preparation requirements. This analysis will be completed when Vendor submittal data is received.

\subsection{Surface Preparation for Existing Pit Interior SPC Repairs}

The design document will incorporate a surface preparation prepared in consultation with the manufacturer of the SPC system when field radiological/toxicological conditions permit. When field radiological/toxicological conditions prohibit surface preparation per manufacturer's consultation, the design document will provide minimum surface preparation details consistent with ALARA.

Verification: (Analysis) Construction Specification W-314-C5, Section 09855 includes a general preparation requirements. 


\subsection{SPC System Application}

The SPC system shall be installed only when ambient and surface temperatures are within the range recommended by the coating manufacturer for the respective coating. The application procedure for the SPC system shall be in accordance with the manufacturers' specification.

Verification: (Analysis) Construction Specification W-314-C5, Section 09855 and inspection during construction will ensure coating application occurs only when ambient conditions are suitable for coating chosen.

(Exam) This verification will also be verified by examination during construction.

3.3.1.3 During the design of facilities, optimization principles, as discussed in ICRP Publication 37, shall be utilized in developing and justifying facility design and physical controls.

Verification: (Analysis) ICRP Publication 37 addresses techniques for use in the optimization of radiation protection based on cost-benefit analysis. The SPC is not intended to provide any radiation protection and thus this requirement is not applicable to this specification.

3.3.1.4 The equipment used for installation and maintenance shall comply with the DST dome loading constraints.

Verification: (Analysis) If equipment is located outside a 20' exclusion zone around the DST, dome loading effects are mitigated. Compliance with this requirement will be verified by the calculation and by the issuing of dome loading permits for locating the equipment from Tank Farm Engineering and Operations.

\subsubsection{Electromagnetic Radiation N/A}

\subsubsection{Identification and Marking N/A}

\subsubsection{Workmanship N/A}

\subsubsection{Interchangeability N/A}

\subsubsection{Safety}

Material Safety Data Sheets

Material Safety Data Sheets (MSDS) for the SPC system components shall be furnished during the data transmittal review stage for approval. Obtain inspection and acceptance by the construction engineer before opening containers or removing labels. 
Verification: (Analysis) Construction Specification W-314-C5, Section 09855 requires submittal of MSDS for coating chosen. This analysis will be completed when Vendor submittal data is received.

\subsubsection{Fire Protection}

\subsection{Fire Characteristics}

Any materials with unusual fire characteristics, such as urethane foams, and any materials that develop significant quantities of toxic or other harmful products of combustion, shall not be used as interior finishes or other interior applications without the approval of the cognizant DOE fire protection authority. The use of foamed plastics in construction shall be prohibited unless it fully complies with Factory Mutual 1-57.

Verification: (Analysis) This requirement is included in Construction Specification W-314-C5, Section 09855. This analysis will be completed when vendor submittal data is received.

\subsection{Interior Finishes}

Nuclear facilities and laboratories shall have interior finish materials (decorations, furnishings, and exposed wall or insulating material) that have an Underwriters Laboratories (ASTM E-84/NFPA 255) flame spread rating of 25 or less, and smoke developed rating of 50 or less.

Verification: (Analysis) See above analysis for 3.3.6.2.1.

\subsubsection{Human Performance/Human Engineering N/A}

\subsection{Documentation}

\subsubsection{Records and Documents}

Records, documents, and document control pertinent to design functions shall be in accordance with HNF-PRO-224 and HNF-PRO-233.

Verification: (Analysis) Submittals required by Construction Specification W-314C5, Section 09855 will assure proper documentation.

(Exam) This requirement will also be verified by $\mathrm{OA}$ assessment of the documents.

\subsection{Logistics}

\subsubsection{Maintenance N/A}




\subsubsection{Supply}

3.5.2.1 The system design shall, to the greatest extent practicable, use readily available parts and components.

Verification: (Analysis) Construction Specification W-314-C5, Section 09855 , lists various manufacturer's products or approved substitute that are suitable for use. These products are considered to be readily available.

\subsubsection{Facilities and Facility Equipment N/A}

\subsection{Personnel and Training}

\subsubsection{Personnel N/A}

\subsubsection{Training N/A}

\subsection{Major Component Characteristics N/A}

\subsection{Quality Assurance Provisions}

There are no requirements identified in this section.

\section{$5.0 \quad$ NOTES}

\subsection{Definitions}

Abrasion Resistance: The property of a surface by which it resists being worn away as the result of friction.

Adhesion: The bond or attraction of a coat of paint to the underlying material, such as a substrate or another coat.

Chip: The detachment of small pieces of the substrate.

Decontamination: The act of removing radioactive nuclides from a surface.

Decontamination Factor: The ratio of the original number of radioactive nuclides on the surface of a specimen to the number remaining after a decontamination process.

Dry-film Thickness: Depth of applied coating when dry, expressed in mils $(0.001 \mathrm{in})$.

Flaking: The detachment of small pieces of the coating film.

Glaze: Coating of ice formed when rain or drizzle freezes on contact with any surface having a temperature that is below freezing.

Holiday: Pinhole, skip, discontinuity, or a void in coating film.

Laitance: A fine, whitish accumulation on concrete surfaces. It consists mainly of cement particles that were carried by water rising to the surface of freshly placed concrete. 
Permeability: The measure of water or water vapor transmission rate through films of coating.

Service Level II Area: that area outside primary containment subject to radiation exposure and radio nuclide contamination in accordance with ASTM D 5144.

Substrate: The base surface to which a coating is to be applied.

Wet-Film Thickness: Depth of applied coating expressed in mils measured immediately after application.

Water Vapor Transmission Rate: The steady water vapor flow in unit time through unit area of a body. 


\section{DISTRIBUTION SHEET}

\begin{tabular}{|l|l|}
\hline $\begin{array}{l}\text { To } \\
\text { Distribution }\end{array}$ & $\begin{array}{l}\text { From } \\
\text { TFR\&SO }\end{array}$ \\
\hline
\end{tabular}

Project Title/Work Order

W-314, Tank Farm Restoration and Safe Operations, RVR: AN Farm to 200E Waste Transfer System (WBS 1.4.L)

\begin{tabular}{|l|}
\hline \\
\hline N.J. Bedell \\
\hline T.W. Bohan \\
\hline K.M. Bowen \\
\hline D.E. Bowers \\
\hline R.F. Carlstrom \\
\hline H.M. Chafin \\
\hline R.E. Elder \\
\hline J.D. Galbraith \\
\hline M.S. Garrett \\
\hline J.L. Gilbert \\
\hline J.D. Guberski \\
\hline J.S. Hammers \\
\hline J.R. LaPointe \\
\hline M.A. Lane \\
\hline J.W. Lentsch \\
\hline D.L. McGrew \\
\hline J.E. Navarro \\
\hline T.J. Rettkowski \\
\hline Project Files \\
\hline Project Library \\
\hline \\
\hline \\
\hline \\
\hline \\
\hline
\end{tabular}

\begin{tabular}{|c|c|c|c|c|}
\hline MSIN & $\begin{array}{l}\text { Text } \\
\text { With All } \\
\text { Attach. }\end{array}$ & Text Only & $\begin{array}{l}\text { Attach.I } \\
\text { Appendix } \\
\text { Only }\end{array}$ & $\begin{array}{c}\text { EDT/ECN } \\
\text { Only }\end{array}$ \\
\hline G3-12 & $x$ & & & \\
\hline R3-47 & $x$ & & & \\
\hline s5-12 & $x$ & & & \\
\hline $55-13$ & $x$ & & & \\
\hline $\mathrm{R} 1-43$ & $x$ & & & \\
\hline R3-25 & $x$ & & & \\
\hline $56-14$ & $x$ & & & \\
\hline R3-73 & $x$ & & & \\
\hline $50-09$ & $x$ & & & \\
\hline$R 3-25$ & $x$ & & & \\
\hline $\mathrm{R} 1-51$ & $x$ & & & \\
\hline R3-25 & $x$ & & & \\
\hline $\mathrm{R} 2-88$ & $x$ & & & \\
\hline G3-12 & $x$ & & & \\
\hline R3-25 & $x$ & & & \\
\hline R3-25 & $x$ & & & \\
\hline H6-60 & $x$ & & & \\
\hline G3-12 & $x$ & & & \\
\hline $\mathrm{R} 1-29$ & $x$ & & & \\
\hline$R 3-25$ & $x$ & & & \\
\hline & & & & \\
\hline & & & & \\
\hline & & & & \\
\hline & & & & \\
\hline & & & & \\
\hline & & & & \\
\hline & & & & \\
\hline & & & & \\
\hline & & & & \\
\hline & & & & \\
\hline & & & & \\
\hline & & & & \\
\hline
\end{tabular}

